\title{
Pressure ulcers : prevalence measurements as a tool for improving care
}

Citation for published version (APA):

Bours, G. J. J. W. (2003). Pressure ulcers : prevalence measurements as a tool for improving care. [Doctoral Thesis, Maastricht University]. Datawyse / Universitaire Pers Maastricht. https://doi.org/10.26481/dis.20030918gb

Document status and date:

Published: 01/01/2003

DOI:

10.26481/dis.20030918gb

Document Version:

Publisher's PDF, also known as Version of record

\section{Please check the document version of this publication:}

- A submitted manuscript is the version of the article upon submission and before peer-review. There can be important differences between the submitted version and the official published version of record.

People interested in the research are advised to contact the author for the final version of the publication, or visit the DOI to the publisher's website.

- The final author version and the galley proof are versions of the publication after peer review.

- The final published version features the final layout of the paper including the volume, issue and page numbers.

Link to publication

\footnotetext{
General rights rights.

- You may freely distribute the URL identifying the publication in the public portal. please follow below link for the End User Agreement:

www.umlib.nl/taverne-license

Take down policy

If you believe that this document breaches copyright please contact us at:

repository@maastrichtuniversity.nl

providing details and we will investigate your claim.
}

Copyright and moral rights for the publications made accessible in the public portal are retained by the authors and/or other copyright owners and it is a condition of accessing publications that users recognise and abide by the legal requirements associated with these

- Users may download and print one copy of any publication from the public portal for the purpose of private study or research.

- You may not further distribute the material or use it for any profit-making activity or commercial gain

If the publication is distributed under the terms of Article $25 \mathrm{fa}$ of the Dutch Copyright Act, indicated by the "Taverne" license above, 


\section{PRESSURE ULCERS}

Prevalence measurements as a tool for improving care 
ISBN 9052783837

O Gerrie J.J.W. Bours, Mastricht 2003

Vormgeving en druk door Datawyse / Universitaire Pers Mastricht Illustratie omslag door Sandrien Wansink 


\section{PRESSURE ULCERS}

\section{Prevalence measurements as a tool for improving care PROEFSCHRIFT}

ter verkrijging van de graad van doctor aan de Universiteit Maastricht, op gezag van de Rector Magnificus, Prof. dr. A.C. Nieuwenhuijzen Kruseman, volgens het besluit van het College van Decanen, in het openbaar te verdedigen op donderdag 18 september 2003 om 14.00 uur door

Gertruda Josephina Johanna Wilhelmina Bours

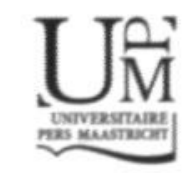




\section{Promotores}

Prof. dr. H. Huijer Abu-Saad

Prof. dr. R.P.T.M. Grol

\section{Co-promotor}

Dr. R.J.G. Halfens

Beoordelingscommissie

Prof. dr. F.C.B. van Wijmen (voorzitter)

Prof. dr. Th. Van Achterberg (Katholieke Universiteit Nijmegen)

Prof. dr. T.W.N. Dassen (Humboldt Universität, Berlin, Germany)

Prof. dr. J.F.M. Metsemakers

Prof. dr. J.L. Severens

Printing of this thesis was financially supported by Nutricia Nederland BV, Paul Hartmann BV, Huntleigh Health Care BV, Coloplast BV, 3M Nederland BV and Johnson \& Johnson Wound Management. 
Voor Karel, Ruud en Sanne 



\section{CONTENTS}

CHAPTER 1

General introduction

9

\section{CHAPTER 2}

The development of a national registration form to measure the prevalence of pressure ulcers in the Netherlands

\section{CHAPTER 3}

Prevalence, prevention and treatment of pressure ulcers:

Descriptive study in 89 institutions in the Netherlands

\section{CHAPTER 4}

Development of a model for case-mix adjustment of pressure ulcer prevalence rates $\quad 55$

\section{CHAPTER 5}

Assessing the performance of Dutch nursing homes using the prevalence of setting-acquired pressure ulcers:

A Bayesian approach by multilevel modeling $\quad 73$

CHAPTER 6

Improving the quality of care in acute care hospitals by pressure ulcer audit and feedback

\section{CHAPTER 7}

General discussion $\quad 101$

SUMMARY $\quad 115$

SAMENVATTING $\quad 119$

DANKWOORD $\quad 125$ 

CHAPTER 1

General introduction 


\subsection{Introduction}

Pressure ulcers are defined as any degenerative change of the skin and underlying tissue caused by (a combination of) pressure, shear and friction forces ${ }^{1,2}$. They are a common, and painful condition among immobile and debilitated patients, causing a great deal of suffering and frustration to patients, their relatives, and caregivers, as well as representing a considerable financial burden to society. Most pressure ulcers are avoidable and their prevention is considered one of the main criteria for evaluating the quality of nursing care ${ }^{3-5}$. At the start of the study, limited information was available about how many patients in Dutch health care settings actually suffered from pressure ulcers. Although some occasional audits had been carried out in the past, mainly in acute care hospitals $^{6-8}$, it was not clear whether these figures were reliable and representative. Furthermore, comparing these figures was problematic because they were based on different registration methods and different grading systems. The purpose of the study reported in this thesis was twofold. On the one hand, it tried to develop a uniform registration and monitoring system for the prevalence of pressure ulcers in order to start a national pressure ulcer prevalence audit in various health care settings and assess the magnitude of the problem in the Netherlands. On the other hand, it intended to improve the quality of care provided to patients, resulting in a decreased prevalence, by providing the participating institutions with feedback about their results and the opportunity to compare their results with those of similar institutions, so the audits could be used as a quality improvement instrument.

\subsection{The occurrence of pressure ulcers}

The occurrence of pressure ulcers can be measured as prevalence or incidence data. Prevalence is defined as the proportion of a population that has one or more pressure ulcers at a specific point in time (point prevalence) or during a specific period (period prevalence) ${ }^{9}$. Incidence is defined as the number of persons who develop a new pressure ulcer at a previously pressure ulcer free location, within a particular time period in a particular population ${ }^{10}$. Incidence data require daily observation and registration over a specified time period, which is very labour-intensive. In addition, such continuous registration easily leads to an underestimation of the occurrence of pressure ulcers by nurses as well as physicians ${ }^{11}$. Because prevalence data are much easier to collect, as they demand a cross-sectional design, it was decided to start with the registration of prevalence figures $^{12,13}$. 
A range of prevalence rates have been reported in the international literature. Meehan ${ }^{14}$ found a prevalence of $9.2 \%$ in 148 hospitals $(n=34,987)$ in the United States. O'Dea ${ }^{15}$ reported a prevalence rate of $18.7 \%$ in seven hospitals $(n=3,213)$ in the United Kingdom. Barrois and colleagues ${ }^{16}$ observed a prevalence of $5.2 \%$ in a survey among 12,050 patients in several acute care hospitals in the Paris region. Pressure ulcers tend to occur more frequently in nursing homes than in acute care settings. Zulkowski ${ }^{17}$ found a prevalence rate of $33.2 \%$ among 990 nursing home patients, although Shiels and $\mathrm{Roe}^{18}$ found a rate of only $7.9 \%$ in a nursing home population of 1,278 patients. Prevalence surveys among persons cared for at home have yielded rates of $4.9 \%-29.1 \%^{19}, 19.2 \%^{20}$, and $21.9 \%^{21.22}$.

Prevalence rates reported in the literature are difficult to compare, because the methodology used differs. For instance, some authors used a questionnaire to be completed by nurses on the ward to assess the prevalence rates ${ }^{16,18,19}$. Other authors used a retrospective chart review ${ }^{17.23}$. In some studies, only patients with a predetermined high risk of developing pressure ulcers were physically examined $^{14,15}$. These methods may underestimate the prevalence of pressure ulcers, as nursing staff are not always fully aware of the presence of pressure ulcers in patients without physical examination, and documentation in the nursing records is not always reliable $e^{24.25}$. Another issue that makes reported pressure ulcer occurrence difficult to compare is the use of different definitions of pressure ulcers, as particular types of pressure damage may be included or excluded. Some studies have included a discoloration of the skin as a pressure ulcer ${ }^{21.26 .27}$, while others included discoloration only when it was non-blanchable ${ }^{23,28}$. Some studies have excluded discoloration and only defined the lesion as a pressure ulcer when the skin was already broken ${ }^{29,30}$. The problems relating to the definition of pressure ulcers and the lack of a standardized method of data collection highlight the need to use standard diagnostic criteria to assess pressure ulcers and a standard methodology to collect this type of data across Dutch health care settings as a strategy for monitoring pressure ulcer care.

\subsection{Quality of care: case-mix adjustment}

Traditionally, quality of care has been assessed along three dimensions: structure, process and outcome ${ }^{31}$. Donabedian ${ }^{31}$ describes structure as the attributes of the settings in which care occurs. This includes material resources such as equipment and money, human resources such as the number and qualifications of staff, organizational structures such as medical staff organization, and methods of peer review. Process is described as what is actually done in giving and receiving care and includes the activities of practitioners in making a diagnosis and recommending or implementing treatment, as well as patients' activities in seeking care 
and carrying it out. Outcome refers to the effects of care on the patient's health status, including the patient's knowledge and behavioral changes, and the patient's level of satisfaction with the care. Measuring an outcome indicating the quality of care has the advantage that it reflects all aspects of the processes of care and not only those that are measurable or measured ${ }^{32}$. Pressure ulcers are commonly believed to be an outcome indicator of the quality of nursing care, as most pressure damage is preventable when adequate preventive strategies are employed in patients vulnerable to pressure ulcer development ${ }^{5,33,34}$.

At the start of the present study, participating health care settings were compared for their performance in terms of pressure ulcer care using crude prevalence rates. However, it became apparent that using these rates could bias the conclusions about the quality of care because of differences in patient population. It became obvious that health care settings that admitted patients with a higher risk of developing pressure ulcers would have higher pressure ulcer rates. Therefore, it was essential to control for risk factors in evaluating whether the differences in the observed prevalence could be attributed to differences in the quality of the pressure ulcer care ${ }^{35.36}$. Hence, a valid case-mix adjustment tool specifically designed for pressure ulcers needed to be developed and tested in order to use the case-mix adjusted prevalence as an indicator of the quality of pressure ulcer care.

\subsection{Quality of care: ranking institutions}

Estimating performance almost inevitably leads to a ranking of institutions to assess their relative performance ${ }^{37}$. Rankings are often presented and used without regard to the statistical uncertainty involved in them. Such rankings are particularly sensitive to sampling variability, as is shown by the fact that small institutions are more often found among the worst or best performing settings than larger institutions, probably for statistical reasons ${ }^{38}$. However, there has been no straightforward method to place interval estimates around such ranks ${ }^{37}$. Recent computational advances, specifically the Markov-Chain Monte Carlo approach, allows plausible estimates of performance to be simulated and hence a large sample of possible rankings to be derived that can be summarized and used to quantify interval estimates. This quantification of the uncertainty associated with institutional performance makes it possible to investigate the value of an institution's rank as a reflection of its relative performance and to determine the extent to which conclusions may be based on explicit rankings. Thus, confidence intervals around the ranks had to be calculated to evaluate the precision of the ranks. 


\subsection{Quality of care: quality improvement}

Improving the quality of care has been suggested to be a cyclic process, involving setting targets, changing practice and measuring change ${ }^{39-42}$. While many interventions have been used to improve quality of care, their effectiveness has been highly variable. Most interventions have some effects, but it is not yet clear which interventions work best in what setting ${ }^{43,44}$. Thomson and colleagues $^{45,46}$ concluded after a systematic review of the literature that the effects of audit and feedback are at best moderate. However, these studies provided no evidence about the effectiveness of longitudinal monitoring and giving feedback. In a study by Winkens and colleagues ${ }^{47}$ such continuous monitoring and feedback proved to be effective in reducing test ordering. Most studies, however, have been aimed at physicians and it cannot be assumed that this quality improvement strategy will also work for other groups of health care professionals with a different educational preparation and management structure. Only a few studies have described the occurrence of pressure ulcers over time with a view to assessing changes in the quality of the pressure ulcer care. Whereas some studies have shown improvement ${ }^{48,49}$, other studies have not $^{28.50 .51}$. However, it was not clear whether they used audit and feedback as the strategy for quality improvement. It remains to be shown whether continuous registration of indicators of the quality of the pressure ulcer care and the provision of feedback to the participating health care providers results in an improved quality of care.

\subsection{Research questions}

The aim of the present study was twofold. The study was set up, firstly, to assess the prevalence of pressure ulcers and the activities Dutch health care workers undertake in pressure ulcer care across different health care settings in the Netherlands. Its second aim was to improve the quality of pressure ulcer care. This thesis discusses the following research questions:

1a. Which variables have to be measured in a national registration form on pressure ulcers and what are the reliability and feasibility of the newly developed form (chapter 2)?

$1 \mathrm{~b}$. What are the prevalence and severity of pressure ulcers in various care settings, what activities do Dutch health care workers undertake to prevent and treat pressure ulcers, and are these activities in compliance with Dutch guidelines (chapter 3)? 
2. How can a valid case-mix adjustment model be developed to compare the prevalence rates of acute care hospitals in order to rank these hospitals on their performance (chapter 4 )?

3. What is the value of performance rankings as a reflection of relative performance (chapter 5)?

4. Do regular registration and the provision of feedback result in an improvement of the quality of pressure ulcer care (chapter 6)?

\subsection{Outline of the thesis}

This thesis reports on two main topics, namely the registration of pressure ulcers and whether this registration leads to improve the quality of care.

Chapter 2 reports on the development of a registration form and the design of a method to carry out a nationwide pressure ulcer prevalence survey. Based on the results of this study, the first national pressure ulcer prevalence survey was carried out in 1998. The results of this first national survey are addressed in chapter 3, which provides an overview of the prevalence rates and the preventive interventions and wound dressings used in various health care settings, and assesses whether these activities are in accordance with the Dutch guidelines.

Chapter 4 describes the development and evaluation of a model for case-mix adjustment of pressure ulcer prevalence rates, with the purpose of using this case-mix adjusted rate as an outcome indicator for the quality of care.

Chapter 5 shows how prevalence rates can be used as performance measures, especially for settings with small numbers of patients. It also evaluates the value of ranking as a measure of performance.

Chapter 6 discusses the impact of five years of prevalence surveys on the quality of care by describing the changes that have occurred over time in pressure ulcer prevalence rates, the adequate prevention of pressure ulcers, and conditions regarding pressure ulcer prevention policy.

Finally, chapter 7 presents a summary and discussion of the main findings, as well as some methodological reflections and recommendations for practice.

Most of the chapters in this thesis are based on articles published in or submitted for publication to scientific journals and were therefore written with the intention to be read independently. Some overlap between the chapters is therefore inevitable. 


\section{References}

1. Kwaliteitsinstituut voor de Gezondheidszorg CBO. Richtlijn decubitus. Tueede herziening Utrecht: Kwaliteitsinstituut voor de Gezondheidszorg CBO; 2002.

2. European Pressure Ulcer Advisory Panel. Pressure ulcer treatment guidelines. Available at: http://www.epuap.org. Accessed November 20, 2002.

3. Bates-Jensen BM. Quality indicators for prevention and management of pressure ulcers in vulnerable elders. Ann Intern Med. 2001;135:744-751.

4. Lyder CH, Preston J, Grady JN, et al. Quality of care for hospitalized Medicare patients at risk for pressure ulcers. Arch Intern Med. 2001;161:1549-1554.

5. Livne M, Steinmann M. Pressure ulcer prevention project: an international outcomes report from Israel. Outcomes Manag Nurs Pract. 2002;6:99-102.

6. Haalboom JRE. Decubitus in het ziekenhuis. Ned Tijdsch Geneeskd. 1984; 128:1957-1958.

7. Haalboom JRE. Decubitus in het ziekenhuis, vier jaar later. Ned Tijdsch Geneeskd. 1988;132: 1544-1545.

8. Hill-Rom. Decubitus prevalentie onderzoeken 1996: SSI Medical Services B.V.; 1996.

9. Rothman KJ, Greenland S. Modern Epidemiology. New York: Lippincott Williams \& Wilkins; 1998.

10. Defloor T, Bours GIJW, Schoonhoven L, Clark M. Draft EPUAP statement on prevalence and incidence monitoring. Epuap Review 2002;4:13-15.

11. Gunning-Schepers LJ, Wendte JF, Welleman E. Decubitus in Nederland: cen onderzoek naar de mogelijkheden om het voorkomen van decubitus in Nederland te meten. Amsterdam: Instituut voor Sociale Geneeskunde, Universiteit van Amsterdam; 1993.

12. Halfens R. Registratie. Paper presented at: Decubitus op de agenda, 1996; Ede.

13. Halfens RJG, Piersma J. Landelijke aanpak van decubitus. TVZ. 1997: 107:352-354.

14. Meehan M. Multisite pressure ulcer prevalence survey. Decubitus. 1990;3:14-17.

15. O'Dea K. Prevalence of pressure damage in hospital patients in the UK. $J$ Wound Care. 1993;2:221-225.

16. Barrois B, Allaert FA, Colin D. A survey of pressure sore prevalence in hospitals in the greater Paris region. J Wound Care. 1995;4:234-236.

17. Zulkowski K. MDS + items not contained in the pressure ulcer RAP associated with pressure ulcer prevalence in newly institutionalized elderly. Ostomy Wound Manage. 1999;45(1): 24-33.

18. Shiels C, Roe B. Pressure sore care: a survey of residential and nursing homes for elderly people. Elder Care. 1998;10(2):30-34.

19. Inman C, Firth JR. Pressure sore prevalence in the community. Prof Nurse. 1998;13:515-520.

20. Langemo DK, Olson B, Hunter S, Burd C, Hansen D, Cathcart-Silberberg T. Incidence of pressure sores in acute care, rehabilitation, extended care, home health, and hospice in one locale. Decubitus. 1989;2(2):42.

21. Vandenbroele H, T'Siobbel G, Geys L, van Loon H. Decubitus in de thuisverpleging: het risico en de screening. Brussel: Nationale Federatie van de Wit-Gele -Kruisvereniging: 1994.

22. Oot-Giromini BA. Pressure ulcer prevalence, incidence and associated risk factors in the community. Decubitus. 1993;6(5):24-32.

23. Schue RM, Langemo DK. Pressure ulcer prevalence and incidence and a modification of the Braden scale for a rehabilitation unit. J Wound Ostomy Continence Nurs. 1998;25:36-43.

24. Cockbill-Black S, Bond J, Bersée-Mills A, et al. Audit of pressure area care and documentation. Prof Nurse. 1999;15:173-176. 
25. Gunningberg L, Lindholm C, Carlsson M, Sjoden PO. The development of pressure ulcers in patients with hip fractures: inadequate nursing documentation is still a problem. $J A d v$ Nurs. 2000;31:1155-1164.

26. Gruen RL, Chang S, MacLellan DG. The point prevalence of wounds in a teaching hospital. Austr N Zealand J Surp. 1997;67:686-688.

27. Eckman KL. The prevalence of dermal ulcers among persons in the U.S. who have died. Decubitus. 1989;2(2):36-40.

28. Barczak CA, Barnett RI, Jarczynski-Childs E, Bosley LM. Fourth national pressure ulcer prevalence survey. Adv Wound Care. 1997;10:18-26.

29. Berlowitz DR, Ash AS, Brandeis GH, Brand HK, Halpern JL, Moskowitz MA. Rating long-term care facilities on pressure ulcer development: importance of case-mix adjustment. Ann Intern Med. 1996;124:557-563.

30. Brandeis GH, Berlowitz DR, Hossain M, Morris JN. Pressure ulcers: the minimum data set and the resident assessment protocol. Adv Wound Care. 1995;8:18-25.

31. Donabedian A. The quality of care. How can it be assessed? JAMA. 1988;260:1743-1748.

32. Mant J. Process versus outcome indicators in the assessment of quality of health care. Inter $J$ Quality Health Care. 2001;13:475-480.

33. National Pressure Ulcer Advisory Panel. Pressure ulcers in America: prevalence, incidence, and implications for the future: an executive summary of the National Pressure Ulcer Advisory Panel Monograph. Adv Skin Wound Care. 2001;14:208-215.

34. Fox C. Pressure ulcers: are they inevitable or preventable? [editorial]. Br J Nurs. 2002;11:S3.

35. Salem-Schatz S, Moore G, Rucker M, Pearson SD. The case for case-mix adjustment in practice profiling: when good apples look bad. JAMA. 1994;272:871-874.

36. Daley J, Shwartz M. Developing risk-adjustment methods. In: Iezoni LI, ed. Risk adjustment for measuring healthcare outcomes. 2nd ed. Chicago: Health Administration Press; 1997: 279-329.

37. Goldstein H, Spiegelhalter DJ. League Tables and Their Limitations: Statistical Issues in comparison of institutional Performance. J Royal Stat Soc A. 1996;159:385-443.

38. Goodhardt G. In discussion of: Goldstein H, Spiegelhalter DJ. League Tables and Their Limitations: Statistical Issues in comparison of institutional Performance. $J$ Royal Stat Soc A. 1996; 159:385-443.

39. Grol RTPM, van Everdingen JJE, Casparie AF. Imoering van richtlijnen en veranderingen. Een handleiding voor de medische, paramedische en verpleegkundige praktijk. Utrecht: De Tijdstroom; 1994.

40. Harteloh P. Casparie A. Kualiteit van zorg. Van een zorginhoudelijke benadering naar een bedriifskundige aanpak. Vierde herziene druk. Maarssen: Elsevier/De Tijdstroom; 1998.

41. Berwick DM. A primer on leading the improvement of systems. $\mathrm{Br}$ Med $\mathrm{J}$. 1996;312:619-622.

42. Hollands L, Hendriks L, Ariëns H. Elementen uan kwaliteitszorg. Begrippen en opvattingen van kwaliteitszong. 2e druk. Utrecht: LEMMA; 2002.

43. Grol RTPM. Improving the Quality of Medical Care. Building bridges among professional pride, payer profit, and patient satisfaction. JAMA. 2001; 286: 2578-2585.

44. Grimshaw JM, Shirran L, Thomas R, et al. Changing provider behavior: an overview of systematic reviews of interventions. Med Care. 2001;39(suppl 2):Il 2-II 45.

45. Thomson O'Brien MA, Oxman AD, Davis DA, Haynes RB, Freemantle N, Harvey EL. Audit and feedback: effects on professional practice and health care outcomes [Cochrane Review]. In: The Cochrane Library, Issue 1, 2002. Oxford: Update Software. Accessed February 12, 2002. 
46. Thomson O'Brien MA, Oxman AD, Davis DA, Haynes RB, Freemantle N, Harvey EL. Audit and feedback versus alternative strategies: effects on professional practice and health care outcomes [Cochrane Review]. In: The Cochrane Library, Issue 1, 2002. Oxford: Update Software. Accessed March 7, 2002.

47. Winkens RAG, Pop P, Grol RPTM, et al. Effect of routine individual feedback over nine years on general practitioners' requests for tests. $\mathrm{Br}$ Med J. 1996; 312:490.

48. Jacquerye A, Holtzer L, Gredreike Y. The national implementation of a continuous development programme of quality of care in the prevention of pressure sores: positive outcomes. Epuap Revieu 1999;1:51.

49. Berlowitz DR, Bezerra HQ, Brandeis GH, Kader B, Anderson J. Are we improving the quality of nursing home care: the case of pressure ulcers. J Am Geriatr Soc. 2000;48:59-62.

50. Wendte JF Monitoring the prevalence of pressure ulcers: does it support implementation projects? [abstract]. Paper presented at: Education: experiences we can share: 5 th European Pressure Ulcer Advisory Panel open meeting, September 27-29, 2001, 2001; Le Mans, France.

51. Coleman EA, Martau JM, Lin MK, Kramer AM. Pressure ulcer prevalence in long-term nursing home residents since the implementation of OBRA '87. J Am Geriatr Soc. 2002;50: 728-732. 
18 


\section{CHAPTER 2}

The development of a national registration form to measure the prevalence of pressure ulcers in the Netherlands

Gerrie J.J.W. Bours, Ruud J.G. Halfens, Maarten Lubbers, Jeen R.E. Haalboom. Based on paper published in: Ostomy/Wound Management 1999;45(11):28-40. 


\section{Abstract}

To gain insight into the prevalence of pressure ulcers in Dutch health care institutions it was decided to start a national registration intending to measure yearly the prevalence of pressure ulcers in different health care settings. A registration form was developed based on a literature study and a Delphi method. The reliability and the feasibility of the devised form were tested in a pilot-study, which was carried out in a university hospital, a nursing home and in a home health care setting. Interrater reliability of the grading system varied between the institutions from 0.49 to 0.97 (Cohens Kappa). In the home health care interrater reliability was 0.80 (Pearson correlation coefficient) for the total Braden scale. The prevalence rates were $10.1 \%(n=368)$ in the university hospital, $83.6 \%$ $(n=122)$ in the nursing home and $12.7 \%(n=1,541)$ in the home health care institution. The most common lesions were found on the sacrum and below the knee (heel and malleolus). It was concluded that it is possible to collect accurate and reliable data on the scope and severity of pressure ulcers with a uniform instrument in different health care settings. 


\subsection{Introduction}

Pressure ulcers are a common, costly and painful condition. Although much attention has been paid to the prevention of pressure ulcers in the Netherlands, considerable time is still spent on the treatment of pressure ulcers. Limited information is available about the prevalence of pressure ulcers in the different health care settings. Prevalence surveys show that prevalence rates vary between 5 and $15 \%$ in hospitals ${ }^{1-4}$, between 7 and $23 \%$ in nursing homes ${ }^{5-7}$ and in the home health care institutions between 19 and $33 \%^{8-11}$. However, these prevalence rates are not always comparable because of the use of different instruments and grading systems. Furthermore, in some studies it is assumed that patients have no signs of pressure ulcers because patients were classified as having no risk to develop pressure ulcers. Therefore we aimed to develop a uniform national registration system in the Netherlands to measure nationally the annual prevalence of pressure ulcers yearly in different health care settings ${ }^{12,13}$. A uniform national instrument enables comparisons to be made on a national level, a regional level, within each institution and within each unit. By attaining the measurements yearly, insight can be gained into the prevalence of pressure ulcers over time at each of the four levels. Furthermore the effect of new policy regarding pressure ulcers can be detected at each level ${ }^{13,14}$. The following research questions were formulated:

1) Which variables have to be measured in a national registration form on pressure ulcers?

2) What is the reliability and feasibility of the newly developed form?

\subsection{Methods}

Initially, a literature review was performed to investigate which variables had to be measured and in what manner. This review revealed an important source of information - a comparable project in Belgium, where three national measurements of the prevalence had already been conducted ${ }^{15}$. Next, the researchers set out to gain consensus about the variables and the way they have tot be measured. To do this, they used a Delphi-method. Thirty-four Dutch experts in the field of pressure ulcers, representing six different health care settings, participated in the Delphi study. The experts received by mail a draft registration form, which described the variables, and the way they had to be measured. The participants were asked to provide a written judgment regarding each item of the registration form. The items on which more than $75 \%$ of the experts could agree would be used in the final form. 
Table 2.1 Grading system

\begin{tabular}{|c|c|}
\hline Grade & Description \\
\hline I & Non-blanchable discoloration; \\
\hline II & $\begin{array}{l}\text { Partial-thickness skin loss involving epidermis, blister or shallow ulcer without undermi- } \\
\text { ning of adjacent tissue; }\end{array}$ \\
\hline III & $\begin{array}{l}\text { Full-thickness skin loss involving damage or necrosis of the epidermis and/or dermis not } \\
\text { extending to underlying bone, tendon or joint; }\end{array}$ \\
\hline IV & $\begin{array}{l}\text { Full-thickness skin loss involving damage or necrosis of the epidermis and/or dermis } \\
\text { extending to underlying bone tendon or joint. }\end{array}$ \\
\hline
\end{tabular}

Finally, a pilot study was conducted in a university hospital, a nursing home (which is defined in the Netherlands as a skilled care facility for psychogeriatric patients, terminally ill patients, and rehabilitation patients), and a home healthcare agency, with the aim of determining the reliability and feasibility of the form.

In each healthcare setting, a coordinator was assigned to assume primary responsibility for the study. All of the nurses were trained to use the registration form and to pay close attention to the grading system and the risk assessment scale. In the three health care settings informed consent was sought. Only patients who gave permission to participate were included in the survey.

The coordinator for the nursing home and the university hospital assembled respective teams of nurses and created a schedule so that each patient was registered by a nurse from his or her own unit and a nurse working on another unit. The survey in these two institutions was carried out in 1 day. In both institutions, two nurses examined each patient for the presence or absence of pressure ulcers. In the nursing home all patients were observed. However, in the university hospital, some units were omitted from the survey including maternity/obstetric, pediatric, and psychiatric. The two nurses who examined the patients had to agree on the grade of the pressure ulcer (see table 2.1). If the two nurses disagreed, the nurse who was not working on the unit where the patient was admitted made the final decision about the grade of the pressure ulcer. In the hospital and in the nursing home, inter-rater reliability was assessed for the grading system for every location, which was inspected by the researcher who observed the same patients at the same occasion.

In the home healthcare setting, the measurements were carried out by all primary nurses. The nurses were invited to examine the presence or absence of pressure ulcers in every patient who had given permission to do so the first time he or she was visited during a period of 2 weeks. Measuring on one day could result in an overestimation because very ill and/or immobile patients with a high risk for developing pressure ulcers receive care by the primary nurse more often (ie, every day) than patients who are not considered high risk. Measuring 
on one day could result in predominantly assessing the patients who are at high risk for developing pressure ulcers. Inter-rater reliability was assessed for the grading system as well as for the risk assessment scale. The staff nurses who were wound care specialists made a second random inspection of one patient every day.

A questionnaire was used to evaluate the feasibility of the form in terms of time necessary to fill out the form, clarity of the form, and the load for the nurses, patients and institutions.

\subsection{Results}

\section{Literature and Delphi-panel}

The literature study resulted in a draft registration form with six categories of items containing the variables and the way they had to be measured. This form was send to the Delphi panel. Table 2.2 provides the health care institutions represented on the Delphi panel and the response by institution.

The response rate was $91 \%$ in the first round and $74 \%$ in the second round. In both the first and the second rounds, the researcher tried to reduce the nonresponse rate by calling the participants. Nonresponse was generally due to vacation, illness, negligence or too busy with work. After two Delphi rounds there was consensus among the panel regarding which items would be on the registration form. The panel identified the following items:

The characteristics of the healthcare institution. In this category, a code for each healthcare institution is recorded, together with the kind of healthcare institution and 10 enabling conditions at the institution regarding a policy on the prevention of pressure ulcers. The enabling conditions are listed in table $2.3 \mathrm{a}$.

Table 2.2 Response by institution

\begin{tabular}{lccc}
\hline Institution & $\mathrm{N}$ & Response Delphi 1 & Response Delphi 2 \\
Hospital & 9 & 7 & 6 \\
Home care & 8 & 8 & 6 \\
Nursing home & 8 & 8 & 3 \\
Rehabilitation & 4 & 3 & 2 \\
Mentally health care & 2 & 2 & 1 \\
Psychiatric care & 2 & 2 & 1 \\
Other & 1 & 1 & $25(74 \%)$ \\
Total & 34 & $31(91 \%)$ &
\end{tabular}


Table 2.3a The presence of enabling conditions at the institutions

\begin{tabular}{|c|c|c|c|c|}
\hline \multicolumn{2}{|c|}{ Enabling conditions at the institutions } & \multirow{2}{*}{$\begin{array}{l}\text { Nursing home } \\
\text { Y }\end{array}$} & \multirow{2}{*}{$\begin{array}{l}\text { Hospital } \\
\qquad \mathrm{Y}\end{array}$} & \multirow{2}{*}{$\begin{array}{c}\text { Home care } \\
\qquad \mathrm{N}\end{array}$} \\
\hline 1 & $\begin{array}{l}\text { Does your institution have a pressure ulcer } \\
\text { committee? }\end{array}$ & & & \\
\hline 2 & $\begin{array}{l}\text { Does your institution have guidelines } \\
\text { (a protocol) for the prevention of pressure } \\
\text { ulcers? }\end{array}$ & $\mathrm{Y}$ & $\mathrm{Y}$ & $\mathrm{Y}$ \\
\hline 3 & $\begin{array}{l}\text { Does your institution have guidelines for the } \\
\text { treatment of pressure ulcers? }\end{array}$ & $\mathbf{Y}$ & $\mathbf{Y}$ & $\mathrm{Y}$ \\
\hline 4 & $\begin{array}{l}\text { Does your institution have a person who is } \\
\text { responsible for keeping the prevention and/or } \\
\text { treatment guidelines up-to-date and bringing } \\
\text { them to the staffs attention? }\end{array}$ & $\mathrm{Y}$ & $\mathrm{Y}$ & $\mathrm{Y}$ \\
\hline 5 & $\begin{array}{l}\text { Does your institution check if staff work in } \\
\text { accordance with the guidelines? }\end{array}$ & $\mathrm{Y}$ & $\mathrm{Y}$ & $\mathrm{Y}$ \\
\hline 6 & $\begin{array}{l}\text { Will patients with pressure ulcers be reported to } \\
\text { a central person in the institution } \\
\text { (for instance a tissue viability nurse)? }\end{array}$ & $\mathbf{Y}$ & $\mathrm{N}$ & $\mathrm{N}$ \\
\hline 7 & $\begin{array}{l}\text { Does your institution regularly register the inci- } \\
\text { dence or prevalence of pressure ulcers? }\end{array}$ & $\mathrm{Y}$ & $\mathrm{Y}$ & $\mathrm{Y}$ \\
\hline 8 & $\begin{array}{l}\text { Are the preventive materials, such as support } \\
\text { surfaces, managed centrally in the institution? }\end{array}$ & $\mathrm{N}$ & $\mathrm{Y}$ & $\mathrm{Y}$ \\
\hline 9 & $\begin{array}{l}\text { Has the institution organized an extra training } \\
\text { or a special meeting on the prevention and } \\
\text { treatment of pressure ulcers? }\end{array}$ & $\mathrm{Y}$ & $\mathrm{Y}$ & $\mathrm{Y}$ \\
\hline 10 & $\begin{array}{l}\text { Does the institution have a leaflet with informa- } \\
\text { tion about the prevention of pressure ulcers for } \\
\text { patients and/or family caregivers? }\end{array}$ & $\mathrm{N}$ & $\mathrm{N}$ & $\mathrm{N}$ \\
\hline Tot & & $80 \%$ & $80 \%$ & $70 \%$ \\
\hline
\end{tabular}

The characteristics of the unit or team. This category denotes the kind of unit and eight enabling conditions at the unit regarding a policy on the prevention of pressure ulcers. These enabling conditions are listed in table 2.3b.

Characteristics of the patient. In this category, demographic data such as date of birth, gender, date of admission and the medical diagnosis are registered.

Assessment of the risk for pressure ulcers. The risk-assessment scale used in this study is the Braden scale. This tool consists of six subscales that reflect determinants of pressure (sensory perception, activity, and mobility) and factors influencing tissue tolerance (moisture, nutrition, and friction and shear as defined by Bergstrom et al) ${ }^{16}$. Five of the six subscales are rated from 1 (least favorable) to 4 (most favorable); the friction and shear subscale is rated from 1 to 3 . The maximum total score is 23 . This scale has been thoroughly described in the literature compared with other scales ${ }^{17.18}$. Furthermore, it has been tested in a 
Table 2.3b The presence of enabling conditions at the unit or team

\begin{tabular}{|c|c|c|c|c|}
\hline & \multirow{2}{*}{$\begin{array}{l}\text { Nursing } \\
\text { home } \\
\mathrm{N}=6\end{array}$} & \multirow{2}{*}{$\begin{array}{l}\text { Hospital } \\
\mathrm{N}=30\end{array}$} & \multirow{2}{*}{$\begin{array}{l}\text { Home care } \\
\mathrm{N}=15\end{array}$} \\
\hline \multicolumn{2}{|c|}{ Enabling conditions at the unit or team } & & & \\
\hline 1 & $\begin{array}{l}\text { There is at least one person on the unit or team } \\
\text { who is specialized in the field of pressure ulcers } \\
\text { (for instance a tissue viability nurse). }\end{array}$ & $100 \%$ & $60 \%$ & $100 \%$ \\
\hline 2 & $\begin{array}{l}\text { Patients at risk or with pressure ulcers on the unit } \\
\text { or team are managed in a mono-disciplinary way. }\end{array}$ & $100 \%$ & $100 \%$ & $80 \%$ \\
\hline 3 & $\begin{array}{l}\text { Patients at risk or with pressure ulcers at the unit } \\
\text { or team are managed in a multi-disciplinary way. }\end{array}$ & $83 \%$ & $77 \%$ & $40 \%$ \\
\hline 4 & $\begin{array}{l}\text { Guidelines for the prevention of pressure ulcers are } \\
\text { utilized on the unit. }\end{array}$ & $100 \%$ & $97 \%$ & $100 \%$ \\
\hline 5 & $\begin{array}{l}\text { Guidelines for the treatment of pressure ulcers are } \\
\text { utilized on the unit. }\end{array}$ & $100 \%$ & $97 \%$ & $100 \%$ \\
\hline 6 & $\begin{array}{l}\text { For each patient, the results of risk assessment are } \\
\text { documented in nursing records. }\end{array}$ & $83 \%$ & $70 \%$ & $40 \%$ \\
\hline 7 & $\begin{array}{l}\text { The activities that have to be done for the preven- } \\
\text { tion or treatment of pressure ulcers for patients at } \\
\text { risk are documented in the nursing records. }\end{array}$ & $100 \%$ & $87 \%$ & $87 \%$ \\
\hline 8 & $\begin{array}{l}\text { The necessary preventive materials are delivered to } \\
\text { the patient within } 24 \text { hours. }\end{array}$ & $83 \%$ & $67 \%$ & $0 \%$ \\
\hline Tot & & $94 \%$ & $82 \%$ & $68 \%$ \\
\hline
\end{tabular}

greater variety of populations than any other scale. A Dutch translation is available and the first results are satisfactory ${ }^{19}$. In the present study, patients with scores of 20 or below were considered to be at risk for developing pressure ulcers. Those with scores of 21 and over were considered not to be at risk for pressure ulcer development. Using this cut-off point, Halfens and colleagues reported $73 \%$ sensitivity and $70 \%$ specificity in three different Dutch hospitals ${ }^{13}$.

Characteristics of the pressure ulcers. Under this item of the form, each pressure ulcer is recorded and linked to its identifying grade. A four-stage grading system that is comparable to other grading systems is used ${ }^{20}$. Furthermore, the location of the pressure ulcers is noted as well as the time the pressure ulcer was observed for the first time and where it originated.

Preventive methods. In this category the support surfaces and general interventions that are performed to prevent pressure ulcers are recorded.

\section{Empirical study}

Characteristics of the institution and unit

For each health care setting, 10 enabling conditions were scored, which give an impression of the favorable conditions of the institutions regarding a policy on the prevention of pressure ulcers. The nursing home and the hospital both had a 
Table 2.4 Prevalence rates for each grade by setting

$\begin{array}{lccc} & \text { Nursing home } & \text { Hospital } & \text { Home care } \\ & \mathrm{N}=122 & \mathrm{~N}=368 & \mathrm{~N}=1.541 \\ \text { Grade I } & 60.7 \% & 4.1 \% & 5.4 \% \\ \text { Grade II } & 13.9 \% & 4.6 \% & 5.3 \% \\ \text { Grade III } & 7.4 \% & 1.1 \% & 1.5 \% \\ \text { Grade IV } & 1.6 \% & 0.3 \% & 0.5 \% \\ \text { Total } & 83.6 \% & 10.1 \% & 12.7 \%\end{array}$

rating of $80 \%$; the home healthcare setting had a rating of $70 \%$. Table 2.3 a presents an overview for the ratings on these conditions.

For each unit or team within the three institutions, eight enabling conditions were scored. The mean scores for these conditions were $94 \%(n=6)$ for the nursing home, $82 \%(n=30)$ for the hospital and $68 \%(n=15)$ for the home healthcare agency. Table $2.3 \mathrm{~b}$ provides an overview of the ratings on these enabling conditions.

\section{Characteristics of the patients}

A total of 2,031 patients were screened; 368 in the hospital, 122 in the nursing home, and 1,541 in the home healthcare setting. The mean age in the hospital was 61.7 years $(\mathrm{SD}=18.7)$, in the nursing home, the mean age was 78.3 $(\mathrm{SD}=12.7)$, and in the home healthcare setting, the mean age was 76.5 $(\mathrm{SD}=13.4)$. In the three health care settings, the proportion of women was $66 \%$ in the nursing home, $50 \%$ in the hospital and $69 \%$ in the home healthcare setting. The mean number of days since admission was $952(\mathrm{SD}=1,233)$ in the nursing home, $13(\mathrm{SD}=19)$ in the hospital and $518(\mathrm{SD}=713)$ in the home healthcare setting. Of the 2,031 patients screened in the three healthcare settings screened, $46 \%$ (941) were identified as being at risk for developing pressure ulcers. Of the 941 patients who were at risk, 94 were nursing home patients representing $77 \%$ of this group; 178 were hospital patients, representing $48 \%$ of this group; and 669 were home healthcare patients, representing $43 \%$ of this group according to the total score of the Braden scale using a cut-off point of 20. The mean Braden score was $16.4(\mathrm{SD}=4.1)$ in the nursing home, 19.4 $(\mathrm{SD}=4.1)$ in the hospital and $19.9(\mathrm{SD}=3.1)$ in the home healthcare setting.

\section{Characteristics of the pressure ulcers}

In the nursing home, the pressure ulcer prevalence rate was $83.6 \%, 60.7 \%$ of which were grade I ulcers. In the hospital and in the home healthcare setting, the prevalence rates were $10.1 \%$ and $12.7 \%$, respectively from which $4.1 \%$ and $5.4 \%$ of which were classed as grade 1 . Table 2.4 gives an overview of the pressure ulcers grades for the three healthcare settings. 
Table 2.5 Duration of the pressure ulcers

\begin{tabular}{llllc}
\hline & $<2$ weeks & $2-13$ weeks & $3-6$ months & $>6$ months \\
Nursing home & $25.4 \%$ & $30.4 \%$ & $19.7 \%$ & $24.7 \%$ \\
Hospital & $31.7 \%$ & $60.3 \%$ & $3.2 \%$ & $4.8 \%$ \\
Home care & $18.9 \%$ & $42.4 \%$ & $16.9 \%$ & $21.8 \%$
\end{tabular}

Of the 2,031 patients screened, 333 patients had pressure ulcers; 102 of these patients were in the nursing home, 37 were in the hospital, and 194 were in the home healthcare setting. The total number of ulcers were 220 (which is an average of 2.2 ulcers per person) in the nursing home, 65 (average $=1.8$ per person) in the hospital, and 254 (average $=1.3$ per person) in the home healthcare setting.

The sacrum was the most common location for ulcers. In the nursing home, $31.3 \%$ of all pressure ulcers evaluated were on the sacrum; in the hospital, $41.1 \%$ were on the sacrum; and in the home healthcare setting, $44.2 \%$ were on the sacrum. The second most common site for pressure ulcers was the malleolus for the nursing home with $20.8 \%$, and the heels for the hospital and the home healthcare with $37.5 \%$ and $19.7 \%$, respectively.

In the nursing home, $94.1 \%$ of the pressure ulcers originated in the institution where the patient stayed during the prevalence survey. In the hospital and in the home healthcare institution, these percentages were $65.6 \%$ and $61.2 \%$. Both the hospital and the home healthcare agency reported that about $20 \%$ of the pressure ulcers had developed while the patient was in another institution.

In all three settings, pressure ulcers were most commonly present between 2 and 13 weeks $(30.4 \%, 60.3 \%$ and $42.4 \%$ for the nursing home, hospital, and the home healthcare setting respectively). Table 2.5 provides an overview of the duration of the pressure ulcers by healthcare institution.

\section{Preventive methods}

The application of support surfaces used for the prevention and treatment of pressure ulcers, were very heterogeneous within the three institutions. In the nursing home, $80 \%(n=75)$ of the patients who were at risk for developing pressure ulcers according to the Braden scale, using a cut-off point of $20^{13}$, had a support surface. Of these $48 \%(n=36)$ were lying on a static air mattress overlay and $24 \%(n=18)$ were lying on a foam mattress. The remainder of the patients were lying on other mattresses such as hollow fiber or water mattress.

In the hospital, $73 \%(n=130)$ of the at risk patients had a support surface, $29 \%$ $(n=37)$ of whom were on alternating mattresses, $25 \%(n=32)$ of whom were on water mattresses, and $21 \%(n=27)$ on foam mattresses. The remainder of the patients were lying on other mattresses such as static air mattress overlay or an 
Table 2.6 Judgments on the pressure ulcers in the three settings

\begin{tabular}{|c|c|c|c|c|c|c|}
\hline Observer 1 & Grade 0 & Grade I & Grade II & Grade III & Grade IV & Total \\
\hline \multicolumn{7}{|l|}{ Observer 2} \\
\hline \multicolumn{7}{|l|}{ University Hospital* } \\
\hline Grade 0 & 654 & 1 & & & & $655(97.18 \%)$ \\
\hline Grade I & & 16 & & & & $16(2.37 \%)$ \\
\hline Grade II & & & 3 & & & $3(0.45 \%)$ \\
\hline Grade III & & & & & & $0(0.00 \%)$ \\
\hline Grade IV & & & & & & $0(0.00 \%)$ \\
\hline Total & $\begin{array}{l}654 \\
(97.03 \%)\end{array}$ & $\begin{array}{l}17 \\
(2.52 \%)\end{array}$ & $\begin{array}{l}3 \\
(0.45 \%)\end{array}$ & $\begin{array}{l}0 \\
(0.0 \%)\end{array}$ & $\begin{array}{l}0 \\
(0.0 \%)\end{array}$ & ${ }^{674}(100.00 \%)$ \\
\hline \multicolumn{7}{|l|}{ Nursing home** } \\
\hline Grade 0 & 279 & 9 & & & & $288(83.72 \%)$ \\
\hline Grade 1 & 8 & 41 & & & & $49(14.24 \%)$ \\
\hline Grade 2 & & 1 & 2 & & & $3(0.87 \%)$ \\
\hline Grade 3 & & & & 2 & & $2(0.58 \%)$ \\
\hline Grade 4 & & & & & 2 & $2(0.58 \%)$ \\
\hline Total & $\begin{array}{l}287 \\
(83.43 \%)\end{array}$ & $\begin{array}{l}51 \\
(14.82 \%)\end{array}$ & $\begin{array}{l}2 \\
(0.58 \%)\end{array}$ & $\begin{array}{l}2 \\
(0.58 \%)\end{array}$ & $\begin{array}{l}2 \\
(0.28 \%)\end{array}$ & ${ }^{344}(100.00 \%)$ \\
\hline \multicolumn{7}{|l|}{ Home care ${ }^{\star \star \star}$} \\
\hline Grade 0 & 1,306 & 5 & 7 & 2 & & $1,320(97.92 \%)$ \\
\hline Grade I & 6 & 4 & 3 & & & $13(0.96 \%)$ \\
\hline Grade II & 4 & 2 & 6 & & & $12(0.89 \%)$ \\
\hline Grade III & & & & 1 & 1 & $2(0.15 \%)$ \\
\hline Grade IV & & & & & 1 & $1(0.07 \%)$ \\
\hline Total & $\begin{array}{l}1.316 \\
(97.63 \%)\end{array}$ & $\begin{array}{l}11 \\
(0.81 \%)\end{array}$ & $\begin{array}{l}16 \\
(1.19 \%)\end{array}$ & $\begin{array}{l}3 \\
(0.22 \%)\end{array}$ & $\begin{array}{l}2 \\
(0.15 \%)\end{array}$ & ${ }^{1,348}(100.00 \%)$ \\
\hline * University hospita & $\mathrm{n}=45$ pati & ents; 674 ob & ervations & & & \\
\hline $\begin{array}{l}\star \star \text { Nursing home } n= \\
\star \star \star \text { Home care } n=90\end{array}$ & $\begin{array}{l}23 \text { patients: } \\
\text { patients and }\end{array}$ & $\begin{array}{l}344 \text { observ: } \\
1,348 \text { obse }\end{array}$ & $\begin{array}{l}\text { tions } \\
\text { vations }\end{array}$ & & & \\
\hline
\end{tabular}

LAL mattress. In the home healthcare setting, $28 \%(n=185)$ of the patients at high risk for developing pressure ulcers had a support system, $62 \%$ of whom $(n=115)$ were lying on a hollow fiber mattress and $11 \%(n=20)$ were on a foam mattress. The remainder of the patients were lying on other mattresses such as a static overlay, an LAL, or water mattress.

Reliability and feasibility

To address the reliability of the form in the nursing home and in the hospital, a total of 344 ( $n=23$ patients) and 674 ( $n=45$ patients) observations respectively were made, respectively, by two nurses on the same occasion. In these groups, 
Table 2.7 Cohen's Kappa for the subscales of the Braden scale

\begin{tabular}{|c|c|c|c|}
\hline Subscale & Cohen's kappa & Mean observer 1 & Mean observer 2 \\
\hline Sensory perception & 0.50 & $3.68^{\star}(0.65)$ & $3.55^{\star}(0.73)$ \\
\hline Nutrition & 0.58 & $3.20(0.70)$ & $(0.66)$ \\
\hline Moisture & 0.56 & $(0.71)$ & $3.65(0.68)$ \\
\hline Activity & 0.69 & $(0.84)$ & $3.31(0.84)$ \\
\hline Mobility & 0.54 & $(0.89)$ & $3.30(0.87)$ \\
\hline Friction and shear & 0.61 & $(0.76)$ & $2.44(0.74)$ \\
\hline
\end{tabular}

* Difference was statistically significant $(p=0.028)$

respective prevalence rates of $95.7 \%$ and $24.4 \%$ were found. The nurses were in agreement regarding the staging of ulcers in $94 \%$ of the nursing home patients and $99.7 \%$ of the hospital patients. Cohen's Kappa of the pressure ulcer staging, was 0.97 and 0.81 , respectively, indicating agreement among the nurses. In the home healthcare agency, a staff nurse who specialized in wound care made the second random inspection, made a total of 1,348 ( $n=90$ patients) judgments regarding pressure ulcer staging. The prevalence of pressure ulcers in this sample was $20 \%$. The percentage of agreement among nurses was $98 \%$, which was mainly due to the amount of agreement on the large number of patients without pressure ulcers. However, Cohen's Kappa for the grading system was 0.49 , which demonstrates more disagreement than in the nursing home and hospital. Table 2.6 presents the judgments of the nurse pairs in the three institutions. In the university hospital, there was disagreement over one pressure ulcer and whether it was a grade I pressure ulcers or not a pressure ulcer at all. In the nursing home, most disagreement among nurses was over whether a patient's skin showed signs of grade I pressure ulcer or showed no signs at all, while the home healthcare nurse pairs mostly disagreed on no pressure ulcers and grade I and on no pressure ulcers and grade II pressure ulcer.

For the total score on the Braden scale, the Pearson correlation coefficient between the two raters was $0.81(\mathrm{p}<0.01)$, which indicates a high agreement. There was no significant difference $(p<0.01)$ within the mean score on the Braden scale between the nurse pairs (19.58; $\mathrm{SD}=3.28$ and $19.41 ; \mathrm{SD}=3.39)$.

Table 2.7 presents the Cohen's Kappa and the mean scores on the subscales of the Braden scale. Cohen's Kappa varied between 0.50 and 0.69 , which is sufficient. The difference between the mean scores on the subscale 'sensory perception' was statistically significant $(\mathrm{p}=0.028)$. The other mean scores on subscales showed no differences between the nurse pairs.

Judgments on the feasibility of the form varied between the three health care settings. For example, many home healthcare nurses indicated that the form was oriented toward hospital healthcare, which hampered them in filling out the 
form correctly. The nurses in the nursing home and in the hospital experienced some difficulty in filling out the Braden scale because they were unfamiliar with it. Some of the nurses had difficulty with the distinction between grades III and IV of the grading system. They also missed some mention of the way pressure ulcers were treated. Furthermore, they suggested adjusting the form by removing general preventive interventions, such as inspection of the skin. These interventions were found to be important recording in daily nursing reports but not in a yearly prevalence study.

The average time necessary to fill out the form varied between 4 minutes in the hospital, 8 minutes in the home healthcare setting, and 11 minutes in the nursing home. In general, the nurses in the home healthcare setting were less satisfied with the form and the nurses in the nursing home were the most content with the form.

\subsection{Conclusion and discussion}

In this study, a uniform national registration system was developed on the basis of a literature review and a Delphi panel. The six categories of data to be collected can be analyzed in a manner that permits comparison with national and international studies. If the data are not comparable, the studies are generally not as valuable because the results are not comparable rendering benchmarking difficult. No assumptions can be made about which interventions should be performed ${ }^{21}$. Testing the registration form in three different health care institutions showed that the reliability of the grading system and the risk assessment scale was generally good. In the home healthcare setting, the grading system and risk assessment scale seem less reliable than in the other settings. One explanation for the lower reliability of the grading system could be that the second judgment in the home healthcare setting was several hours after the first judgment, during which time the grade of the pressure ulcers could have been changed, especially with respect to grade I. An explanation of the lower reliability of the risk assessment scale in the same setting could be that the home healthcare nurses did not read carefully the instructions and misinterpreted the risk factors. Sensory perception, nutrition and moisture proved to be difficult risk factors to assess for home healthcare nurses, as they indicated afterwards. Difficulty interpreting moisture and nutrition has already been mentioned by Oot Giromoni ${ }^{10}$ and Halfens et al. ${ }^{13}$. These authors suggest redefining the subscales "nutrition" and "moisture" in such a way that home healthcare nurses could assess nutrition in relation to the condition of the skin and 'moisture' in relation to incontinence. 
The feasibility of the registration form proved to be satisfactory, although the nurses should have more training on the grading system and the risk assessment scale.

This study gives not only results of the reliability and feasibility of the registration form, but also results of the prevalence rates in the three institutions. Pressure ulcer prevalence was extremely high, especially in the nursing home. Although the interrater reliability is high in the nursing home, there is reason to doubt about the reliability of these figures. The measurements took place between 7.00 AM and 8.00 AM when the patients were still in bed. Therefore, a great deal of blanchable discoloration was present. This problem was also mentioned by Bergstrom and colleagues ${ }^{22}$ who suggested assigning grade I only if grade I is still observed within 24 to 72 hours. Nevertheless, more precise instruction is needed in diagnosing grade I more accurately.

The results of the prevalence rate in the home healthcare setting are very exciting because there are no studies known in the Netherlands and only a few elsewhere regarding home healthcare. The results show that pressure ulcer prevalence in this setting is almost comparable with the prevalence rate in hospitals, while the percentage high risk patients is also comparable. A possible explanation could be that the quality within this home healthcare agency is almost as good as within the hospital, although a home healthcare does not have the same facilities as a hospital. More research is needed before these results can be generalized.

The most common location for pressure ulcers in this study was the sacral area and below the knee (heel and malleolus) which is consistent with usual assumptions regarding at-risk $\operatorname{sites}^{2,5,8,23-25}$. However, in the nursing home the second most common site was the malleolus, while in the hospital and in the home healthcare setting, only a small number of people had ulcers here. This could be explained by a different bed-position in the nursing home.

The scarce use of support surfaces in the home healthcare setting is striking. Only $28 \%$ of the patients at high risk for developing pressure ulcers (Braden score cut-off point $=20$ ) had a support surface. On the one hand, this suggests that home healthcare nurses may be less alert to high-risk patients. On the other hand, it suggests that the Braden scale may be less applicable in the home healthcare setting because nurses are unable to assess nutrition and moisture by them selves. They have to rely on relatives in order to rate these items. Redefining these subscales as mentioned earlier could solve this problem.

This study shows that it is possible to collect accurate and reliable data on the scope and severity of pressure ulcers with a uniform instrument in different healthcare settings. These data are fundamental for evaluating the effectiveness of care strategies in the different settings. 


\section{References}

1. Meehan M. Multisite pressure ulcer prevalence survey. Decubitus. 1990; 3:14-17.

2. Barczak CA, Barnett RI, Jarczynski-Childs E, Bosley LM. Fourth national pressure ulcer prevalence survey. Adv Wound Care. 1997;10:18-26.

3. O'Dea K. The prevalence of pressure sores in four European countries. J Wound Care. 1995;4:192-195.

4. Barrois B, Allaert FA, Colin D. A survey of pressure sore prevalence in hospitals in the greater Paris region.J Wound Care. 1995;4:234-236.

5. Weiler PG, Kecskes D. Pressure sores in nursing home patients. Aging. 1990; 2:267-275.

6. Burd C, Langemo DK, Olson B, Hanson D, Hunter S, Sauvage T. Skin problems: epidemiology of pressure ulcers in a skilled care facility. J Gerontol Nurs. 1992;18:29-39.

7. Smith DM. Pressure ulcers in the nursing home. Ann Intern Med. 1995; 123:433-442.

8. Langemo DK, Hanson D, Cathcart-Silberberg T, Hunter S. Prevalence of pressure ulcers in five patient care settings. J Enterost Therapy. 1990;17:187-192.

9. Fuhrer MJ. Garber SL, Rintala DH, Clearman R. Pressure ulcers in community-resident persons with spinal cord injury: prevalence and risk factors. Arch Phys Med Rehabil. 1993;74: 1172-1177.

10. Oot-Giromini BA. Pressure ulcer prevalence, incidence and associated risk factors in the community. Decubitus. 1993;6(5):24-32.

11. Vandenbroele H, T'Siobbel G, Geys L, Loon Hv. Decubitus in de thuisverpleging: het risico en de screening. Brussel: Nationale Federatie van de Wit-Gele -Kruisvereniging; 1994.

12. Halfens RJG, Bours GJJW, Lubbers M, Piersma J, Buss IC. The development of a national registration system for pressure sores in the Netherlands [abstract]. Paper presented at: New approaches to the management of chronic wounds; 27-29 April, 1997, 1997; Ramada Hotel, Milan, Italy.

13. Halfens RJG, van Achterberg T, Bal RM. Validiteit en betrouwbaarheid van de Bradenschaal: een instnument om de kans op decubitus te meten. Maastricht: Universiteit Maastricht, Vakgroep Verplegingswetenschap; 1997.

14. Dealey C. Measuring the prevalence and incidence of pressure sores. $\mathrm{Br} J$ Nurs. 1993;2: 998-1006.

15. Belgische Werkgroep voor kwaliteitszorg ter preventie van decubitus. Preventie van decubitus. 1995:1-33.

16. Bergstrom N, Braden B, Laquzza A, Holman V. The Braden scale for predicting pressure sore risk: reliability studies [abstract]. Nurs Res. 1985;34:383.

17. Bridel J. The epidemiology of pressure sores. Nurs Stand. 1993;7(5):25-30.

18. Hamilton F An analysis of the literature pertaining to pressure sore risk-assessment scales. J Clin Nurs. 1992;1:185-193.

19. Beekman EP, Timmermans PPH, Halfens RJG. De Bradenschaal: validiteit en betrouwbaarheid van een meetinstrument voor het risico op decubitus. Verplecgkunde. 1996;11: 205-214.

20. Haalboom JRE, Everdingen JEv, Cullum N. Pressure sores: incidence, prevalence and classification. In: Parish LC, Witkowski JA, Crissey JT, eds. The decubitus ulcer in clinical practice. Berlin, Heidelberg, New York: -Springer-Verlag; 1997:12-23.

21. Gallagher SM. Outcomes in clinical practices: pressure ulcer prevalence and incidence studies. Ostomy Wound Manape. 1997;43(1):28-40.

22. Bengstrom N, Braden B, Kemp M, Champagne M, Ruby E. Multi-site study of incidence of pressure ulcers and the relationship between risk level, demographic characteristics, diagnoses, and prescription of preventive interventions. J Am Geriatr Sor. 1996:44:22-30. 
23. Allcock $\mathrm{N}$, Wharrad $\mathrm{H}$, Nicolson $\mathrm{A}$. Interpretation of pressure-sore prevalence. J Adv Nurs. 1994;20:37-45.

24. Mechan M. National pressure ulcer prevalence survey. Adv Wound Care. 1994;7:27-30.

25. Hill-Rom. Decubitus prevalentie onderzoeken 1996: SSI Medical Services B.V.; 1996. 
34 


\section{CHAPTER 3}

Prevalence, prevention and treatment of pressure ulcers:

Descriptive study in 89 institutions in the Netherlands

Gerrie J.J.W. Bours, Ruud J.G. Halfens, Huda Huijer Abu-Saad, Richard T.P.M. Grol.

Based on paper published in: Research in Nursing \& Health.2002;25:99-110. 
Chapter 3

36

\section{Abstract}

The purpose of the present study was to assess the prevalence of pressure ulcers and the use of Dutch guidelines for the prevention and treatment of pressure ulcers. A total of 16,344 patients in 89 health care institutions were surveyed on one day. The mean prevalence of pressure ulcers was $23.1 \%$. Dutch guidelines on some aspects of prevention and treatment of pressure ulcers were not being followed. Only $53 \%$ of the patients, who should have been positioned on a support surface, were positioned on such a device. Fewer than one-third of the patients who should be repositioned, receive nutritional support, or be educated received these interventions, and only $33.6 \%$ of all pressure ulcers were dressed as recommended. More attention to the dissemination and implementation of the guidelines is needed to reduce this high prevalence of pressure ulcers. 


\subsection{Introduction}

Pressure ulcers are a pervasive problem among immobile and debilitated patients, causing a great deal of suffering and frustration to patients, their relatives, and caregivers. Pressure ulcers also increase the workload of healthcare professionals and as a consequence increase health care costs dramatically ${ }^{1-3}$. A range of prevalence rates have been reported. Allman and colleagues ${ }^{4}$ found that the prevalence of pressure ulcers was $4.7 \%$ in a survey of 634 hospitalized adult patients; Gruen and colleagues 5 reported a prevalence of $11.1 \%$ in a 1 day survey of all 360 patients in a teaching hospital, and Bours and colleagues ${ }^{6}$ found a prevalence of $10.1 \%$ in a 1 day survey of 368 patients in a university hospital. In more extensive prevalence surveys, Meehan ${ }^{7}$ found that the prevalence of pressure ulcers was $9.2 \%$ in 148 acute care hospitals $(n=34,987)$ with a widely distributed geographically in the United States, whereas O'Dea ${ }^{8}$ reported a prevalence rate of $18.6 \%$ in seven teaching and general hospitals $(n=3,213)$ in the United Kingdom, and Barczak and colleagues ${ }^{9}$ found a prevalence of $10.1 \%$ in 265 acute care hospitals $(n=39,874)$ in the United States. The prevalence of pressure ulcers among residents of nursing homes have been found to vary between $7.9 \%{ }^{10}$ and $83.6 \%$.

Surveys among persons cared for at home have indicated a varied prevalence of pressure ulcers of $4.9 \%{ }^{11}, 12.7 \%{ }^{6}, 19.2 \%{ }^{12}, 21.9 \%{ }^{13}$ and $29.1 \%{ }^{14}$. These studies show that pressure ulcers occur with sufficient frequency to warrant concern.

To decrease the magnitude of this problem, guidelines for the prevention and treatment of pressure ulcers have been developed in several countries ${ }^{15-18}$. Important facets outlined in these guidelines are identifying individuals at risk of developing pressure ulcers, conducting educational programs to improve the outcome for those individuals, and providing protection against the adverse effects of external mechanical forces (pressure, friction, and shear). Furthermore, the guidelines indicate how existing pressure ulcers should be treated. Assessing a pressure ulcer is important for determining how to treat it. Other important aspects mentioned in the guidelines are the assessment of complications, the use of pressure ulcer prevention devices, and wound treatment, cleaning, and dressing. Skin care programs based on such guidelines have been shown to result in a decrease in pressure ulcers, reduced wound healing time, appropriate referral of unresponsive chronic wounds, decreased discrepancies in wound documentation, decreased length of stay, improved financial outcome, and improved client knowledge and participation ${ }^{19-24}$.

The Dutch guidelines on decubiti, published by the Dutch Institute for Health Care Improvement, contain instructions for the prevention, diagnosis, and treatment of pressure ulcers. The first guidelines were drawn up in 1985 by a panel of Dutch experts on the topic, based on available national and interna- 
tional research, theoretical arguments, and clinical experience ${ }^{25}$. A draft version of the guidelines was presented and discussed at an open national meeting. Suggestions were incorporated, and the guidelines were accepted as revised. After this conference the guidelines were disseminated to all health care institutions including hospitals, nursing homes, and home care institutions. Furthermore, the guidelines were published in professional journals for nurses and physicians. They were revised in $1992^{17}$.

The guidelines divide preventive methods into three categories. The first category encompasses all methods recommended as useful for all patients, such as repositioning the patient at least every 3 hours and preventing or treating malnutrition. The second category encompasses all methods recommended as useful in some individual cases, such as the application of support surfaces. The third and final category encompasses the methods regarded as not useful, such as using creams to promote the blood flow.

The guidelines for pressure ulcer treatment are divided into two categories. The first category encompasses treatments recommended as useful for each level of severity of the pressure ulcer, such as hydrocolloid dressings for grade II pressure ulcers. The second category encompasses treatments that are not considered useful, such as the use of hydrogen peroxide. The guidelines contain standard care plans for prevention and treatment for each level of severity of pressure ulcers.

Until recently, available data on the prevalence of pressure ulcers in the Netherlands was limited to a few hospitals that occasionally conducted prevalence surveys. Based on these surveys, the annual costs of prevention and treatment of pressure ulcers were estimated to be 700 million Dutch guilders (approximately $\$ 350$ million US) in intramural healthcare settings and perhaps the same amount for home care settings ${ }^{26}$. The Health Council of the Netherlands has estimated the costs at $1.3 \%$ of the total costs of health care in the Netherlands ${ }^{27}$. Because prevention is considered less costly than treatment, the Dutch Ministry of Health established a national steering group, which in 1997 started to develop initiatives to decrease the incidence and prevalence of pressure ulcers and to reduce the severity of ulcers ${ }^{28}$. One of the objectives was to start a uniform national registration system to measure the prevalence of pressure ulcers in various health care settings and to assess the prevalence and severity of ulcers. These measurements were expected to serve as a trigger for the participating institutions to develop new policies on pressure ulcers. The present article describes the results of the first national prevalence survey in the Netherlands, which answered the following questions: (a) What are the prevalence, severity, and persistence of pressure ulcers in various care settings? (b) What activities are performed by Dutch health care workers to prevent pressure ulcers, and are 
these activities in accordance with the Dutch guidelines? (c) What wound dressings are used by Dutch health care workers for the treatment of pressure ulcers, and are these dressings in accordance with the Dutch guidelines?

\subsection{Method}

\section{Settings}

All hospitals (general, university, and psychiatric), nursing homes, institutions for the physically and mentally handicapped, and home care institutions in the Netherlands were invited by mail to participate in the first national pressure ulcer survey, an initiative of the Dutch Steering Group on the prevention of pressure ulcers. Information about enrollment was published in several nursing journals. An impediment to voluntary participation in the survey was that institutions had to pay to participate because no funding was available. In the hospitals, nursing homes, residential homes, and the one participating institution for the physically handicapped the survey was performed on May $26^{\text {th }}, 1998$. Home care institutions carried out the survey over a period of 4 days, starting on the same day as the survey in the hospital health care settings. All participating institutions received a written protocol for the survey, sufficient data collection forms, a training package for the RNs or enrolled nurses responsible for the data collection teaching them about the data collection method and the use of the form, and a custom-made computer program for entering and analyzing the data.

In total, 89 institutions participated in the survey, and a total of 16,344 patients were examined. The institutions included $4(50 \%)$ of the eight Dutch university hospitals, with 1,663 patients; $39(36.5 \%)$ of the 107 Dutch general hospitals, with 8,374 patients; 20 (6\%) of the 336 Dutch nursing homes, with 3,267 patients; one $(25 \%)$ of the 4 institutions for the physically handicapped, with 46 patients; $6(4.5 \%)$ of the 132 Dutch home healthcare institutions, with 1,471 patients; and $19(1.4 \%)$ of the 1,394 Dutch residential homes, with a census of 1,523 patients. Not all hospitals included all wards. Wards most frequently excluded were psychiatric wards, maternity/obstetric wards, and pediatric wards. Hospitals were well represented in this sample, relative to the total number of hospitals in the Netherlands. None of the psychiatric hospitals and institutions for the mentally handicapped, which were also invited to enroll, participated in the study. The 19 residential homes subscribed spontaneously, without invitation. About 150 institutions returned the questionnaire sent them, with reasons for non-participation listed. The most frequent reasons given for nonparticipation were no or rare occurrence of pressure ulcers in an institution or already having enough information on the prevalence in an institution. Other 
stated reasons for non-participation were a lack of available funding or staff, or having other critical priorities, such as reorganizations or mergers. About $\mathbf{5 0}$ institutions said they would consider participating if the survey were to be carried out again.

\section{Instrument}

The data collection instrument designed for this survey was based on information gathered from a literature review and on a Delphi study with 34 experts on pressure ulcers. The instrument included six categories of data to be collected:

The characteristics of the health care institutions, for instance, whether a pressure ulcer committee was present in the institution.

The characteristics of the ward or team, for instance, whether there was at least one person on the unit or ward who specialized in pressure ulcers. Data from the first two categories enabled an estimate of conditions for effective prevention of pressure ulcers.

The characteristics of the patients (age, sex, date of admission, and reason for admission). An assessment of the risk of pressure ulcers using the Braden scale and two additional risk factors (nutrition and incontinence). The Braden scale is one of the best-known and most widely used tools for evaluating risk, with proven validity and reliability for risk assessment ${ }^{6,29-31}$. A Dutch translation was available. The scale consists of six subscales that reflect determinants of pressure (sensory perception, activity, and mobility) and factors influencing tissue tolerance (moisture, nutrition, and friction and shear as defined by Bergstrom et al. ${ }^{29}$. Five of the six subscales are rated from 1 (least favorable) to 4 (most favorable); the friction and shear item is rated from 1 to 3 . The maximum score is 23 . In the present study, patients with scores of 20 or below were considered at risk of developing pressure ulcers, with those scores of 21 and over were considered not to at risk. Using this cut-off point, Halfens and colleagues ${ }^{31}$ reported a sensitivity of $73 \%$ and a specificity of $70 \%$ for the assessment in three different Dutch hospitals. Nutrition was added because it was thought to be more important than the nutrition item (operationalized as dietary intake) in the Braden scale. The incontinence item was added because the Braden scale does not distinguish between moist (sweating) and wet (urine). Both items are rated from 1 (most favorable) to 4 (least favorable).

Assessment of the severity of pressure ulcers using a four-stage grading system similar to the pressure ulcer classification of the American and European Pressure Ulcer Advisory Panel, which defines grade I as nonblanchable discoloration; grade II as partial thickness skin loss involving epidermis, blister, or shallow ulcer without undermining of adjacent tissue; grade III as full thickness skin loss involving damage or necrosis of epidermis and/or dermis not extending to underlying bone, tendon or joint; and grade IV as full thickness 
skin loss involving damage or necrosis of the epidermis and/or dermis extending to underlying bone tendon or joint ${ }^{32}$. Each pressure ulcer was recorded and linked to its identified grade with respect to site, origin, time of first observation, and type of dressing found at examination. Dressings were classified into eight dressing types (dry dressing, enzyme dressing, anti-bacterial dressing, alginate dressing, film dressing, hydrocolloid dressing, hydrogel dressing, and foam dressing) according to the descriptions provided by the Dutch Wound Care Consultants Society ${ }^{33}$.

The type of support surface used and the preventive interventions of repositioning, prevention of malnutrition, and education of the patient and/or relatives. Repositioning was defined as planned repositioning at least every $3 \mathrm{hr}$, as noted in the nursing records. Preventing malnutrition was defined as nutritional support prescribed by a dietician. Education of the patient and/or relatives was defined as providing the patient and/or relatives with a clearly written leaflet with information about the cause and prevention of pressure ulcers.

How practical the instrument would be - how long it would take to fill out the form, how clear it was, and how much it would add to the workload of nurses, patients, and institutions - was determined by pretesting it in three types of health care institutions: acute care hospital, nursing home, and home care; using the instrument was found to be feasible Cohen's Kappa values for the grading system were, $.81, .97$ and .49 respectively in the hospital, nursing home, and home care setting. The interrater reliability of the Braden scale was assessed only in the home care settings. Pearson's correlation for the total Braden score was $.81(p<.01)$. Cohen's Kappa for the subscales ranged from .50 to .69 , which is sufficient ${ }^{34}$. More information about the instrument is provided elsewhere ${ }^{6}$.

\section{Procedure}

Each participating institution was responsible for appointing a qualified institutional coordinator, for instance a nurse specializing in tissue viability, to assume primary responsibility for the study. The coordinator was also to be the contact person at each organization surveyed. All institutional coordinators were trained collectively by the researcher, whose instruction included how to organize the survey in the institution and the uses of the data collection form and computer program. Special attention was paid to the pressure ulcer staging system, using photographs of each pressure ulcer grade, and the use of the risk assessment scale.

The institutional coordinators selected and trained a team of RNs (or enrolled nurses in the nursing and residential homes) in their institution to perform the measurements using a training package provided by the researcher. This package contained slides, photographs of each pressure ulcer grade, a manual for the data collection form, the data collection forms themselves, two 
case studies (one for hospital-type health care settings and one for home care settings) with which the nurses gain some practice in filling out the risk assessment scale, and a manual on how to use the computer program.

Each patient was assessed both by a nurse on his or her own ward and by a nurse unfamiliar with the patient and the ward. The nurses who examined the patients had to try to agree on the grade of the pressure ulcer. In case of disagreement, the nurse unfamiliar with the patient made the final decision about the staging.

In the home care setting, the home care nurses examined the patients. All patients visited by the home care nurse during the 4 measurement days were examined for pressure ulcers. To ensure reliable assessment, wound care nurses were asked to examine a small, randomly selected group of patients each day in a second assessment.

The survey protocol was reviewed and approved by the medical ethics committees of the participating health care institutions prior to beginning the study. Informed consent was sought from all participating patients in the different health care settings. Patients on each participating ward who gave permission were included in the survey.

\section{Compliance with the Dutch guidelines for prevention and treatment}

In the present study we evaluated activities performed for the prevention and treatment of pressure ulcers in order to assess whether the Dutch guidelines were being followed. The use of support surfaces and repositioning and the steps taken to prevent malnutrition and to educate patients with the aim of preventing pressure ulcers were evaluated. Wound dressings used to treat pressure ulcers were evaluated against the Dutch guidelines. The guidelines recommend the use of support surfaces for patients at high risk of developing pressure ulcers or with existing pressure ulcers. To evaluate whether Dutch health care workers acted in accordance with these guidelines, the patients were categorized into 5 groups: (a) patients at high risk of developing pressure ulcers (Braden $\leq 20$ ) but without clinical signs of such ulcers; (b) patients with grade I ulcers; (c) patients with grade II ulcers; (d) patients with grade III ulcers; and (e) patients with grade IV ulcers. The support surfaces used were classified into three categories: (a) air-fluidized beds, low-air-loss bed/overlay and alternating air bed/overlay; (b) static air bed/overlay and waterbed/overlay; and (c) foam, gel, and fiber mattresses.

The Dutch guidelines recommend repositioning for patients who are unable to move on their own. Patients who scored less than 3 on the mobility subscale of the Braden scale, which means that they were unable to move sufficiently on their own, were assumed to need repositioning. In these cases, only positioning on 
an air-fluidized bed makes repositioning superfluous according to the Dutch guidelines.

The Dutch guidelines recommend nutritional support for the prevention of pressure ulcers. Patients who had a score of less than 4 on the additional risk item of nutrition, which means that they had had at least a few days of inadequate nutritional intake, were indicated to be in need of nutritional support by a dietician.

The Dutch guidelines mention the importance of educating the patient and/relatives for the prevention of pressure ulcers. All patients at high risk of developing pressure ulcers (Braden score $\leq 20$ ) ought to receive such education.

The Dutch guidelines provide specific treatment recommendations for each severity level of pressure ulcers. The wound dressings found in the survey were compared with these recommendations. Because all health care workers are supposed to work in accordance with the Dutch guidelines, no distinction was made in this section among the health care settings.

\section{Data management}

Those conducting the study at each participating institution entered their own raw data into the specially designed menu-driven computer program, built in a Microsoft Access environment, and sent a disk with the data to the researcher within 1 month of the survey's conclusion. The institutional coordinators were asked to verify the forms before entering the data into the computer. The researcher checked the data for completeness and used the SPSS software package to compute its descriptive statistics. If data were incomplete, the researcher contacted the institutional coordinator and asked for the missing data. This resulted in cases with random missing data only for age $(n=12)$ and length of stay ( $n=487)$. These missing data were not used for determining the descriptive statistics of the variables age and length of stay.

\subsection{Results}

\section{Characteristics of the patients}

Table 3.1 lists by institution the characteristics of the patients examined during the survey. Mean age varied from 53.59 in the university hospitals to 85.91 in the residential homes. The lowest mean Braden score was found in the institution for the physically handicapped, suggesting that this type of institution has the highest percentage of patients at high risk of developing pressure ulcers. The highest mean Braden score was found in the residential homes. Female patients predominated in all settings. The mean number of days since admission to the institution ranged from 16 in the university hospitals to 6,243 in the institution 
Table 3.1 Patient characteristics

\begin{tabular}{|c|c|c|c|c|c|c|}
\hline & $\begin{array}{l}\text { University } \\
\text { hospitals }\end{array}$ & $\begin{array}{l}\text { General } \\
\text { hospitals }\end{array}$ & $\begin{array}{l}\text { Nursing } \\
\text { homes }\end{array}$ & $\mathrm{IPH}^{*}$ & $\begin{array}{l}\text { Home care } \\
\text { institutions }\end{array}$ & $\begin{array}{l}\text { Residential } \\
\text { homes }\end{array}$ \\
\hline Mean age in year & 53.59 & 66.63 & 80.65 & 53.98 & 75.55 & 85.91 \\
\hline SD & 22.05 & 17.72 & 10.30 & 16.18 & 12.82 & 6.34 \\
\hline Mean Braden score & 19.17 & 18.89 & 17.11 & 16.41 & 19.58 & 20.64 \\
\hline SD & 4.02 & 3.84 & 4.06 & 2.85 & 3.25 & 3.07 \\
\hline Female $(\%)$ & 51 & 54 & 71 & 52 & 62 & 82 \\
\hline Patients at risk (\%) & 51 & 56 & 74 & 91 & 51 & 34 \\
\hline Mean days since admission & 16 & 19 & 883 & 6243 & 773 & 1605 \\
\hline SD & 43.64 & 30.16 & 111.94 & $4,093.12$ & $1,423.89$ & $1,778.58$ \\
\hline Median & 7 & 8 & 557 & 6501 & 306 & 1009 \\
\hline Nutrition (1-4) & 3.69 & 3.67 & 3.75 & 3.87 & 3.81 & 3.89 \\
\hline SD & 0.62 & 0.62 & 0.51 & 0.40 & 0.51 & 0.38 \\
\hline Incontinence $(1-4)$ & 3.62 & 3.62 & 2.36 & 3.41 & 3.26 & 3.23 \\
\hline SD & 0.86 & 0.79 & 1.20 & 0.97 & 0.95 & 0.94 \\
\hline
\end{tabular}

* IPH $=$ Institution for the physically handicapped

Table 3.2 Prevalence by grade and by type of institution, in percentages

\begin{tabular}{lcccccc}
\hline & Grade I & Grade II & Grade III & Grade IV & Total & Min - Max \\
University hospital & 5.6 & 4.9 & 2.1 & 0.6 & 13.2 & $7.8-21.0$ \\
General hospital & 11.5 & 7.4 & 3.4 & 1.0 & 23.3 & $10.0-43.0$ \\
Nursing home & 17.5 & 8.5 & 3.7 & 2.7 & 32.4 & $7.8-66.0$ \\
IPH & 13.0 & 10.9 & 6.5 & 4.3 & 34.8 & - \\
Home care & 10.1 & 5.9 & 4.4 & 0.9 & 21.3 & $16.0-31.0$ \\
Residential home & 10.4 & 3.0 & 1.7 & 0.5 & 15.6 & $4.1-34.0$
\end{tabular}

* IPH $=$ Institution for the physically handicapped

for the physically handicapped. The mean score on the risk item of incontinence varied from 3.23 in the residential home to 3.62 in both types of hospital. Scores on the additional nutrition item ranged from 3.67 in the general hospital to 3.89 in the residential homes.

\section{Prevalence, severity, and persistence of pressure ulcers}

Of the 16,344 patients examined, 3,782 patients had one or more pressure ulcers, an overall prevalence of $23.1 \%$, which ranged from $13.2 \%$, in the university hospitals to $34.8 \%$, in the institution for the physically handicapped. Table 3.2 shows prevalence by grade for the six types of health care institutions. The most severe pressure ulcer was used to determine prevalence by grade for patients who had more than one pressure ulcer. In general, grade I accounted for approximately $50 \%$ of the prevalence in all institutions. 
Table 3.3 Anatomic location of pressure ulcers in percentages

\begin{tabular}{|c|c|c|c|c|c|c|}
\hline Location & $\begin{array}{l}\text { University } \\
\text { hospital }\end{array}$ & $\begin{array}{l}\text { General } \\
\text { hospital }\end{array}$ & $\begin{array}{l}\text { Nursing } \\
\text { home }\end{array}$ & $\mathrm{IPH}^{*}$ & $\begin{array}{l}\text { Home } \\
\text { care }\end{array}$ & $\begin{array}{l}\text { Residential } \\
\text { home }\end{array}$ \\
\hline Sacrum & 36.6 & 38.8 & 29.9 & 25.0 & 32.4 & 28.4 \\
\hline Heel & 37.4 & 32.6 & 24.8 & 25.0 & 24.8 & 28.8 \\
\hline Malleolus & 9.8 & 8.5 & 9.4 & 17.9 & 10.1 & 8.7 \\
\hline Elbow & 9.8 & 8.5 & 3.3 & - & 5.5 & 2.9 \\
\hline Ischium & 0.8 & 3.3 & 5.8 & 10.7 & 6.1 & 5.8 \\
\hline Trochanter & 0.8 & 3.4 & 7.8 & 14.3 & 6.7 & 8.3 \\
\hline Ear & 2.4 & 2.4 & 2.5 & 7.1 & 1.5 & 3.5 \\
\hline Knee & 1.1 & 0.9 & 2.1 & - & 1.1 & 2.3 \\
\hline Shoulder & 1.9 & 1.2 & 3.7 & - & 3.1 & 2.1 \\
\hline Other & 7.6 & 2.6 & 10.7 & - & 8.6 & 9.3 \\
\hline
\end{tabular}

Of all patients with pressure ulcers, $15.0 \%(n=568)$ were rated as not at risk (Braden score $>20)$. Of these, $84.7 \%$ had grade I $(n=365)$ or grade II $(n=116)$ pressure ulcers, whereas $15.3 \%$ had grade III $(n=71)$ or grade IV $(n=16)$ pressure ulcers.

In total 6,829 ulcers were found at all institutions, an average per patient who had ulcers of $1.81(\mathrm{SD}=1.36)$. The average number of ulcers per patient among those reporting any ulcers was $1.68(\mathrm{SD}=0.94)$ for the university hospitals, 1.73 $(\mathrm{SD}=1.18)$ for the general hospitals, $1.96(\mathrm{SD}=1.53)$ for the nursing homes, $1.75(\mathrm{SD}=0.86)$ for the institution for the physically handicapped, 1.67 $(\mathrm{SD}=1.52)$ in the home care setting and $2.04(\mathrm{SD}=1.90)$ for the residential homes. Residential and nursing homes had the greatest percentage of grade I ulcers, whereas more severe ulcers (grade III and IV) were more frequently recorded for those in the institution for the physically handicapped and in home care. Table 3.3 lists the percentages of pressure ulcers by anatomic location for the various settings. The sacrum and heels were the most common ulcer sites of patients in all institutions.

In addition to prevalence, the persistence of pressure ulcers was determined. The data on ulcer persistence, listed in table 3.4, show that about a quarter of the pressure ulcers of those in nursing homes and home care persisted for longer than 6 months, but for those in residential homes it was more than $50 \%$ and for those in the institution for the physically handicapped it was more than $75 \%$.

\section{Preventive methods and agreement with the Dutch guidelines}

Data were collected on the use of support surfaces (i.e., pressure relief as well as pressure reduction surfaces), the application of repositioning, the prevention of malnutrition, and the education of the patient and/or caregiver. The use of 
Table 3.4 Persistence of pressure ulcers

\begin{tabular}{lcccc}
\hline & $<2$ weeks & 2 to 13 weeks & 3 to 6 months & $>6$ months \\
University hospital & $62.0 \%$ & $31.7 \%$ & $4.6 \%$ & $1.6 \%$ \\
General hospital & $58.5 \%$ & $36.7 \%$ & $3.1 \%$ & $1.7 \%$ \\
Nursing home & $24.2 \%$ & $35.6 \%$ & $15.5 \%$ & $24.7 \%$ \\
IPH* & $3.8 \%$ & $15.4 \%$ & $15.4 \%$ & $75.4 \%$ \\
Home care & $20.3 \%$ & $34.7 \%$ & $18.6 \%$ & $26.5 \%$ \\
Residential home & $12.2 \%$ & $21.6 \%$ & $13.6 \%$ & $52.4 \%$
\end{tabular}

* IPH $=$ Institution for the physically handicapped

support surfaces was evaluated for patients at high risk of developing pressure ulcers (Braden score $\leq 20$ ) but with no clinical signs of such ulcers, and for patients with grade I, grade II, grade III and grade IV pressure ulcers. The support surfaces were divided into three categories: (a) air-fluidized beds, low-air-loss bed/overlay and alternating air bed/overlays, (b) static air bed/overlays and waterbed/overlay, and (c) foam, gel, and fiber mattresses.

Figure 3.1 shows the reported use of these pressure ulcer prevention devices. According to the accounts, $13.3 \%$ of all patients with grade IV pressure ulcers,

\author{
an foam, gel, fiber matresses \\ $\square$ static air bed/overlays, waterbed/overlay \\ 日air-fluidized, low-air-loss, alternating air bed/overlays
}

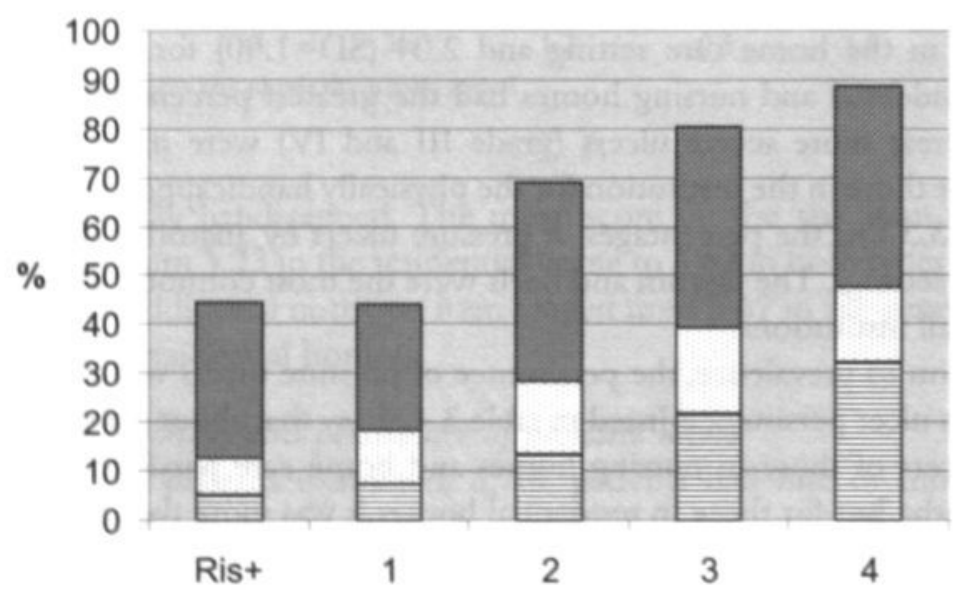

Figure 3.1 Use of supportive systems

Rist : Patients at high risk of developing pressure ulcers (Braden cut-off $\leq 20$ );

1: Patients with a grade I pressure ulcer; 2 : Patients with a grade II pressure ulcer;

3: Patients with a grade III pressure ulcer; 4: Patients with a grade IV pressure ulcer. 
about $20.8 \%$ of all patients with grade III pressure ulcers, $30.3 \%$ of all patients with grade II ulcers and $58.8 \%$ of all patients with grade I ulcers were positioned on a standard mattress without pressure relief or reduction properties. Of the patients at high risk of developing pressure ulcers, only $44.6 \%$ were positioned on a pressure-relieving or pressure-reducing bed or mattress. This means $47.0 \%(n=4,619)$ of all patients $(n=9,825)$ in need of a special bed or mattress according to the Dutch guidelines were not positioned on such a special bed or mattress.

Of all patients $28.0 \%(n=4,580)$ had scores of less than 3 on the mobility subscale of the Braden scale. Of these, 34 patients were positioned on an air-fluidized bed, which makes repositioning redundant according to the Dutch guidelines. Only $31.2 \%$ of the 4,546 patients who should have received repositioning according to the Dutch guidelines actually were repositioned.

The Dutch guidelines recommend nutritional support for the prevention of pressure ulcers. Thus, the 3,581 patients $(21.9 \%)$ who scored below 4 on the nutrition item should have received nutritional support; however, only $27.2 \%$ of them were actually being given nutritional support.

The education of patients at high risk of developing pressure ulcers showed the same type of shortcoming: only $14.7 \%(n=1,365)$ had been informed about the causes of pressure ulcers and methods to prevent them.

\section{Wound dressings and agreement with the Dutch guidelines}

Table 3.5 gives an overview of the wound dressings used by grade in the various institutions participating in the survey. The dressings are compared with the

Table 3.5 Wound dressings by pressure ulcer grade and recommendations in Dutch guidelines

\begin{tabular}{|c|c|c|c|c|c|c|c|c|}
\hline & $\begin{array}{c}\text { Grade } \\
\text { I }\end{array}$ & $\begin{array}{l}\text { Guide- } \\
\text { lines }\end{array}$ & $\begin{array}{c}\text { Grade } \\
\text { II }\end{array}$ & $\begin{array}{l}\text { Guide- } \\
\text { lines }\end{array}$ & $\begin{array}{c}\text { Grade } \\
\text { III }\end{array}$ & $\begin{array}{l}\text { Guide- } \\
\text { lines }\end{array}$ & $\begin{array}{c}\text { Grade } \\
\text { IV }\end{array}$ & $\begin{array}{l}\text { Guide- } \\
\text { lines }\end{array}$ \\
\hline No dressing & $41.8 \%$ & + & $16.7 \%$ & + & $8.0 \%$ & - & $3.5 \%$ & - \\
\hline Dry dressing & $28.8 \%$ & - & $27.7 \%$ & + & $17.4 \%$ & + & $14.7 \%$ & - \\
\hline Enzyme dressing & $0.3 \%$ & - & $1.4 \%$ & - & $6.0 \%$ & $+1-$ & $10.8 \%$ & - \\
\hline Anti-bacterial & $4.7 \%$ & - & $12.4 \%$ & - & $22.2 \%$ & - & $31.3 \%$ & + \\
\hline Alginate dressing & $0.0 \%$ & - & $0.6 \%$ & - & $3.2 \%$ & - & $9.3 \%$ & - \\
\hline Film dressing & $1.7 \%$ & + & $4.1 \%$ & - & $1.2 \%$ & + & $0.4 \%$ & + \\
\hline Hydrocolloid dressing & $3.9 \%$ & - & $13.0 \%$ & + & $17.4 \%$ & - & $5.4 \%$ & $+1-$ \\
\hline Hydrogel dressing & $0.1 \%$ & - & $0.6 \%$ & - & $1.5 \%$ & - & $3.9 \%$ & - \\
\hline Foam dressing & $0.1 \%$ & - & $1.2 \%$ & - & $2.9 \%$ & - & $2.3 \%$ & - \\
\hline Other dressing & $18.6 \%$ & - & $22.3 \%$ & - & $20.2 \%$ & - & $18.4 \%$ & - \\
\hline
\end{tabular}


recommendations in the Dutch guidelines. Only $43.5 \%$ of the grade I pressure ulcers were being treated in accordance with the Dutch guidelines, compared with $48.5 \%$ of grade II ulcers, $24.6 \%$ of grade III ulcers, and $37.1 \%$ of grade IV ulcers.

\subsection{Discussion}

This first national survey on this topic in the Netherlands shows that the prevalence of pressure ulcers is very high, much higher than the rates reported in the literature ${ }^{9.35-38}$. There were major flaws in the prevention of pressure ulcers and in the wound dressings used according to the Dutch guidelines.

Our figures may be exaggerated because not all wards in all settings were included. In particular, maternity, obstetric, short-stay, and psychiatric wards were excluded by many hospitals. In addition, there was a potential bias in the data collection; health care settings had to pay to participate in the study and may have wanted to make the best use of their money by including wards with the highest risk of decubiti. The opposite may also have occurred: health care setuings may have inciluded' those wardś with low prevalence rates to ensure more favorable outcomes for their institution in the survey. The latter situation seems unlikely, however, because the institutions' motivation to participate was to obtain information about their prevalence of pressure ulcers at their sites. Furthermore, there were no political consequences for settings with a high rate.

An important reason for institutions not to participate in the study was that they had to pay for it, and several institutions told us that they were unable to do so. It is likely that the institutions that participated in the survey were those that were very eager to improve the quality of care for pressure ulcers. It is difficult to generalize the results to other groups, but we believe that the prevalence may even be higher in other institutions.

Of the patients with pressure ulcers, $15 \%$ were classified as not at risk according to the Braden scale. We used a Braden score $\leq 20$ to define patients at high risk of developing pressure ulcers, but all patients were physically examined. Because most investigators use a Braden cut-off of $16^{39}$, the percentage of patients not at risk yet affected by pressure ulcers may be substantial. We may cautiously conclude that some other studies have underestimated the prevalence because they did not inspect all patients and incorrectly assumed that all pressure ulcers were known to the nursing staff or that patients who were evaluated as not at risk were not affected ${ }^{4,7,8,13,37,40}$. To generate figures on prevalence for comparison, the methodology should be consistent across the studies. We strongly recommend developing guidelines on how to perform prevalence surveys across different countries. The European Pressure Ulcer Advisory Panel 
has already made some progress in this respect, as the first European Pressure Ulcer survey across various European countries has been prepared and was to have taken place in $2001^{41}$.

Most pressure ulcers were grade I, meaning they had non-blanchable discoloration. A possible explanation for this high percentage is the misidentification of ulcers as grade I because nurses also included blanchable erythema as grade I ulcers. More training on the diagnosis of the grade of the pressure ulcers would be helpful in this respect. Repeated measurements of the grade I ulcers within a time interval of 24 to 72 hours, as suggested by Bergstrom and colleagues ${ }^{20}$, could also increase the accuracy of reported prevalence. On the other hand, recognizing blanchable erythema is also important in preventing pressure ulcers, as can be seen from a study performed by Derre ${ }^{42}$, in which it was found that blanchable erythema developed into a grade II pressure ulcer or worse in $37 \%$ of the patients observed.

The institutional coordinators did not report any difficulties with the assessment of grade I in dark-skinned individuals. In the Netherlands the definition of grade I has never been rewritten for those with dark skin, as was done by the National Pressure Ulcer Advisory Panel ${ }^{43}$. However, in our study during training attention was paid to the assessment of this grade in dark-skinned patients during the training. Because the proportion of dark-skinned people in the Dutch population is expected to increase by 0.6 million over the next ten years, increasing from $9.0 \%$ to $12.0 \%$ of the population ${ }^{44}$, a new definition of grade I should be formulated for an accurate assessment of this grade in the population as a whole.

In the present study the sacrum and the heels were found to be the most common anatomical sites of pressure ulcers, a result consistent with the findings of other studies reporting risk sites ${ }^{9,35,45-47}$. However, the nursing and residential homes and the home care setting showed greater variation for anatomical location than did the hospitals. This may be because hospital patients are more completely bedridden.

Many patients had suffered from one or more pressure ulcers for considerable periods of time. In the residential homes, more than $50 \%$ of the pressure ulcers had lasted for more than 6 months. A possible explanation is that the educational level of health care workers in residential homes is lower than that of those in nursing homes and home care settings ${ }^{48}$, which could affect the accuracy of their decisions and the information they use to make decisions on the treatment of pressure ulcers. This content is supported by Lamond and Farnell ${ }^{49}$, who found a significant difference between experts and novices in the accuracy of decisions in how to treat pressure ulcers. Education in wound care can improve the treatment of pressure ulcers, a finding also supported by Blegen et al. ${ }^{50}$, Buss et al. ${ }^{51}$, 
and Specht et al. ${ }^{52}$. The persistent nature of the pressure ulcers in patients in the institution for the physically handicapped can be attributed to the population in this institution: they are at very high risk of developing pressure ulcers.

Data from the present study confirm the results of previous research: existing guidelines were not being complied with $^{51.53}$. Major flaws were found in the prevention of pressure ulcers. A general lack of pressure ulcer prevention strategies in clinical practice also was found by Pieper and colleagues ${ }^{54}$. Although pressure ulcer care is a fundamental care activity, many health care professionals fail to recognize the importance of maintaining competence ${ }^{55}$. In one study the obstacles to preventive interventions reported by the nursing staff, were insufficient time, low staffing levels, lack of product availability, and the low priority given to prevention of pressure ulcers by some nursing staff ${ }^{56}$.

It was found in the current study that many types of wound dressing, especially those used for grades III and IV pressure ulcers, were not chosen appropriately according to the Dutch guidelines. The discrepancy between the dressings used and the guidelines recommendations could be a product of the Dutch guidelines being out of date, as they were last revised 8 years ago. However, the Health Council of the Netherlands still regards the guidelines as still relevant today ${ }^{27}$. Furthermore, it is difficult to evaluate whether the wounds were treated appropriately, as the data collection form did not allow for detailed description of the wound and the wound treatment. However, previous research has shown that Dutch nurses do not have sufficient knowledge of the guidelines for the prevention of pressure ulcers ${ }^{53}$, so it is reasonable to assume that there is also a gap in their knowledge of the treatment of pressure ulcers.

The prevalence of pressure ulcers in the Netherlands is too high, which can be attributed in part to nurses not acting in accordance with the Dutch guidelines for the prevention and treatment of pressure ulcers. This high prevalence rate may not be unique to the Netherlands. We think that because varied methodologies were used in the surveys, it may have masked a high prevalence rates in other countries, and we strongly recommend examining all patients and not only those at risk, to avoid underestimation of the outcome measures. The findings of the present study suggest that it is important to pay more attention to the dissemination and implementation of the Dutch guidelines in order to reduce the high prevalence of pressure ulcers.

\section{References}

1. Allman RM, Goode PS, Burst N, Bartolucci AA, Thomas DR. Pressure ulcers, hospital complications, and disease severity: impact on hospital costs and length of stay. Adv Wound Care. 1999:12:22-30. 
2. Erwin-Toth P. Cost-effective pressure ulcer management in extended care. Ostomy Wound Manage. 1995;41(7A suppl):64S-69S.

3. Haalboom JRE. De kosten van decubitus. Ned Tijdschr Geneeskd. 1991; 135:606-610.

4. Allman RM, Laprade CA, Noel LB, et al. Pressure sores among hospitalized patients. Ann Intern Med. 1986;105:337-342.

5. Gruen RL, Chang S, MacLellan DG. The point prevalence of wounds in a teaching hospital. Austr N Zealand J Surg. 1997;67:686-688.

6. Bours GJJW, Halfens RJG, Lubbers M, Haalboom JRE. The development of a national registration form to measure the prevalence of pressure ulcers in the Netherlands. Ostomy Wound Manage 1999;45(11):28-40.

7. Meehan M. Multisite pressure ulcer prevalence survey. Decubitus. 1990; 3(4):14-17.

8. O'Dea K. Prevalence of pressure damage in hospital patients in the UK. $J$ Wound Care. 1993;2:221-225.

9. Barczak CA, Barnett RI, Jarczynski-Childs E, Bosley LM. Fourth national pressure ulcer prevalence survey. Adv Wound Care. 1997;10:18-26.

10. Shiels C, Roe B. Pressure sore care: a survey of residential and nursing homes for elderly people. Elder Care. 1998;10:30-34.

11. Inman C, Firth JR. Pressure sore prevalence in the community. Prof Nurse. 1998;13:515-520.

12. Langemo DK, Olson B, Hunter S, Burd C, Hansen D, Cathcart-Silberberg T. Incidence of pressure sores in acute care, rehabilitation, extended care, home health, and hospice in one locale. Decubitus. 1989;2(2):42.

13. Vandenbroele H, T'Siobbel G, Geys L, Loon Hv. Decubitus in de thuisverpleging: het risico en de screening. Brussel: Nationale Federatie van de Wit-Gele -Kruisvereniging; 1994.

14. Oot-Giromini BA. Pressure ulcer prevalence, incidence and associated risk factors in the community. Decubitus. 1993;6(5):24-32.

15. US Department of Health and Human Services. Pressure ulcers in adults: prediction and prevention. (AHCPR Publication No. 92-0047). Rockville, MD: author; 1992.

16. US Department of Health and Human services. Pressure ulcer treatment. (AHCPR Publication No. 95-0652). Rockville, MD: author; 1994.

17. Centraal Begeleidingsorgaan Intercollegiale toetsing. Herziening consensus decubitus. Utrecht: CBO; 1992.

18. European Pressure Ulcer Advisory Panel. A policy statement on the prevention of pressure ulcers from the European Pressure Ulcer Advisory Panel [practice guideline]. $\mathrm{Br} J$ Nurs. 1998;7:888-890.

19. Arblaster G. Pressure sore incidence: a strategy for reduction. Nurs Stand. 1998; 12:49-52,54

20. Bergstrom N, Braden B, Kemp M, Champagne M, Ruby E. Multi-site study of incidence of pressure ulcers and the relationship between risk level, demographic characteristics, diagnoses, and prescription of preventive interventions. J Am Geriatr Soc. 1996;44:22-30.

21. Hanson DS, Langemo D, Olson B, Hunter S, Burd C. Decreasing the prevalence of pressure ulcers using agency standards. Home Healthcare Nurse. 1996; 14:525-531.

22. Kartes SK, Harrison MB, Wells G, Fisher A, Prince M. A team approach for risk assessment, prevention, and treatment of pressure ulcers in nursing home patients. J Nurs Care Qual. 1996;10:9-17.

23. Regan MB, Byers PH, Mayrovitz HN. Efficacy of a comprehensive pressure ulcer prevention program in an extended care facility. Adv Wound Care. 1995;8:51-52.

24. Suntken G, Starr B, Ermer-Seltun J, Hopkins L, Preftakes D. Implementation of a comprehensive skin care program across care settings using the AHCPR pressure ulcer prevention and treatment guidelines. Ostomy Wound Manage. 1996; 42(2):20-32. 
25. Centraal Begeleidingsorgaan Intercollegiale Toetsing. Consensus-bijeenkomst decubituspreventie. Utrecht: CBO; 1985.

26. Haalboom JRE, Bakker H. Herziening consensus preventie en behandeling decubitus. Ned Tijdsch Geneeskd. 1992;136:1306-1308.

27. Gezondheidsraad. Decubitus. Den Haag: Gezondheidsraad, 1999; (publicatienummer 1999/23).

28. Stuurgroep-Decubitus. Decubitus kan beter voorkomen worden: actieplan: preventie van decubitus. Woerden: NIGZ; 1997.

29. Bergstrom N, Braden BJ, Laguzza A, Holman V. The Braden scale for predicting pressure sore risk. Nurs Res. 1987;36:205-210.

30. Braden BJ, Bergstrom N. Predictive validity of the Braden scale for pressure sore risk in a nursing home. Res Nurs Health. 1994;17:459-470.

31. Halfens RJG, Achterberg Tv, Bal RM. Validity and reliability of the Braden scale and the influence of other risk factors: a multi-centre prospective. Inter J Nurs Stud.2000;37:313-319.

32. Haalboom JRE, Everdingen JEv, Cullum N. Pressure sores: incidence, prevalence and classification. In: Parish LC, Witkowski JA, Crissey JT, eds. The decubitus ulcer in clinical practice. Berlin, Heidelberg. New York: Springer-Verlag: 1997:12-23.

33. Blanken-Spindler J, ed. WCS Wondenboek. Leiden: Woundcare Consultant Society; 1991.

34. Bouter LM, van Dongen MCJM. Epidemiologisch onderzoek. Opzet en interpretatie. Houten: Bohn Stafleu Van Loghem; 1995.

35. Allcock N, Wharrad H, Nicolson A. Interpretation of pressure-sore prevalence. J Adv Nurs. 1994;20:37-45.

36. Barrois B, Allaert FA, Colin D. A survey of pressure sore prevalence in hospitals in the greater Paris region.J Wound Care. 1995;4:234-236.

37. Shannon ML, Skorga P. Pressure ulcer prevalence in two general hospitals. Decubitus. $1989 ; 2(4): 38-43$.

38. Smith DM. Pressure ulcers in the nursing home. Ann Intern Med. 1995;123:433-442.

39. Defloor T. Drukreductie en wisselhouding in de preventie van decubitus [Proefschrift]. Gent, Universiteit Gent; 2000.

40. O'Dea K. The prevalence of pressure sores in four European countries. $J$ Wound Care. 1995;4:192-195.

41. Bours G, Defloor T, Clark M, Bennett G, Meaume S. EPUAP prevalence project: minimum data set pilot: report on activities of the EPUAP prevalence report [abstract]. Paper presented at: Pressure ulcers: technology in the new millennium: 4th European Pressure Ulcer Advisory Panel open meeting, Pisa, Italy, September 27th-30th, 2000; September 27th-30th, 2000, 2000; Palazzo dei Congressi, Pisa, Italy.

42. Derre B. Evolutie van beginnende decubitus op intensieve zorgen [doctoraalscriptie]. Gent: Universiteit Gent, Faculteit Geneeskunde, Medische Sociale Wetenschappen; 1998.

43. Henderson CT, Ayello EA, Sussman C, et al. Draft definition of stage I pressure ulcers: inclusion of persons with darkly pigmented skin. Adv Wound Care. 1997;10:16-19.

44. Centraal bureau voor de statistiek. Driekuart bevolkingsgnei bestaat uit allochtonen. Voorburg/ Heerlen: Centraal bureau voor de statistiek; 2001.

45. Hill-Rom. Decubitus prewalentie onderzoeken 1996: SSI Medical Services B.V.; 1996.

46. Langemo DK, Hanson D, Cathcart-Silberberg T, Hunter S. Prevalence of pressure ulcers in five patient care settings. J Enterost Ther. 1990;17:187-192.

47. Weiler PG, Kecskes D. Pressure sores in nursing home patients. Aging. 1990; 2:267-275.

48. Commissie kwalificatiestructuur. Gekuvalificeend voor de tockomst: kuvalificatic, structuur en eindtermen wor de verpleging en verzonging. Zoetermeer: Ministerie van Onderwijs, Cultuur en Wetenschap; 1996. 
49. Lamond D, Farnell $\mathrm{S}$. The treatment of pressure sores: a comparison of novice and expert nurses' knowledge, information use and decision accuracy. J Adv Nur. 1998;27:280-286.

50. Blegen MA, Goode CJ. Reed L. Nurse staffing and patient outcomes. Nurs Res. 1998;47:43-50.

51. Buss IC, Halfens RJG, Huijer Abu-Saad H, Kok G. Evidence-based nursing practice: both state of the art in general and specific to pressure sores. J Prof Nurs. 1999;15:73-83.

52. Specht JP, Bergquist S, Frantz RA. Adoption of a research-based practice for treatment of pressure ulcers. Nurs Clin North Am. 1995;30:553-563.

53. Halfens RJG, Eggink M. Knowledge, beliefs and use of nursing methods in preventing pressure sores in Dutch hospitals. Inter J Nurs Stud. 1995;32:16-26.

54. Pieper B, Sugrue M, Weiland M, Spraque K, Heiman C. Risk factors, prevention methods, and wound care for patients with pressure ulcers. Clin Nurse Spec. 1998;12:7-12.

55. Land L. A review of pressure damage prevention.J Adv Nurs. 1995;22:329-337.

56. Provo B, Piacentine L, Dean-Baar S. Practice versus knowledge when it comes to pressure ulcer prevention.J Wound Ostomy Continence Nurs. 1997;24: 265-269. 
54 | 
CHAPTER 4

Development of a model for case-mix adjustment of pressure ulcer prevalence rates

Gerrie J.J.W. Bours, Ruud J.G. Halfens, Martijn P.F. Berger, Huda Huijer Abu-Saad, Richard T.P.M. Grol.

Based on paper published in: Medical Care. 2003;41:45-55. 


\section{Abstract}

Acute care hospitals participating in the Dutch national pressure ulcer prevalence survey use the results of this survey to compare their outcomes and assess their quality of care regarding pressure ulcer prevention. The development of a model for case-mix adjustment is essential for the use of these prevalence rates as an outcome measure. The purpose of the present study is the development of a valid model for case-mix adjustment to compare the prevalence rates in the acute care hospitals that participated in the 1998 Dutch pressure ulcer prevalence survey, for the purpose of performance comparisons among the hospitals.

Subjects were patients residing in the 43 acute care hospitals that participated in the national pressure ulcer prevalence survey on May 26, 1998. The study examined the validity of a model for case-mix adjustment of pressure ulcer prevalence rates and compared hospitals to evaluate the impact of adjusted prevalence rates on their performance. A logistic model was developed for case-mix adjustment, using age, nutrition, incontinence, activity, mobility, sensory perception, friction-and shear, and ward specialization. This model was found to have content, construct and internal validity. Case-mix adjustment influenced the hospitals' performance. The data of the national pressure ulcer prevalence survey can be used to develop a valid model for case-mix adjustment.

Conclusions about the quality of care were influenced by the use of case-mix adjusted outcomes as a measure of this quality. 


\subsection{Introduction}

The development of pressure ulcers is a common adverse event among hospital patients, causing a great deal of suffering and frustration to patients, their relatives and caregivers. Pressure ulcers are common, require the coordinated care of a multi-disciplinary team of health care workers, and can often be prevented by providing appropriate interventions ${ }^{1}$. In view of these properties, pressure ulcer data can be seen as an important indicator of the quality of care, if based on the average rate for a sufficiently large sample of patients admitted to the same facility ${ }^{2}$. Using the average rate to compare facilities on their performance may be the first step towards a benchmarking analysis, a process of learning and changing through comparison with others ${ }^{3}$. However, health care facilities may differ considerably in terms of patient population, and it is obvious that a hospital that admits patients at higher risk of developing pressure ulcers will have higher prevalence or incidence rates. Therefore, it is essential to control for risk factors in evaluating whether the differences in the observed prevalence or incidence rates can be attributed to differences in the quality of care regarding pressure ulcers ${ }^{4}$. This can be achieved by developing a case-mix adjustment model that accounts for patients' risk for developing pressure ulcers.

Only a few studies have compared facilities on the basis of their risk-adjusted pressure ulcer rates ${ }^{2,35-7}$. The appendix presents a brief summary of these studies, the majority of which used existing administrative data sets or a Minimum Data Set to derive their case-mix adjustment model. A limitation of using existing databases is that the case-mix adjustment model is restricted to those factors recorded in the database. Furthermore, there is the disadvantage that it is not always clear whether the outcome measure is based on an accurate assessment. Only one study was designed to collect data on pressure ulcers ${ }^{3}$. However, the authors did not describe how they developed their case-mix adjustment model, nor did they mention any properties of the model.

The results of the Dutch National Pressure Ulcer Survey, which was started in 1998 as part of a nationwide action plan to decrease the prevalence of pressure ulcers $^{8}$, offer an opportunity to examine the influence of case-mix adjustment in interpreting the observed differences in pressure ulcer rates. The survey was specifically designed to record pressure ulcer rates using a uniform registration form. Well-trained teams of RNs collected the data. The interrater reliability of the grading system used and that of the risk factors determined were found to be good'. The risk factors were based on a conceptual scheme of the development of pressure ulcers ${ }^{10,11}$, and incorporated the Braden scale and two additional risk factors: incontinence and nutrition. Using these factors, which are widely used to assess patients' risk for developing pressure ulcers, can increase 
the validity of the case-mix adjustment model and as a result have credibility in clinical practice, which is necessary for the acceptance of the quality indicator ${ }^{4}$.

The outcome measure used in the present study was based on prevalence rates and not on incidence rates. Although prevalence rates are affected by admission and discharge practices and only provide an assessment of the situation at one particular moment, they are easier to collect in a systematic and reliable way, and indicate the magnitude of the problem, which was one of the goals of the national survey. No validated method exists to collect incidence data on such large scale. Furthermore, incidence data is expensive and labor-intensive to collect, and often result in an underestimation ${ }^{12.13}$.

The purpose of the present study was to develop a valid case-mix adjustment model to compare the prevalence rates in the acute care hospitals that participated in the 1998 Dutch Pressure Ulcer Prevalence Survey, in order to rank the hospitals on their performance. For this purpose, the following research questions were formulated: (1) Which risk factors are associated with the presence of pressure ulcers in the acute care hospitals that participated in the 1998 National Pressure Ulcer Prevalence Survey? (2) What are the properties of a logistic model based on these risk factors? (3) Do hospitals with lower adjusted rates have better scores on the quality improvement indicators and do they perform more adequate preventive interventions? (4) Does case-mix adjustment result in different prevalence rates for the individual hospitals compared with their unadjusted prevalence rates?

\subsection{Materials and methods}

\section{Design}

The survey was carried out on May 26, 1998. The data were collected using a uniform method in different health care settings in the Netherlands. A trained coordinator selected and trained a team of nurses to perform the measurements in each institution. To ensure reliability, the data were collected in such a way that both a nurse of his or her own ward and a nurse who was unfamiliar with the patient assessed each patient. The data collection instrument designed for this study was based on a literature review and a Delphi study including 34 experts. The instrument was tested in a pilotstudy and was found to be reliable and feasible". The instrument included six categories of items to be collected:

Characteristics of the health care institution. This item provides an estimate of enabling conditions at facility level regarding the prevention of pressure ulcers (table 4.1).

Characteristics of the ward or team. These provide an estimate of enabling conditions at ward level regarding the prevention of pressure ulcers. 
Table 4.1 Enabling conditions at the hospitals

Does your hospital have a pressure ulcer committee?

Does your hospital have guidelines (a protocol) for the prevention of pressure ulcers?

Does your hospital have guidelines (a protocol) for the treatment of pressure ulcers?

Does your hospital have a person who is responsible for keeping the prevention and / or treatment guidelines up-to-date and bringing them to the staff's attention?

Does your hospital check if staff works in accordance with the guidelines?

Are patients with pressure ulcers reported to a central person in the institution (for instance a tissue viability nurse)?

Does your hospital regularly record the incidence or prevalence of pressure ulcers?

Are preventive materials, such as support surfaces, managed centrally at your hospital?

Are preventive materials, such as support surfaces, managed in a decentralized way at your hospital?

Has your hospital organized an extra training or a special meeting on the prevention and treatment of pressure ulcers in the last two years?

Does your hospital have a leaflet with information about the prevention of pressure ulcers for patients and / or caregivers?

Table 4.2 Used grading system

\begin{tabular}{|c|c|}
\hline Grade & Description \\
\hline I & Non-blanchable discoloration; \\
\hline II & $\begin{array}{l}\text { Partial-thickness skin loss involving epidermis, blister or shallow ulcer without undermi- } \\
\text { ning of adjacent tissue; }\end{array}$ \\
\hline III & $\begin{array}{l}\text { Full-thickness skin loss involving damage or necrosis of the epidermis and/or dermis not } \\
\text { extending to underlying bone, tendon or joint; }\end{array}$ \\
\hline IV & $\begin{array}{l}\text { Full-thickness skin loss involving damage or necrosis of the epidermis and/or dermis } \\
\text { extending to underlying bone tendon or joint. }\end{array}$ \\
\hline
\end{tabular}

Characteristics of the patients (age, sex, date and reason of admission). Assessment of the risk for pressure ulcers using the Braden scale and two additional risk factors (nutrition and incontinence). The Braden scale is one of the best-known and most widely used tools for evaluating pressure ulcer risk, with proven validity and reliability for risk assessment ${ }^{9,14-16}$. The scale consists of six subscales that reflect determinants of pressure (sensory perception, activity, and mobility) and factors influencing tissue tolerance (moisture, nutrition, and friction and shear as defined by Bergstrom and colleagues $\left.^{14}\right)$. Five of the six subscales are rated from 1 (least favorable) to 4 (most favorable); the friction and shear item is rated from 1 to 3 . Nutrition and incontinence were added; both rated from 1 (most favorable) to 4 (least favorable).

Assessment of the severity of pressure ulcers, using a four-stage grading system similar to the pressure ulcer classification of the Agency for Health Care 
Policy and Research and the European Pressure Ulcer Advisory Panel ${ }^{17,18}$ (table 4.2).

Assessment of the used support surfaces, and repositioning, which was defined as planned repositioning at least every three hours as noted in the nursing records.

A detailed description of the data collection procedure is provided elsewhere ${ }^{9,19,20}$.

\section{Sample}

The 1998 pressure ulcer prevalence survey included $4(50.0 \%)$ of the 8 Dutch university hospitals and $39(36.5 \%)$ of the 107 Dutch general hospitals, with a total of 10,037 cases. Children younger than 13 years $(n=165)$ were excluded from the database because only a few hospitals had included pediatric wards in their survey. Furthermore, risk factors for developing pressure ulcers may be different for children because their skin does not have the problems associated with the aging process in adults ${ }^{21,22}$.

Also excluded were those patients admitted with pressure ulcers $(n=470)$, as the ultimate purpose of the present study was to use the adjusted prevalence rate as a quality indicator, and settings are not accountable for the development of pressure ulcers not acquired in their setting. A total of 9,402 cases were left for the analyses.

\section{Analysis}

All analyses were performed using the Statistical Package for Social Science (SPSS) and an alpha of .05 was used for all analyses. The main outcome event was defined as the presence of a grade II or worse pressure ulcer, because accurately diagnosing grade I (non-blanchable discoloration) is very difficult ${ }^{23,24}$.

The data set was randomly split into two subsets of equal sizes. One half was used to develop the logistic model, the other half to measure its performance. The analysis started by fitting a full model involving all the available risk factors measured during the prevalence survey. These were the six subscales of the Braden scale and the risk factors nutrition, incontinence, and age ${ }^{16,19.25}$. Ward specialization was added to capture a component of medical status. Nonsignificant variables were deleted one by one. Once no further reduction seemed justifiable, product terms were entered on a trial basis, one by one, and were retained predominantly on the basis of statistical significance.

Based on the prediction of the logistic model for each patient, we estimated the probability of the outcome, conditional on that patient's specific risk factors. The fit of the model was assessed using the Hosmer-Lemeshow statistic which was obtained by calculating the Pearson chi-square statistic of observed and 
expected values ${ }^{26}$. Model discrimination was measured using the area under the receiver-operating characteristic curve, equaling the c-statistic ${ }^{27}$.

The expected rate of pressure ulcers was calculated for each hospital. The expected rate is the average predicted probability of pressure ulcers among the subjects in their hospital, as computed by the above method, controlling for the type of patients admitted.

The adjusted prevalence rate was determined by calculating the ratio of observed to expected rates. This ratio was multiplied by the mean of the rates observed in all hospitals, resulting in an indirectly standardized rate.

The validity of the adjusted prevalence as a measure of quality of care was assessed along two dimensions of validity: content validity and construct validity. Content validity was ensured by reviewing the risk factors and selecting those correlated with the development of pressure ulcers in the literature as candidate risk factors.

Construct validity was assessed by correlating the adjusted rates with the total number of enabling conditions at the hospitals regarding pressure ulcer prevention policy. The assumption was that hospitals with more conditions in place should have a lower adjusted prevalence. A sum score was calculated for the 11 enabling conditions used for each hospital. The conditions 8 and 9 were counted as one condition because they both indicate the management of preventive materials. An affirmative answer on either condition 8 or condition 9 resulted in a positive score on this item. The scores ranged from 0 (the minimum score) to 10 (the maximum score). A sufficient score was defined as 7 or higher, based on the median. Cronbach's Alpha of these enabling conditions was 0.80 , showing that the internal consistency reliability was high. A student's T-test was used to test for differences in the adjusted prevalence rates between hospitals with sufficient conditions and hospitals with insufficient conditions. Furthermore, Pearson correlation coefficient was calculated between the adjusted prevalence rate and the total number of enabling conditions. Finally, the percentage of patients receiving adequate preventive interventions was calculated for each facility. As it is very difficult to assess the adequacy of preventive interventions, it was decided to assess them only for a specific care group, that of immobile patients, that is, those scoring less than 3 on the mobility subscale of the Braden scale (very limited or total limited mobility). According to the Dutch guidelines for prevention and treatment of pressure ulcers, immobile patients need a support system and repositioning according to a time schedule ${ }^{28}$. If the immobile patients were indeed receiving these interventions, the preventive interventions were scored as adequate. For each hospital, the percentage of these patients receiving adequate interventions was calculated. Pearson correlation coefficient was calculated between the percentage of immobile patients receiving adequate 
interventions and the adjusted prevalence. A negative correlation between the adjusted prevalence and the total number of enabling conditions on the one hand and the percentage of immobile patients receiving adequate preventive interventions actually used among the limited mobility patients however indicates that the outcome measure is valid.

The benefit of the adjustment procedure was evaluated by correlating the total number of enabling conditions and the percentage of immobile patients receiving adequate preventive interventions with the observed prevalence. A weaker correlation was expected between the total number of enabling conditions and the observed prevalence. A weaker correlation or even a reversed sign was expected between the percentage of immobile patients receiving adequate preventive interventions and the observed prevalence.

The influence of case-mix adjustment was assessed by examining the unadjusted and adjusted ranks of the 15 hospitals with the lowest observed prevalence rates. To evaluate whether hospitals represented statistically significant outliers relative to the norm, the $95 \% \mathrm{CI}$ was calculated around the observed/expected rate, taking the number of residents per facility into consideration, and using the normal approximation to the binomial. A facility was classified as an outlier if the $\mathrm{CI}$ did not include 1 . The average number of enabling conditions and the percentage of adequate preventive interventions were compared between high and low outliers.

\subsection{Results}

\section{Sample}

The analyses included a total of 9,402 patients, admitted to 43 different acute care hospitals participating in the 1998 national pressure ulcer prevalence survey. Of these, $53.9 \%$ were female. The other patient characteristics are shown in table 4.3. The prevalence of pressure ulcers for all hospitals was $9.2 \%$, including $6.1 \%$ grade II, $2.5 \%$ grade III and $0.6 \%$ grade IV, with a range from $4.1 \%$ for the hospital with the lowest prevalence to $21.2 \%$ for the hospital with the highest prevalence.

\section{Risk factors}

The logistic model yielded eight of the ten risk factors associated with the presence of pressure ulcers: age, activity, mobility, friction and shear, incontinence, nutrition, sensory perception, and ward specialization. Two product terms were significant in the model: age $\mathrm{x}$ sensory perception and sensory perception $\mathrm{x}$ friction and shear. However, because the model also fitted well without interaction terms, we preferred to present a more parsimonious model (table 4.4). 
Table 4.3 Characteristics of the patient population in the 43 acute care hospital ( $n=9,402)$

\begin{tabular}{|c|c|c|c|}
\hline Characteristic & & Characteristic & \\
\hline Age & & Ward specialization & \\
\hline Mean & 65.14 & Internal medicine & $32.7 \%$ \\
\hline SD & 17.71 & Surgical & $26.5 \%$ \\
\hline \multirow[t]{2}{*}{ Median } & 69 & Intensive care & 3.99 \\
\hline & & Neurology & $11.7 \%$ \\
\hline Length of stay & & Orthopedics & $8.6 \%$ \\
\hline Mean & 18.22 & Geriatrics & $1.2 \%$ \\
\hline SD & 29.24 & Other & $15.4 \%$ \\
\hline Median & 8 & & \\
\hline Nutrition & & Incontinence & \\
\hline No problem & $75.9 \%$ & None & $80.5 \%$ \\
\hline Moderate & $18.3 \%$ & Occasional & $7.3 \%$ \\
\hline Severe & $4.6 \%$ & Usually urine/faeces & $9.4 \%$ \\
\hline Very severe & $1.2 \%$ & Completely & $2.8 \%$ \\
\hline Sensory perception & & Mobility & \\
\hline No impairment & $81.1 \%$ & No limitations & $49.8 \%$ \\
\hline Slightly limited & $12.8 \%$ & Slightly limited & $25.1 \%$ \\
\hline Highly limited & $4.0 \%$ & Very limited & $16.3 \%$ \\
\hline Completely limited & $2.1 \%$ & Completely immobile & $8.8 \%$ \\
\hline Moisture & & Dietary intake & \\
\hline Rarely moist & $75.8 \%$ & Excellent & $49.2 \%$ \\
\hline Occasionally moist & $15.8 \%$ & Adequate & $32.7 \%$ \\
\hline Very moist & $6.4 \%$ & Probably inadequate & $13.1 \%$ \\
\hline Constantly moist & $2.0 \%$ & Very poor & $5.0 \%$ \\
\hline Activity & & Friction and Shear & \\
\hline Walks frequently & $39.8 \%$ & No apparent problem & $61.7 \%$ \\
\hline Walks occasionally & $23.9 \%$ & Potential problem & $21.1 \%$ \\
\hline Chairfast & $17.4 \%$ & Problem & $17.2 \%$ \\
\hline Bedfast & $19.0 \%$ & & \\
\hline
\end{tabular}

\section{Model properties}

Table 4.5 presents the deciles of risk, showing the expected and observed rates of pressure ulcers. The Hosmer-Lemeshow statistic resulted in a chi-square of 8.3 $(\mathrm{df} 8 ; \mathrm{p}=.41)$ for the derivation sample and a chi-square of $7.8(\mathrm{df} 8 ; \mathrm{p}=.45)$ for the validation sample, indicating that for both the derivation and validation samples, expected rates of pressure ulcers were similar to the observed rates.

The mean of the expected prevalence rates for all patients was $9.2 \%$, with a range from $6.2 \%$ to $14.3 \%$. The c-statistic was 0.84 for the derivation sample and 0.85 for the validation sample, indicating that the model discriminates well and retains its ability to distinguish high-risk patients from low-risk patients when applied to the validation sample. 
Table 4.4 Association between patient characteristics and the presence of pressure ulcers in a multiple logistic model

\begin{tabular}{|c|c|c|c|c|}
\hline Variable & Odds ratio & $95 \% \mathrm{CI}$ & Df & $\mathrm{p}$ \\
\hline Age & 1.03 & $1.02-1.03$ & 1 & 0.00 \\
\hline $\begin{array}{l}\text { Activity* } \\
\text { Walks frequently }\end{array}$ & & & 3 & 0.01 \\
\hline Walks frequently & 1.47 & $0.93-2.31$ & 1 & 0.10 \\
\hline $\begin{array}{l}\text { Walks occasionally } \\
\text { Chairfast }\end{array}$ & 1.92 & $1.17-3.15$ & 1 & 0.01 \\
\hline Bedfast & 1.20 & $0.72-2.03$ & 1 & 0.49 \\
\hline Nutrition (1-4) & 1.21 & $1.04-1.41$ & 1 & 0.02 \\
\hline Mobility* & & & 3 & 0.01 \\
\hline \multicolumn{5}{|l|}{ No limitations } \\
\hline Slightly limited & 1.68 & $1.11-2.53$ & 1 & 0.01 \\
\hline Very limited & 1.39 & $0.86-2.51$ & 1 & 0.19 \\
\hline Completely immobile & 2.22 & $1.27-3.87$ & 1 & 0.01 \\
\hline Friction and shear $(1-3)^{*}$ & 2.46 & $2.02-3.00$ & 1 & 0.00 \\
\hline Incontinence & & & 3 & 0.00 \\
\hline \multicolumn{5}{|l|}{ Not } \\
\hline Occasional & 0.91 & $0.62-1.32$ & 1 & 0.60 \\
\hline Usually urine/faeces & 1.67 & $1.23-2.27$ & 1 & 0.00 \\
\hline Completely & 1.34 & $0.82-2.21$ & 1 & 0.24 \\
\hline Sensory perception $(1-4)^{\star}$ & 1.19 & $1.01-1.39$ & 1 & 0.03 \\
\hline Ward specialization & & & 6 & 0.00 \\
\hline \multicolumn{5}{|l|}{ Internal medicine } \\
\hline Surgical & 1.14 & $0.86-1.52$ & 1 & 0.36 \\
\hline Intensive care & 0.59 & $0.35-1.01$ & 1 & 0.06 \\
\hline Neurology & 0.38 & $0.25-0.57$ & 1 & 0.00 \\
\hline Orthopedics & 1.10 & $0.73-1.65$ & 1 & 0.65 \\
\hline Geriatrics & 0.66 & $0.28-1.54$ & 1 & 0.33 \\
\hline Other & 0.67 & $0.44-1.01$ & 1 & 0.05 \\
\hline
\end{tabular}

* These risk factors are the inverted subscales of the Braden scale.

Table 4.5 Deciles of risk table showing expected and observed rates of pressure ulcers for the derivation and validation samples

\begin{tabular}{ccccc}
\hline & \multicolumn{2}{c}{ Derivation sample $(\mathrm{n}=4,731)$} & \multicolumn{2}{c}{ Validation sample $(\mathrm{n}=4,671)$} \\
Decile & Expected rate \% & Observed rate \% & Expected rate \% & Observed rate \% \\
1 & 0.7 & 0.4 & 0.6 & 0.4 \\
2 & 1.2 & 0.2 & 1.1 & 0.4 \\
3 & 1.6 & 1.7 & 1.6 & 1.7 \\
4 & 2.1 & 1.7 & 2.1 & 1.9 \\
5 & 2.8 & 3.4 & 2.8 & 3.0 \\
6 & 4.0 & 5.5 & 4.1 & 4.4 \\
7 & 6.5 & 6.6 & 6.6 & 6.5 \\
8 & 11.7 & 11.6 & 11.8 & 9.7 \\
9 & 19.7 & 20.1 & 20.6 & 23.8 \\
10 & 40.1 & 39.2 & 40.4 & 39.8
\end{tabular}




\section{Validity of the adjusted prevalence rate as a measure of quality of care}

The presence of enabling conditions differed among the 43 hospitals. The average of the 11 enabling conditions was $5.98(\mathrm{SD}=2.74)$, whereas the median score was 7 , with a range from 0 to 10 . The adjusted prevalence was $8.54 \%$ for hospitals with sufficient conditions and $10.49 \%$ for hospitals with insufficient conditions, a difference that was significant ( $\mathrm{t} 2.11$; $\mathrm{df} 41$ : $\mathrm{p}=.04)$.

Pearson correlation coefficient between the adjusted prevalence and the total number of enabling conditions was $-0.33(\mathrm{df} 41 ; \mathrm{p}=.03)$, which indicates that settings with more enabling conditions had lower adjusted prevalence. Pearson correlation coefficient between the observed prevalence and the total number of enabling conditions was -0.27 ( $\mathrm{df} 41 ; \mathrm{p}=.08$ ), which was not significant.

The average percentage of immobile patients receiving adequate preventions in all the settings was $24.4 \%(\mathrm{SD}=17.3)$, with a range from $0.0 \%$ to $82.0 \%$. Pearson correlation coefficient between the adjusted prevalence and the percentage of immobile patients receiving adequate preventive interventions was $-0.36(\mathrm{df} 41 ; \mathrm{p}=.02)$, which was significant. Pearson correlation coefficient between the observed prevalence and the percentage of immobile patients receiving adequate interventions was -0.32 ( $\mathrm{df} 41 ; \mathrm{p}=.04)$, which was also significant. Pearson correlation coefficient between the average percentage of immobile patients receiving adequate preventive interventions and the total number of enabling conditions was 0.31 ( $\mathrm{df} 41 ; \mathrm{p}<.04$ ), indicating that an increase of the enabling conditions is associated with an increase in the average use of adequate interventions.

\section{Influence of case-mix adjustment on the hospitals' performance}

The adjusted prevalence rates ranged from $3.0 \%$ to $17.5 \%$. Adjustment for the risk factors made a difference for the hospitals. For example, one pair of hospitals had nearly identical observed rates $(7.2 \%$ and $7.3 \%)$, but after adjustment for the risk factors, their prevalence rates were $9.6 \%$ and $7.5 \%$.

The relative ranking of the hospitals was also affected by case-mix adjustment (table 4.6). The hospitals whose unadjusted ranks were 9 and 10 ranked 4 th and 25 th, respectively, when the adjusted rates were used. For hospital J, this corresponded to a shift from tenth to twenty-fifth place after case-mix adjustment.

The $95 \% \mathrm{CI}$ around the observed/expected rate ratio identified one poorquality outlier, and two high-quality outliers. The low-quality outlier had only 1 enabling condition and provided adequate preventive interventions for $11.4 \%$ of the immobile patients. The two high-quality outliers had a total of 10 and 9 enabling conditions, respectively, and provided adequate preventions for $21.1 \%$ and $82.0 \%$ of the immobile patients, respectively. 
Table 4.6 Unadjusted and adjusted ranks and rates of the 15 hospitals with the lowest unadjusted pressure ulcer rates.

\begin{tabular}{lcccc}
\hline Hospital & Unadjusted rank & Unadjusted rate, \% & Adjusted rank & Adjusted rate, \% \\
A & 1 & 4.07 & 3 & 4.17 \\
B & 2 & 4.17 & 2 & 3.17 \\
C & 3 & 4.44 & 1 & 3.04 \\
D & 4 & 5.13 & 11 & 7.53 \\
E & 5 & 5.72 & 13 & 8.01 \\
F & 6 & 5.93 & 5 & 5.67 \\
G & 7 & 6.43 & 10 & 7.03 \\
H & 8 & 6.50 & 6 & 5.95 \\
I & 9 & 6.67 & 4 & 5.55 \\
J & 10 & 7.24 & 25 & 9.62 \\
K & 11 & 7.26 & 12 & 7.54 \\
L & 12 & 7.50 & 14 & 8.18 \\
M & 13 & 7.60 & 21 & 9.22 \\
N & 14 & 7.62 & 32 & 10.98 \\
O & 15 & 7.71 & 18 & 9.00
\end{tabular}

\section{4 Discussion}

The present study shows that the annual prevalence survey can be used to develop a valid model for case-mix adjustment. Eight of the 10 risk factors associated with the presence of pressure ulcers were incorporated in the model. Our database was primarily designed for the registration of pressure ulcer prevalence rates, and the candidate predictors were mainly those risk factors that have been used in existing risk assessment scales ${ }^{14,28}$ and are based on conceptual schemes about pressure ulcers ${ }^{10,11}$. This increases the content validity and facilitates clinical acceptance of the case-mix adjustment model and acceptance of the quality indicator. The outcome measure showed construct validity in that it differed between hospitals with and without sufficient enabling conditions and in that there was a significant negative correlation between the total enabling conditions, the percentage of immobile patients receiving adequate preventive interventions and the adjusted prevalence rate.

However, the correlations between the observed prevalence and the percentage of immobile patients receiving adequate interventions, and between the observed prevalence and the total number of enabling conditions, which may be an indication of the benefit of the case-mix adjustment, were not very different from the correlations with the adjusted prevalence. As expected, the correlation with the total enabling conditions was weaker. The correlation with the percentage of immobile patients receiving adequate preventive interven- 
tions was significant, though, as expected, it was weaker. This may have been caused by the very restrictive operationalization of adequate interventions, which may have an effect on the observed prevalence as well. After all, adequate preventive interventions should result in a lower incidence and prevalence, and case-mix adjustment should strengthen this correlation.

We examined the use of case-mix adjustment in interpreting the pressure ulcer prevalence rates of acute care hospitals and found a model that performed well in cross-validated tests of validation and discrimination. The c-statistic value was superior to those found in various other studies with pressure ulcer prediction rules ${ }^{2.5}$. Comparisons with the acute care population are difficult to make as, to the authors' best knowledge; no studies have described the properties of the model using the ROC-curve in this type of population.

The fact that the internal validation measures in the present study were better than those in the above-mentioned studies could be due to our study being primarily designed to gather data on prevalence, and to the fact that risk factors for pressure ulcer development were deliberately recorded. Using administrative data has the disadvantage that the ICD coding nomenclature does not provide a complete picture of the extent and nature of all dimensions of the risk of developing pressure ulcers ${ }^{29}$. Furthermore, the retrospective nature of discharge diagnoses may result in an underestimation of the outcome of interest. In addition, the risk factors assessed at $t_{0}$ are not always the actual risk factors at $t_{1}$, depending on the time interval between the two dates, as the population studied will not be stable during this interval. Careful examination of patients in a pressure ulcer prevalence survey yields more reliable data, resulting in a more valid outcome measure for comparing the quality of care. If the data is to be used for important research or policy questions (for instance financial incentives), administrative databases may not be suitable, and more reliable data will be needed.

Adjustment for patient risk factors is important in comparing health care settings on outcome performance as a measure of quality of care; since the hospitals' adjusted ranks were found to differ from their unadjusted ranks. These differences in ranking may be more important for benchmarking than the actual differences in (adjusted) prevalence. Furthermore, three outliers relative to the norm were identified, in which a difference was found between the total number of enabling conditions and adequate preventive interventions in favor of the high quality outliers.

The risk model we used was derived from a database specifically designed to assess pressure ulcer prevalence rates, and proved to be valid. However, no absolute judgments can be made about the quality of care, because the only measure of quality used was the prevalence of pressure ulcers. Quality of care is not necessarily uniform across all dimensions of care, a view that is supported by 
Mukamel and Brower ${ }^{30}$. They used several outcome measures to assess the quality of care in nursing homes, and when they used case-mix adjustment, the relative ranking of their settings was not the same for all outcomes.

On the other hand, poor performance in terms of pressure ulcer management has been found to be related to problems with other quality measures ${ }^{31}$ and deficiency citations during state inspections ${ }^{2}$.

Random variation affects estimates of hospital performance and thus limits the conclusions that can be drawn safely from a comparison of patient outcomes in health care settings. Random variation arises in measuring the quality of care on the basis of an outcome rate in a sample of patients, and increasing the sample sizes would reduce the standard error. The hospitals in our study were quite large: the smallest hospital had a sample size of 52 , while four hospitals had sample sizes between 70 and 90 , and all others had sample sizes above 100 (range 112-538). The smaller the samples size at the hospitals, the greater the care that must be taken in interpreting the quality indicator. Furthermore, it should be remembered that the outcome measure was the result of a one-day prevalence survey. Even with our rather large sample, the actual prevalence of pressure ulcers may have differed due to random fluctuations. Repeating the strategy by combining data from several years will minimize the effect of random variation on the prevalence rate.

Our outcome measure was based on the prevalence rates at the various hospitals. Prevalence rates are affected by both incidence and healing rates. Because processes of care relating to the prevention of pressure ulcers are different from those relating to their treatment, hospitals with a high prevalence cannot know exactly whether they should improve their preventive policies or their treatment policies. However, as we removed those patients from the database that were admitted with a pressure ulcer, one could argue that in any case, the prevalence should be largely attributed to inappropriate interventions. Furthermore, assessing incidence rates is expensive and it is difficult to do this reliably throughout the country. Such assessments often result in rates being underestimated $^{12}$, whereas quantifying this underestimation for each hospital yields the same problems.

In conclusion, the development of a case-mix adjustment model is an essential strategy for a meaningful comparison of pressure ulcer prevalence rates across acute care hospitals. It may be a helpful method to compare rates at various hospitals, especially if their patient populations differ substantially. The hospitals can gain valuable insights into their relative performance and may be stimulated to improve their pressure ulcer prevention strategies. 
Appendix 1. Summary of risk-adjusted models of pressure ulcer rate

Author Setting Risk factors used Modeling

Bankert Acute Braden scale (sensory perception,

et al. ${ }^{3}$

care

hospitals

moisture, mobility, activity, nutriti-

onal intake, friction and shear).

presence of pressure ulcers

Berlowitz Nursing Dependence in transferring, mobi-

et al. ${ }^{5}$ home lity, and toileting, presence of stasis ulcer and presence of grade 1

pressure ulcer; presence of terminal

illness, receiving wound care,

recency of admission, urinary tract

infection, residing in intermediate

medicine and number of specia-

lized services being received.

\section{Arling Nursing Impaired transfer, impaired bed}

et al home mobility, hemiplegia, quadriplegia,

coma, malnutrition, peripheral

vascular disease, history of PU,

desensitized skin, terminal prog-

nosis, diabetes, pitting edema.

Risk-adjusted outcome

Comments

Not clear; it seems to be

based on clinical jud-

gment using a risk asses-

sment scale for developing pressure ulcers

Empirical modeling and clinical judgment

Clinical judgment

Prevalence of grade 1-4 PU stratified into high

or low risk group rate, multiplied rate of all facilities
Database primarily designed for collecting data on pressure ulcers; no mention of how the risk model was developed; model properties not mentioned;

Administrative database was used; no theoretical underpinning of risk factors; model was cross-validated
MDS + was used; very restrictive risk definition; no theoretical underpinning for risk factor 
Continued Appendix 1. Summary of risk-adjusted models of pressure ulcer rate

$\begin{array}{lll}\text { Author } & \text { Setting } & \text { Risk factors used } \\ \text { Mukamel }^{2} & \begin{array}{l}\text { Nursing } \\ \text { home }\end{array} & \begin{array}{l}\text { Age, female, decubitus level at } \\ \text { admission, RUGs score; RUGs } \\ \text { score squared; transfer limitation } \\ \text { level 3,4,5; mobility restrictions } \\ \text { level 3,4,5; terminally ill; diabetic: } \\ \text { physically restrained }\end{array}\end{array}$

Porell and Nursing Male, newly admitted, dementia,

Caro home Alzheimer, diabetes, genitourinary, skin, ADL status, incontinence,

contracture, decubitus ulcers, not for profit, management firm, net revenue, mean MMQ score

\section{Modeling}

Empirical modeling

\section{Empirical modeling}

Difference between expected and observed decubitus ulcers (presence and severity) over specific time periods

Difference between observed and expected rates of deterioration in decubitus

\section{Comments}

ministrative database was used; no theoretical underpinning for risk factors; validity of the outcome measure was assessed along several dimensions

Administrative database was used; no theoretical underpinning for risk factors. 


\section{References}

1. Buss IC, Halfens RJG, Huijer Abu-Saad H, Kok G. Evidence-based nursing practice: both state of the art in general and specific to pressure sores. J Prof Nurx. 1999;15:73-83.

2. Mukamel DB. Risk-adjusted outcome measures and quality of care in nursing homes. Med Care. 1997;35:367-385.

3. Bankert K, Daughtridge S, Meehan M, Colburn L. The application of collaborative benchmarking to the prevention and treatment of pressure ulcers. Adv Wound Care. 1996:9:21-29.

4. Daley J. Shwartz M. Developing risk-adjustment methods. In: Iezoni LI, eds. Risk adjustment for measuring health care outcomes. Chicago: Health Administration Press; 1997:279-329.

5. Berlowitz DR, Ash AS, Brandeis GH, Brand HK, Halpern JL, Moskowitz MA. Rating long-term care facilities on pressure ulcer development: importance of case-mix adjustment. Ann Intem Med. 1996;124:557-563.

6. Arling G, Karon SL, Sainfort F, Zimmerman DR, Ross R. Risk adjustment of nursing home quality indicators. Gerontologist. 1997;37:757-766.

7. Porell F,Caro FG. Facility-level outcome performance measures for nursing homes. Gerontologist. 1998; 38:665-683.

8. Stuurgroep Decubitus. Decubitus kan beter voorkomen worden: Actieplan: preventie un decubitus. Woerden: Nationaal Instituut voor Gezondheidsbevordering en Ziektepreventic; 1997.

9. Bours GJJW, Halfens RJG, Lubbers M, Haalboom JRE. The development of a national registration form to measure the prevalence of pressure ulcers in the Netherlands. Ostomy Wound Manage. 1999;45(11):28-40.

10. Defloor T. The risk of pressure sores: a conceptual scheme. J Clinic Nurs. 1999;8:206-216.

11. Braden BJ, Bergstrom N. A conceptual schema for the study of the aetiology of pressure sores. Rehabil Nurs. 1987;12:8-12.

12. Gunning-Schepers LJ, Wendte JF, Welleman E. Decubitus in Nederland: een onderzoek naar de mogelijkheden om het voorkomen van decubitus in Nederland te meten. Amsterdam: Instituut voor Sociale Geneeskunde, Universiteit van Amsterdam; 1993.

13. National Pressure Ulcer Advisory Panel. Cuddigan J, Ayello EA, Sussman C, eds. Pressure ulcers in America: prevalence, incidence, and implications for the future. Reston, VA: National Pressure Ulcer Advisory Panel, 2001.

14. Bergstrom N, Braden BJ, Laguzza A, Holman V. The Braden scale for predicting pressure sore risk. Nurs Res. 1987;36:205-210.

15. Braden BJ, Bergstrom N. Predictive validity of the Braden scale for pressure sore risk in a nursing home. Res Nurs Health. 1994;17:459-470.

16. Halfens RJG, Van Achterberg T, Bal RM Validity and reliability of the Braden scale and the influence of other risk factors : a multi-centre prospective. Int J Nurs Stud. 2000;37:313-319.

17. European Pressure Ulcer Advisory Panel. A policy statement on the prevention of pressure ulcers from the European Pressure Ulcer Advisory Panel [practice guideline]. Br J Nurs. 1998;7:888-890.

18. US Department of Health and Human Services. Pressure ulcer treatment. (AHCPR Publication No. 95-0652). Rockville MD: author;1994.

19. Bours GJJW, De Lat E, Halfens RJG, Lubbers M. Prevalence, risk factors and prevention of pressure ulcers in Dutch intensive care units: results of a cross-sectional survey. Intens Care Med. 2001;27:1599-1605.

20. Bours GJJW, Halfens RJG, Huijer Abu-Saad H, Grol, RTPM. Prevalence, prevention and treatment of pressure ulcers: descriptive study in 89 institutions in the Netherlands. Res Nurs Health. 2002;25:99-110. 
21. Zollo MB, Gostisha ML, Berens RJ, Schmidt JE, Weigle CGM. Altered skin integrity in children admitted to a paediatric intensive care unit. J Nurs Care Qual. 1996;11:62-67.

22. Pallija G, Mondozzi M,Webb AA. Skin care of the paediatric patient. $J$ Ped Nurs. 1999;14:80-87.

23. Bergstrom N, Braden B, Kemp M, Champagne M, Ruby E. Multi-site study of incidence of pressure ulcers and the relationship between risk level, demographic characteristics, diagnoses, and prescription of preventive interventions. J Am Geriatr Soc. 1996;44:22-30.

24. Halfens RJG, Bours GJW, Van Ast W. The relevance of the diagnosis pressure ulcer stage 1: an empirical study regarding the course of stage 1 in a general hospital and nursing home population.J Clin Nurs. 2001;10:748-757.

25. Hunt J. Application of a pressure area risk calculator in an intensive care unit. Intens Crit Care Nurs. 1993;9:226-231.

26. Hosmer DW, Lemeshow S. Applied logistic regression. New York: John Wiley \& Sons; 1989.

27. Ash AS, Shwartz M. Evaluating the performance of risk-adjustment methods: dichotomous outcomes. In: Iezoni LI, eds. Risk adjustment for measuring health care outcomes. Chicago: Health Administration Press; 1997: 427-469.

28. Centraal Begeleidingsorgaan voor de Intercollegiale Toetsing. Herziening consensus decubitus. Utrecht: Centraal Begeleidingsorgaan voor de Intercollegiale Toetsing; 1992.

29. Iezoni LI. Risk adjustment for measuring healthcare outcomes. Chicago: Health Administration Press; 1997.

30. Mukamel DB, Brower CA. The influence of risk adjustment methods on conclusions about quality of care in nursing homes based on outcome measures. Gerontologist. 1998;38:695-703.

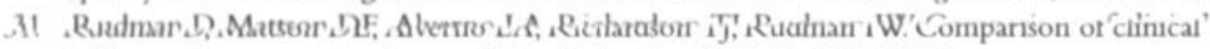
indicators in two nursing homes. J Am Geriatr Soc. 1993; 41:1317-1325. 


\section{CHAPTER 5}

Assessing the performance of Dutch nursing homes using the prevalence of setting-acquired pressure ulcers:

A Bayesian approach by multilevel modeling

Gerrie J.J.W. Bours, Math J.J.M. Candel, Ruud J.G. Halfens, Richard T.P.M. Grol, Huda Huijer Abu-Saad.

(Submitted). 


\section{Abstract}

The purpose of the present study was to show how multilevel modeling techniques can be applied to pressure ulcer prevalence data to obtain hierarchical Bayes estimates of the nursing homes' performance and to investigate the usefulness of performance ranking by quantifying the uncertainty of the rankings. The data collected on the $5^{\text {th }}$ national pressure ulcer prevalence audit in 43 Dutch nursing homes with 5,945 patients were used.

The performance was estimated using the mean posterior distribution of the adjusted random coefficient. The benefit of using this method was evaluated by comparing it with using a fixed model for performance estimation. Simulations employing a MCMC approach obtained the $95 \% \mathrm{PCI}$ around the ranks. Two high quality outliers and three low quality outliers were identified. Small nursing homes were more shrunken towards the mean than large nursing homes. An adjusted fixed coefficient model found eight more nursing homes to be low quality outliers. The fixed model also yielded larger confidence intervals, especially for small nursing homes, than the random coefficient model.

Confidence intervals of the ranks were wide. None of the highest ranking nursing homes could be classified in the top 10 of best performing nursing homes. Using a Bayesian multilevel approach takes the sample size of institutions into account and yields better estimates of performance due to considerable reduction of the variance in the performance estimator. Using rankings to compare performance should be done with caution, especially if no precision is quantified. 


\subsection{Introduction}

Pressure ulcer rates are a well-known indicator of the quality of care ${ }^{1-3}$, and are increasingly being used as a marker of this quality ${ }^{4.5}$. However, unadjusted pressure ulcer rates cannot be used as quality indicators, ${ }^{6}$ because of differences in vulnerability to or risk of pressure ulcer development among patients in a particular setting, because of random variation, and because of differences in the effectiveness of the care provided or the quality of care ${ }^{7}$. Hence, differences that remain after controlling for case-mix differences and after taking care of the random variation may reflect real variations in the quality of care. The next step is to compare health care settings on their performance. The most frequently used methods rely on statistical tabulations of observed versus expected events, such as the ratio of the observed and expected outcomes and the difference between the observed and expected outcomes ${ }^{8,9}$.

The Dutch Council for Public Health and Healthcare recently recommended a systematic analysis of outcome measures of care to encourage quality improvement ${ }^{10}$, while the Dutch State Inspectorate of Health is also increasingly interested in patient outcomes as a marker of the quality of care. The occurrence of pressure ulcers is regarded as one of these outcomes ${ }^{5,11,12}$.

Since 1998, an annual audit of the prevalence of pressure ulcers has been carried out in various health care settings in the Netherlands ${ }^{13}$. Feedback about the results is provided after each survey at institutional and national level. The health care institutions use the feedback at national level to compare their own performance with national results. Initially, the results were not adjusted for case-mix, so the variation in outcomes could be attributed to differences in the patient populations admitted ${ }^{7.14}$. After the third survey, we started to develop a case-mix adjusted model for acute care hospitals that proved to have sufficient content, construct and internal validity ${ }^{15}$. An internally developed standard was used for case-mix adjustment, and the provider-specific ratio of expected to observed outcomes was calculated ${ }^{9}$. However, when the same method was used for nursing homes, it yielded a large variation, probably due to the large percentage $(30 \%)$ of small nursing homes (fewer than 100 patients). Nursing homes are defined in the Netherlands as skilled care facilities for psychogeriatric patients, terminally ill patients and rehabilitation patients. Reducing the standard error of the performance estimate can be achieved in two ways: by increasing the sample size or by increasing the efficiency with which information is obtained from the nursing homes ${ }^{16}$. No influence can be exerted on the size of the nursing homes, but multilevel modeling techniques can overcome small sample problems by appropriately pooling information across institur tions $^{14}$. More precisely, multilevel analysis allows a Bayesian approach to be used in estimating the performances of institutions, yielding good estimates by 
making use of prior information ${ }^{17}$. The Bayes estimator of the performance of a nursing home is some weighted average of an estimate based on data specific to a nursing home and an estimate based on data pooled across all nursing homes. This results in 'shrinkage' towards the estimate based on all nursing homes. Since specific data for the smaller nursing homes are given a smaller weight than those for large nursing homes, shrinkage is greater for smaller nursing homes. Although shrinkage may introduce some bias into the performance estimates, the strength of Bayes estimators resides in a substantial reduction of the statistical uncertainty involved in the performance estimates ${ }^{18}$. Since Bayes estimators involve some quantities that are unknown in practice, hierarchical Bayes estimators are often employed as a practical alternative. These estimators employ so-called uninformative prior distributions for such quantities, and can be regarded as good approximations of Bayes estimators. The hierarchical Bayes estimates can be obtained with the help of Markov-Chain Monte Carlo (MCMC) methods ${ }^{14}$. In fact, this estimation method allows performance estimates to be obtained by means of a random effects approach ${ }^{9}$. The first purpose of the present study was to show how multilevel modelling techniques can be applied to pressure ulcer prevalence data in order to obtain hierarchical Bayes estimates of performance for small and large nursing homes simultaneously.

Performance estimates almost inevitably lead to a ranking of the institutions to assess their relative performance. Rankings are often presented and used without considering the statistical uncertainty involved in them. Adopting the Markov-Chain Monte Carlo approach allows not only point estimates of the performance rankings to be obtained, but also interval estimates that quantify the uncertainty involved in these point estimates ${ }^{14}$. The second purpose of the present study was therefore to examine the value of performance rankings of nursing homes, by also considering the uncertainty involved in these estimates.

\subsection{Methods}

\section{Design}

All data were collected on April $9^{\text {th }} 2002$, using a uniform method, in various health care settings in the Netherlands. This method has been described in detail in earlier articles ${ }^{13,19,20}$. Briefly, a trained team of nurses collected the data in each institution, with two nurses assessing each patient: one nurse from the ward where the patient was admitted, and one nurse who was unfamiliar with the patient. Characteristics of the institution and of the ward were collected, as well as demographics of the patients (age, gender, date and reason of admission), and the presence of pressure ulcers was assessed using a four-stage grading system similar to the classification used by the Agency for Health Care Policy and 
Research and the European Pressure Ulcer Advisory Panel ${ }^{21.22}$. The risk of developing pressure ulcers was assessed by means of the Braden scale, one of the best-known and most widely used tools for risk assessment of this problem ${ }^{23,24}$. The scale consists of six subscales reflecting determinants of pressure (sensory perception, activity, and mobility) and factors influencing tissue tolerance (moisture, nutrition, and friction and shear). Nutrition and incontinence were added as risk factors. The friction-and-shear item was rated from 1 (least favorable) to 3 (most favorable), and all the other items were rated from 1 (least favorable) to 4 (most favorable).

\section{Sample}

A total of 43 nursing homes, with a total of 6,281 patients, participated voluntarily in the national pressure ulcer prevalence audit. Patients admitted with pressure ulcers $(n=336)$ were excluded, because nursing homes were not accountable for the development of these ulcers. This left a total of 5,945 patients for the analyses.

\section{Dependent variable}

The dependent variable was defined as the presence of a grade II pressure ulcer or worse for patients residing in the nursing home on the day of the audit. Grade I was excluded, since accurately diagnosing grade I (non-blanchable erythema) is very difficult ${ }^{25,26}$.

\section{Statistical analysis}

Significant risk factors that could be used to control for case-mix were identified from the database of the 2002 prevalence survey, as this was the database with the largest number of registered patients and the largest number of participating nursing homes. The candidate risk factors were the six subscales of the Braden scale, as well as incontinence, nutrition, and age. Ward specialization was added to capture a component of medical status. The model thus found was then cross-validated using the databases from the audits of the previous years. Goodness of fit was determined using the Hosmer-Lemeshow test, which was obtained by calculating the Pearson chi-square statistics of observed and expected values $^{27}$. The area under the receiver-operating curve was used to test model discrimination equaling the c-statistic, which is the proportion of pairs in which the predicted probability of pressure ulcers is higher for patients with pressure ulcers than for those without such ulcers ${ }^{7}$.

The variables identified as influencing the occurrence of pressure ulcers were then used in a multilevel analysis. Since the dependent variable was coded as the presence of pressure ulcers in a patient, a logistic regression model was employed. Two levels were distinguished: nursing homes at level 2 and patients 
at level 1. In addition to the risk factors, which account for differences in the institutes' case-mix, random coefficients were also included in the analysis model. Random coefficients at level 2 corresponded to variations in the occurrence of pressure ulcers associated with nursing homes, and random coefficients at level 1 allowed for random fluctuations in the occurrence of pressure ulcers within nursing homes. Since the random coefficients were corrected for case-mix, the coefficients at level 2 could be considered to reflect differences in the performance of the nursing homes in terms of the quality of care provided.

Employing a Bayesian approach, MLwin ${ }^{28}$ yields posterior estimates, and associated posterior confidence intervals of the random coefficients, making use of Markov-Chain Monte Carlo (MCMC) methods. MCMC methods involve taking a large number of draws from the joint posterior distribution of all parameters. It is from these draws that a posterior distribution, and summary statistics such as the posterior mean and the posterior confidence interval, can be estimated. Since logistic regression was used, Metropolis Hastings algorithms were used to obtain these draws from the posterior distribution. In a Bayesian framework, prior distributions have to be specified for all parameters of the model. The default non-informative prior distributions of MLwin were used (see Rasbash et al. 2002).

The performance of a nursing home was estimated as the mean of the posterior distribution of the corresponding level- 2 random coefficient. To account for uncertainty in this estimate, a $95 \%$ posterior confidence interval was determined. A nursing home was considered to perform poorly if its confidence interval was above zero (probability of occurrence of pressure ulcers above average), and was considered to perform well if its confidence interval was below zero (probability of occurrence of pressure ulcers below average). The remaining nursing homes could be considered to have average performance.

To show the benefits of the estimates obtained from the random coefficient method for nursing homes with small numbers of patients, the results were compared with those of a method in which provider effects are incorporated as fixed effects in the logistic regression, after adjusting for case-mix using the same risk factors used in the random coefficient model. The fixed effects were parameterized as proposed by DeLong ${ }^{9}$ to obtain the appropriate interpretation.

In practice, nursing homes are often also ranked according to their performance. The flexibility of MCMC methods allows any kind of statistic to be calculated based on the posterior distribution of the level- 2 random coefficients. This means that point estimates can also be obtained for rank numbered performances, as well as the corresponding confidence intervals, in order to assess a nursing home's relative performance. 
Most analyses were performed with the Statistical Package for the Social Science release 10.1. Multilevel analyses were performed with the MLwin program $^{28}$.

\subsection{Results}

\section{Sample}

Of the 5,945 patients, $73.3 \%$ were female. The mean age was $80.9(\mathrm{SD}=10.29)$ with a range from 21 to 102 . The majority of the patients $(56.3 \%)$ had been admitted to psycho-geriatric wards, $31.8 \%$ had been admitted to somatic wards, $7.5 \%$ had been admitted to rehabilitation wards, and $4.5 \%$ were categorized as other (e.g. wards specialized for younger rehabilitation patients). The other characteristics are shown in table 5.1.

Table 5.1 Characteristics of the patient population in the 43 nursing homes $(n=5,945)$

\section{Characteristic}

Age

Mean

SD

Median

\section{Days since admission}

Mean

SD

Median

\section{Gender}

Female

\section{Nutrition}

No problem

Moderate

Severe

Very severe

\section{Incontinence}

None

Occasional

Usually urine / faeces

Complete

\section{Moisture}

Rarely moist

Occasionally moist

Very moist

Constantly moist

\section{Characteristic}

\section{Activity}

80.9

10.26

82

916.9

$1,067.38$

$\mathbf{5 8 0}$

$72.3 \%$

$79.9 \%$

$17.9 \%$

$1.6 \%$

$0.6 \%$

$21.4 \%$

$18.6 \%$

$21.5 \%$

$38.5 \%$

$41.5 \%$

$25.6 \%$

$19.6 \%$

$13.4 \%$

Chairfast

Bedfast

\section{Mobility}

No limitations

Very limited

Excellent

Adequate

Very poor

Problem

Somatic

Other
Walks frequently

Walks occasionally

Slightly limited

Completely immobile

\section{Dietary intake}

Probably inadequate

$28.5 \%$

$16.9 \%$

$44.6 \%$

$10.1 \%$

$33.4 \%$

$23.4 \%$

$24.4 \%$

$18.8 \%$

$45.7 \%$

$40.7 \%$

$11.5 \%$

$2.2 \%$

\section{Friction and shear}

No apparent problem

$41.7 \%$

Potential problem

$29.5 \%$

$28.8 \%$

\section{Sensory perception}

No impairment

Slightly limited

$31.5 \%$

Highly limited

$16.1 \%$

Completely limited

Ward specialization

Psycho-geriatric

Rehabilitation

$31.8 \%$ 
The mean prevalence of grade II or worse pressure ulcers acquired in the nursing home was $11.64 \%$, with a range of $0.0 \%$ to $27.27 \%$. The number of patients involved at each of the nursing homes varied from 8 to 303 , with a mean of 140 .

\section{The case-mix model and its properties}

The logistic model showed that moisture, sensory perception, activity, mobility, dietary intake, friction and shear, and ward specialization were significantly associated with the presence of pressure ulcers. In the cross-validation, the Hosmer-Lemeshow goodness of fit showed that there were significant differences between the observed and expected values for the 1999 and 2001 survey years. However, as this chi-square test depends heavily on the number of cases studied, and possibly on the way cases are assigned to subgroups, ${ }^{29}$ the model was found to be appropriate for case-mix adjustment. The area under the curve as expressed by the c-statistic was 0.75 for the 2002 audit year and varied between 0.70 and 0.74 for the previous audit years, indicating that de model discriminates well between people with pressure ulcers and those without pressure ulcers. Values greater than 0.70 are generally considered good ${ }^{2}$.

\section{Performance assessment}

The variables from the case-mix model were entered as risk factors into the multilevel logistic regression model, employing MCMC estimation to calculate estimates of the performances. A total of 10,000 draws were taken from the posterior distribution (after a burn-in length of 1000 iterations). This turned out to be large enough for reliable estimates of the posterior mean and the posterior confidence interval according to the Brooks-Draper and Raftery-Lewis diagnostics, respectively ${ }^{18,28}$. The resulting model is presented in table 5.2. The variance of the level 2 random coefficients was significant, implying that there were significant differences in performance between nursing homes when controlling for case-mix differences. The posterior means of the level 2 coefficients, as well as the corresponding $95 \%$ confidence intervals, are shown in figure 5.1. It turns out that two nursing homes can be identified as high quality outliers, whereas three nursing homes can be identified as poor quality outliers.

\section{Ranking the nursing homes}

The samples each iteration of the Metropolis Hastings sampler generated from the posterior distribution of the level-2 random coefficients were ranked in order to calculate the point estimates and the corresponding $95 \%$ posterior confidence intervals (PCI) for each nursing home. The results are shown in figure 5.2. The lower the rank, the better the nursing home's performance. An 
Table 5.2 Factors* associated with the presence of pressure ulcers in the multilevel logistic regression model

\begin{tabular}{|c|c|c|}
\hline Parameter & Estimate (SE) & $95 \% \mathrm{PCl}$ \\
\hline \multicolumn{3}{|l|}{ Fixed } \\
\hline Intercept & $-5.172(0.202)$ & $-5.568,-4.776$ \\
\hline \multicolumn{3}{|l|}{ Moisture } \\
\hline \multicolumn{3}{|l|}{ Rarely moist } \\
\hline Occasionally moist & $0.187(0.114)$ & $-0.100,0.470$ \\
\hline Very moist & $-0.006(0.128)$ & $-0.257,0.257$ \\
\hline Constantly moist & $-0.217(0.141)$ & $-0.493,0.060$ \\
\hline Sensory perception & $-0.093(0.061)$ & $-0.213,0.027$ \\
\hline Activity & $0.248(0.071)$ & $0.109,0.387$ \\
\hline Mobility & $0.247(0.064)$ & $0.122,0.372$ \\
\hline Dietary intake & $0.190(0.054)$ & $0.084,0.296$ \\
\hline Friction and shear & $0.635(0.073)$ & $0.492,0.778$ \\
\hline \multicolumn{3}{|l|}{ Ward specialization } \\
\hline \multicolumn{3}{|l|}{ Psycho-geriatric } \\
\hline Somatic & $0.200(0.919)$ & $-1.601,2.001$ \\
\hline Rehabilitation & $0.412(0.101)$ & $0.214,0.610$ \\
\hline Other & $0.776(0.210)$ & $0.364,1.188$ \\
\hline \multicolumn{3}{|l|}{ Random } \\
\hline \multicolumn{3}{|l|}{ Level 2 variance } \\
\hline Intercept & $0.204(0.076)$ & $0.055,0.352$ \\
\hline \multicolumn{3}{|l|}{ Level 1 variance } \\
\hline Intercept & 1.000 & \\
\hline
\end{tabular}

obvious feature is the large posterior confidence intervals for the ranks. As one can see in figure 5.2, none of the lowest ranking nursing homes can be classified as belonging to the top 10 of the best performing homes, as all $95 \% \mathrm{PCI}$ comprise rank 10 . Nor can any of the nursing homes be classified as belonging to the 10 worst performing nursing homes, again because of the width of the 95\% PCIs of the nursing homes with the lowest rank.

\section{Adjusted fixed coefficients versus adjusted random coefficients}

Estimates of the adjusted fixed coefficients and corresponding confidence intervals show that, in addition to the two high-quality and three low-quality nursing homes revealed by the random coefficient estimates, eight more low-quality nursing homes were identified. This illustrates that the estimates based on the random coefficient approach lead to more conservative decisions.

Table 5.3 presents the performance of twelve nursing homes, the six with the smallest adjusted fixed coefficients and the six with the largest adjusted fixed 


\section{Chapter 5}

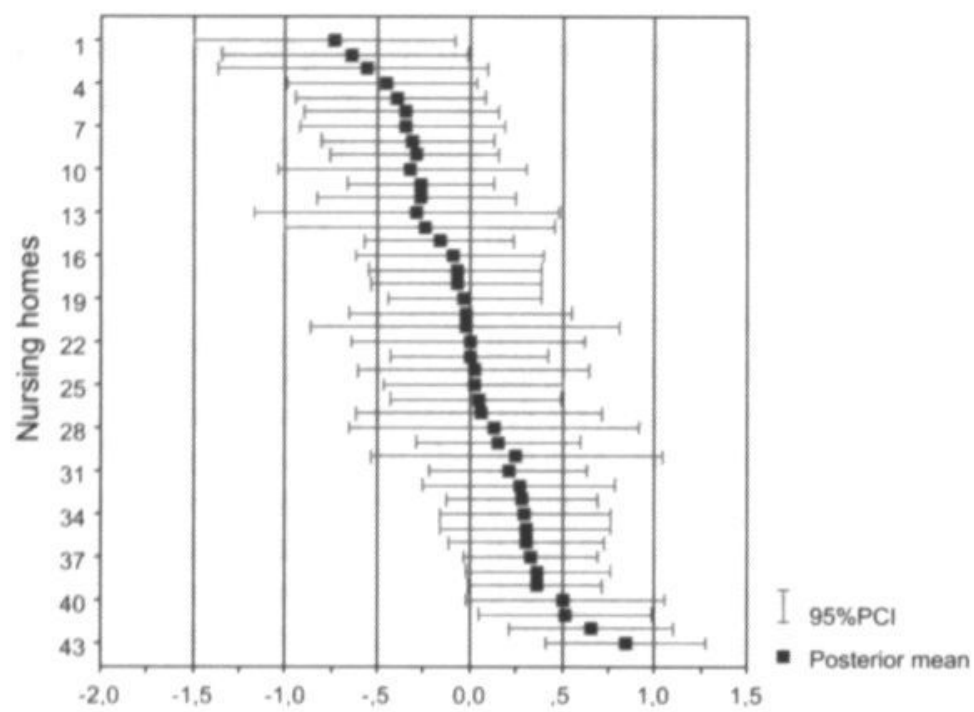

Case-mix adjusted estimate of performance

Figure 5.1 Posterior mean and 95\% PCI for the level 2 random coefficients for each nursing home

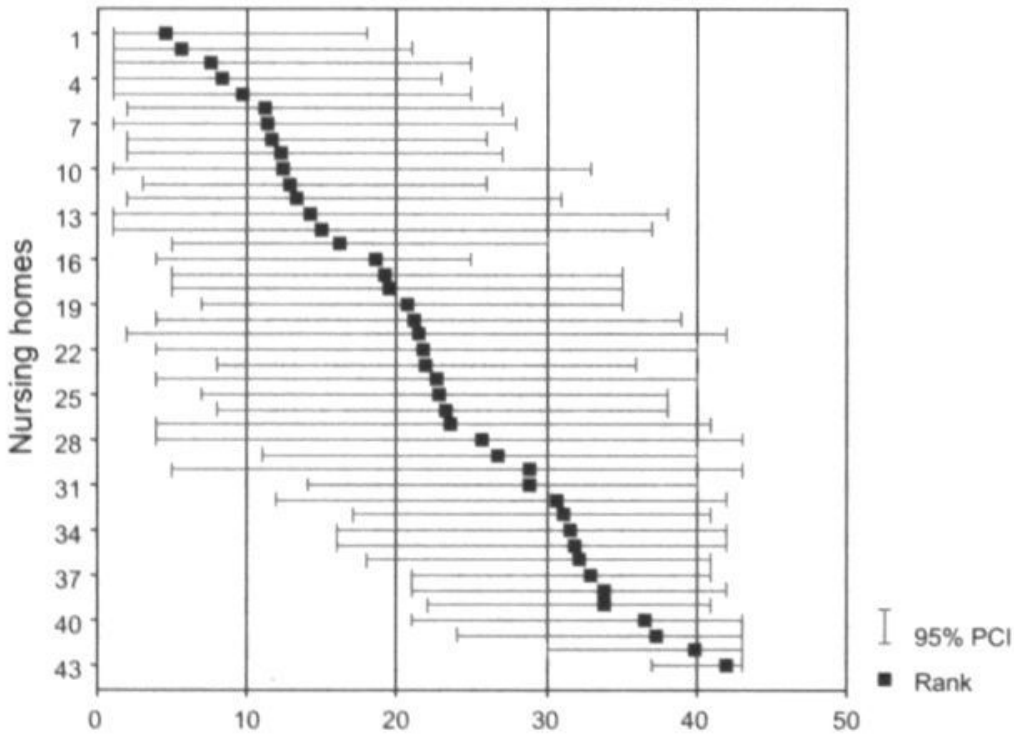

Case-mix adjusted performance ranks

Figure 5.2 Posterior mean and 95\% PCI for the ranks of the nursing homes 
Table 5.3 Performances of the six nursing homes with the smallest and largest adjusted fixed coefficients. Results of the fixed effects approach as well as the random effect approach are given.

\begin{tabular}{lclll}
\hline $\begin{array}{l}\text { Nursing } \\
\text { home }\end{array}$ & $\begin{array}{l}\text { Number } \\
\text { of patients }\end{array}$ & $\begin{array}{l}\text { Adjusted fixed effect } \\
\text { coefficient }(95 \% \mathrm{CI})\end{array}$ & $\begin{array}{l}\text { Adjusted random effect } \\
\text { coefficient }(95 \% \mathrm{PCI})\end{array}$ & Rank $(95 \%$ PCI) \\
A & 20 & $-3.680(-12.828,5.469)$ & $-0.289(-1.167,0.484)$ & $14.136(1-38)$ \\
B & 122 & $-2.124(-4.030,-0.218)$ & $-0.731(-1.493,-0.080)$ & $4.597(1-18)$ \\
C & 93 & $-1.759(-3.689,0.173)$ & $-0.560(-1.363,0.100)$ & $7.492(1-25)$ \\
D & 85 & $-1.279(-2.455,-0.103)$ & $-0.642(-1.341,-0.015)$ & $5.640(1-21)$ \\
E & 36 & $-0.616(-2.068,0.836)$ & $-0.245(-1.010,0.454)$ & $14.898(1-37)$ \\
F & 83 & $-0.607(-1.780,0.567)$ & $-0.326(-1.042,0.308)$ & $12.408(1-33)$ \\
AA & 11 & $0.707(-0.678,2.092)$ & $0.133(-0.654,0.133)$ & $25.678(4-43)$ \\
BB & 125 & $0.856(0.330,1.382)$ & $0.519(0.049,0.984)$ & $37.262(24-43)$ \\
CC & 67 & $0.932(0.287,1.577)$ & $0.508(-0.240,1.057)$ & $36.576(21-43)$ \\
DD & 179 & $0.994(0.495,1.493)$ & $0.659(0.207,0.659)$ & $39.825(30-43)$ \\
EE & 22 & $1.064(-0.220,2.348)$ & $0.246(-0.536,1.038)$ & $28.831(5-43)$ \\
FF & 143 & $1.209(0.724,1.694)$ & $0.842(0.411,1.278)$ & $41.932(37-43)$
\end{tabular}

coefficients. These are compared with the results of the random coefficient model.

Nursing homes A and B were numbers one and two, respectively, with the smallest adjusted fixed coefficients, but differed substantially in the number of patients. In estimating the performance employing a random effects approach, nursing home $\mathrm{B}$ was found to have a better performance than $\mathrm{A}$, as well as a lower mean rank number than $\mathrm{A}$. This illustrates the effect of shrinkage towards the mean, which is larger for nursing homes with smaller numbers of patients. This shrinkage may introduce some bias. On the other hand, the uncertainty involved in the Bayesian estimates of the random coefficients is much smaller. In each instance in table 5.3 , it is evident that the $95 \%$ confidence interval is smaller for the Bayesian estimates of the random coefficients when compared to the estimates of the fixed coefficients. This is particularly true for nursing homes with small numbers of patients.

\subsection{Conclusion and discussion}

This study shows how multilevel analysis can be used to obtain Bayes estimators of the performance of nursing homes with small and large number of patients admitted. Five nursing homes were determined to be outliers, two high quality and three low quality, by evaluating the mean of the posterior distribution of the level-2 random coefficient. This random coefficient model was more conservative than the fixed effects model in terms of decisions of the outlier status, a finding previously demonstrated by Goldstein and Spiegelhalter ${ }^{30}$ and by DeLong and colleagues? 
The method also seemed robust for nursing homes with small number of patients admitted. Small institutions are more often found among the worst or best performing settings than larger institutions, probably for statistical reasons, illustrating that the number of patients affects the performance measurement ${ }^{31}$. This phenomenon was dealt with by using the Bayesian multilevel approach, which resulted in the shrinking of the performance estimates, with the results of small nursing homes shrunk closer to the overall mean. From a statistical view of point, this may be a right and proper way, as small sample sizes often result in overestimates or underestimates ${ }^{32}$. However, from another point of view it can easily be interpreted as unfair. Consider two nursing homes that both perform very well (the best two); one is a small nursing home and the other is large. In the analysis, the small nursing home will have its results shrunk closer to the overall mean and will be assessed as a poorer performer than the larger nursing home (for instance, nursing homes $\mathrm{A}$ and $\mathrm{B}$ in table 5.3). This shrinkage effect should be clearly explained when giving feedback about the results to the institutions. It should be made clear to them that while shrinkage may introduce some bias, it also provides more certainty about the performance, as expressed by a substantial reduction of the variances of the performance estimate, resulting in a substantial shortening of the wide of the confidence interval.

Ranking the institutions on their performance and describing the uncertainty of these rankings by using the MCMC approach showed that most nursing homes had overlapping intervals, and no top 10 could be drawn up. This shows that precision in ranking is rarely feasible, and suggests that rankings of health care settings should be interpreted with caution. This could be an impediment to quality improvement: no incentive is given to the institutions by their rank order, as they are all the 'best quality' setting. Furthermore, large uncertainty intervals may lead to both unfairness and inefficiency and unwarranted conclusions about changes in ranks ${ }^{30}$. More specifically, what at first sight appears to be an improvement for low ranking institutions may simply be a reflection of regression to the mean ${ }^{30}$. However, reporting the direction of the trend of the estimated ranks with its uncertainty over the years may make institutional ranking valuable in improving the quality of care.

The present study used the prevalence of pressure ulcers as the indicator to evaluate the performance of the nursing homes. This indicator measure was evaluated within a framework of multilevel modeling, as the data structure was hierarchical in nature, with patients being nested within nursing homes. In practice, however, real data structures may often be more complex. Patients are not only nested within nursing homes but nursing homes may also be nested within a collaborative structure of health care settings. If the latter is influential, then this level should also be incorporated into the statistical model when trying to 
estimate an effect associated with institutional performance ${ }^{30}$.

A disadvantage of multilevel modeling is its greater complexity, as it demands more mental effort to understand and build ${ }^{17}$. Also, the software is not always easy to use. ${ }^{8}$ General purpose software packages such as SPSS, however, have very limited possibilities for multilevel analysis ${ }^{33}$.

In conclusion, using a Bayesian multilevel approach takes the number of patients in the institutions into account in such a way that small settings will be more shrunken to the mean when ascertaining the setting's true underlying performance. This yields better estimates of performance by a large reduction of the variance of this estimator. Furthermore, as Marshall and Spiegelhalter ${ }^{14}$ have already demonstrated, using ranks to compare performance should be done with caution, especially if no precision is quantified.

\section{References}

1. Mukamel DB, Spector WD. Nursing home costs and risk-adjusted outcome measures of quality. Med Care. 2000;38:78-89.

2. Berlowitz DR, Bezerra HQ, Brandeis GH, Kader B, Anderson J. Are we improving the quality of nursing home care: the case of pressure ulcers. J Am Geriatr Sor. 2000;48:59-62.

3. Allman RM. Pressure ulcers: using what we know to improve quality of care. J Am Geriatr Soc. 2001:49:996-997.

4. National Pressure Ulcer Advisory Panel Cuddigan J, Ayello EA, Sussman C. ed. Pressure ulcers in America: prevalence, incidence, and implications for the future. 2001. Reston, VA: NPUAP

5. Boumans RT. Pressure ulcers - the quality of care indicator [abstract]. Paper presented at: 6 th European Pressure Ulcer Advisory Panel Open Meeting, 2002; Budapest, Hungary.

6. Mukamel DB. Risk-adjusted outcome measures and quality of care in nursing homes. Med Care. 1997; 35:367-385.

7. Daley J, Shwartz M. Developing risk-adjustment methods. In: Iezoni LI, ed. Risk adjustment for measuring healthcare outcomes. 2nd ed. Chicago: Health Administration Press; 1997:279-329.

8. Shwartz M, Ash AS, Iezoni LI. Comparing outcomes across providers. In: Iezoni LI, ed. Risk adjustment for measuring healthcare outcomes. Chicago: Health Administration Press; 1997:471-516.

9. DeLong ER, Peterson ED, DeLong DM, Muhlbaier LH, Hacket S, Mark DB. Comparing risk-adjustment methods for provider profiling. Stat Medicine. 1997;16:2645-2664.

10. Raad voor de Volksgezondheid \& Zorg. Volksgezondheid en zorg. Zoetermeer: Raad voor de Volksgezondheid \& Zorg; 2001.

11. Raas GPM. Verpleegkundige zorg doet ertoe. TVZ. 2002;112:32-35.

12. Halfens RJG, Bours GJJW. Het meten van een zorgresultaat: decubitus. TVZ. 2002;112: 42-45.

13. Bours GJJW, Halfens RJG, Huijer Abu-Saad H, Grol RTPM. Prevalence, prevention and treatment of pressure ulcers: descriptive study in 89 institutions in the Netherlands. Res Nurs Health. 2002;25:99-110.

14. Marshall EC, Spiegelhalter DJ. Institutional Performance. In: Leyland AH, Goldstein H, eds. Multilevel modeling of Health Statistics. New York: John Wiley \& Sons, Ltd; 2001:127-142. 
15. Bours GJJW, Halfens RJG, Berger MPE, Huijer Abu-Saad H, Grol RTPM. The development of a model for case-mix adjustment of pressure ulcer prevalence rates. Med Care. 2003;41:45-55.

16. Rothman KJ, Greenland S. Modern Epidemiology. New York: Lippincott Williams \& Wilkins; 1998.

17. Greenland S. Principles of multilevel modelling. Int J Epid. 2000;29:158-167.

18. Carlin BP, Louis TA. Bayes and Empirical Bayes Methods for Data Analysis. Boca Raton: Chapman \& Hall; 2000.

19. Bours GJJW, Halfens RJG, Lubbers M, Haalboom JRE. The development of a national registration form to measure the prevalence of pressure ulcers in the Netherlands. Ostomy Wound Manage. 1999;45(11):28-40.

20. Bours GJJW, de Lat E, Halfens RJG, Lubbers M. Prevalence, risk factors and prevention of pressure ulcers in Dutch intensive care units: results of a cross-sectional survey. Intens Care Med. 2001:27:1599-1605.

21. European Pressure Ulcer Advisory Panel. A policy statement on the prevention of pressure ulcers from the European Pressure Ulcer Advisory Panel. Br J Nurs. 1998; 7:888-890.

22. US Department of Health and Human services. Pressure ulcer treatment. (AHCPR Publication No. 95-0652). Rockville, MD: author; 1994.

23. Bergstrom N, Braden B, Laquzza A, Holman V. The Braden scale for predicting pressure sore risk: reliability studies. Nurs Res. 1985:346:383.

24. Halfens RJG, van Achterberg T, Bal RM. Validity and reliability of the Braden scale and the influence of other risk factors: a multi-centre prospective. Int J Nurs Stud. 2000;37:313-319.

25. Bergstrom N, Braden B, Kemp M, Champagne M, Ruby E. Multi-site study of incidence of pressure ulcers and the relationship between risk level, demographic characteristics, diagnoses, and prescription of preventive interventions. J Am Geriatr Sor. 1996;44:22-30.

26. Halfens RJG, Bours GJJW, van Ast W. Relevance of the diagnosis 'stage 1 pressure ulcer' : an empirical study of the clinical course of stage 1 ulcers in acute care and long-term care hospital populations. J Clinic Nurs. 2001;10:748-757.

27. Hosmer DW, Lemeshow S. Applied logistic regression. New York: John Wiley \& Sons; 1989.

28. Rasbash J, Browne W, Helay M, Cameron B, Charlton C. MLuin (Version Beta version 1.09.0001). London: Multilevel Models Project Institute of Education; 1999.

29. Ash AS, Shwartz M. Evaluating the performance of risk-adjustment methods: dichotomous outcomes. In: Iezoni LI, ed. Risk adjustment for measuring healthcare outcomes. 2nd edition ed. Chicago: Health Administration Press; 1997:427-469.

30. Goldstein H, Spiegelhalter DJ. League Tables and Their Limitations: Statistical Issues in comparison of institutional Performance. J Royal Statist Soc A. 1996; 159:385-443.

31. Goodhardt G. In discussion of: Goldstein H, Spiegelhalter DJ. League Tables and Their Limitations: Statistical Issues in comparison of institutional Performance. J Royal Statist Soc A. 1996;159:426.

32. Casella G. An introduction to Empirical Bayes Data analysis. Am Statist Assoc. 1985;39:83-87.

33. Snijders TAB, Bosker RJ. Multilevel analysis. An introduction to basis and advanced multilevel modeling. London: Sage Publications Ltd; 1999. 


\section{CHAPTER 6}

Improving the quality of care in acute care hospitals by pressure ulcer audit and feedback

Gerrie J.J.W. Bours, Ruud J.G. Halfens, Math J.J.M. Candel, Huda Huijer Abu-Saad, Richard T.P.M. Grol.

(submitted) 


\section{Abstract}

To examine whether participating in the pressure ulcer prevalence survey results in improvement of the quality of care, the audits employed from 1998 to 2002 were compared over time. Sixty-two acute care hospitals in the Netherlands participated in two or more audits. Each hospital was given hospital-specific performance data and national aggregate data, and peer comparisons to improve the quality of care. The case-mix adjusted prevalence of pressure ulcers of grade II or worse, the percentage of high-risk patients receiving adequate prevention and the total number of enabling conditions present were compared between successive surveys using multilevel analysis, in order to estimate a linear trend model and trend differences for each hospital. The case-mix adjusted prevalence of pressure ulcers decreased over the five-year period, while the percentage of patients receiving adequate prevention and the total number of enabling conditions present increased. The total number of enabling conditions had a significant effect on the decrease in case-mix adjusted prevalence: more enabling conditions led to a lower case-mix adjusted prevalence $($ Chi-square $=125 ; \mathrm{df}=1$; $p<0.00$ ). The percentage of patients receiving adequate prevention also had an effect on the change in case-mix adjusted prevalence, with a higher percentage leading to a lower case-mix adjusted prevalence.

However, this effect was not significant. Monitoring the prevalence and giving feedback results in an improvement of the quality of care in terms of pressure ulcer prevention. It is very important to continue the surveys to prevent lack of attention for the topic leading to a deterioration of the quality of pressure ulcer care. Further research to find the most effective feedback approach is needed. 


\subsection{Introduction}

Pressure ulcers are a serious problem in Dutch health care settings, as was confirmed by the first national prevalence survey in $1998^{1}$. This survey revealed prevalence rates of $23 \%$ in acute care hospitals, $33 \%$ in nursing homes, and $21 \%$ in home care. The main goals of the national surveys were to assess the magnitude of the problem and to decrease the number and severity of pressure ulcers ${ }^{2}$. To date, five national prevalence surveys have been carried out in various health care settings. After each survey, the results were fed back to the participating institutions at ward level and at hospital level.

The institutions were also provided with comparable figures at national level, which they could use for benchmarking ${ }^{3-7}$. On the basis of the literature, we expected that continuous monitoring and feedback of performance data to hospitals will influence actual care provision to patients ${ }^{\mathrm{\gamma}-10}$. Moreover, it was found that most of the coordinators of the participating institutions were indeed planning or implementing activities to change pressure ulcer management after the first audit and feedback ${ }^{11}$. However, it was not clear whether this change in care provision showed a pattern of improvement over five years, nor whether it had an impact on the prevalence rates at the hospitals. The purpose of the present study was therefore to examine whether regular participation in the pressure ulcer prevalence surveys and receiving feedback results in a reduced prevalence and an improvement in the management of pressure ulcers over time. In addition, it assessed the extent to which improved policies for the prevention of pressure ulcers result in lower prevalence.

\subsection{Methods}

\section{Design}

Five national surveys have been carried out since 1998: on May $26^{\text {th }} 1998$, on April 20 th 1999 , on April $11^{\text {th }} 2000$, on April $3^{\text {rd }} 2001$, and on April $9^{\text {th }} 2002$. The data were collected in a systematic way to assess the prevalence of pressure ulcers in various health care settings and various patient groups. A trained coordinator was responsible for data collection in each setting. The coordinator selected and trained a team of nurses to perform the assessments within the institutions. Each patient had to be examined by two nurses, one from the patient's own ward and one who was unfamiliar with the patient, to ensure reliability. Reliability was found to be good ${ }^{12,13}$. A detailed description of the procedure has been provided elsewhere ${ }^{1}$. 


\section{Sample}

The majority of the settings that participated in the national surveys were acute care hospitals. A total of 76 acute care hospitals participated voluntarily in the five surveys. The 1998 survey included 43 acute care hospitals with a total of 10,037 patients, while the 1999 survey included 40 acute care hospitals with 9,252 patients, the 2000 survey included 39 acute care hospitals with 9,197 patients, the 2001 survey included 42 acute care hospitals with 8,889 patients, and the 2002 survey included 58 hospitals with 12,038 patients. Hospitals that participated more than once during these five years were compared between surveys to determine what changes had occurred over time in the prevalence and management of pressure ulcers.

\section{Data collection}

The data collection instrument designed for this study was based on a literature review and a Delphi panel with 34 experts in the field of pressure ulcers. The instrument was field tested in an acute care hospital; a nursing home and a home care agency and was found to be reliable and feasible ${ }^{12}$. The instrument included six categories of items to be collected. The first three were the characteristics of the institution, the characteristics of the ward (an estimate of enabling conditions for pressure ulcer prevention present at hospital and ward level) and the characteristics of the patients (such as age, sex, date of admission and reason for admission). The fourth category involved risk assessment using the Braden scale, with two additional risk factors (nutrition and incontinence). The Braden scale is one of the best-known and most widely used tools for evaluating pressure ulcer risk, with proven validity and reliability for risk assessment ${ }^{1+-17}$. Nutrition was added because it was felt to be more important than the nutrition item included in the Braden scale (defined as dietary intake). The incontinence item was added because the Braden scale does not distinguish between moist (perspiration) and wet (urine). The fifth category of items involved grading the pressure ulcers according to internationally accepted grading systems, defining grade I as nonblanchable discoloration; grade II as partial thickness skin loss involving the epidermis, blisters, or shallow ulcers without undermining of adjacent tissue; grade III as full thickness skin loss, involving damage or necrosis of the epidermis and/or dermis not extending to underlying bone, tendon or joint; and grade IV as full thickness skin loss, involving damage or necrosis of the epidermis and/or dermis extending to underlying bone, tendon or joint ${ }^{18,19}$. Furthermore, each pressure ulcer was linked to its identifying grade with respect to site, origin, time of first observation and dressing. The sixth category related to the prevention of pressure ulcers. This category included the type of support surface used, the use of cushions in a chair and the use of other devices such as 
heel protectors, as well as the preventive interventions of repositioning. preventing malnutrition and patient education. Repositioning was defined as planned repositioning at least every three hours as noted in the nursing records, while preventing malnutrition was defined as the adjusting of food intake by a dietician and patient education was defined as giving each patient a booklet with clear information about the cause and prevention of pressure ulcers.

\section{Feedback}

Feedback was defined as the sharing of non-judgemental information to provide hospitals with insight into any discrepancies (positive or negative) between their performance and a standard, in order to elicit change ${ }^{20}$. After each survey, the hospitals received a computer-generated report about their results at ward and hospital levels. Results at national level were fed back in a written report. The reports included information about the prevalence of pressure ulcers by grade, preventive interventions used for patients at risk (Braden $\leq 20$ ), with or without pressure ulcers, and preventive interventions used for patients at low risk (Braden $>20$ ), with or without pressure ulcers. Furthermore, feedback was given about wound dressings used for pressure ulcers, by grade, and whether these dressings were in accordance with the Dutch guidelines on pressure ulcers $^{21}$. Furthermore, information was provided about the characteristics of the population (demographics, reason for admission and risk assessment according to the Braden scale). In addition, the report explained how these feedback figures had to be interpreted, and a mock report was provided which illustrated how the national results could be compared with the results at hospital level to derive recommendations for improvement of the pressure ulcer prevention strategies. Since 2001, case-mix adjusted prevalence rates were provided to allow them to assess their relative performance.

\section{Effect measures}

The effect measures used to evaluate the results of auditing and feedback were the prevalence of pressure ulcers, the percentage of patients receiving adequate prevention, and the total number of enabling conditions present. These measures were expected to improve as a result of the monitoring and feedback activities. The prevalence of pressure ulcers was defined as the proportion of persons with a grade II pressure ulcer or worse within the total number of persons who were physically examined during the survey. Children younger than 13 and patients admitted with pressure ulcers were excluded from the analysis. As case-mix may change over time, a case-mix adjusted prevalence rate was calculated, to ensure that the differences in rates were not due to differences in case-mix $\operatorname{mix}^{22-24}$. 
Table 6.1 Enabling conditions assessed in each prevalence survey

Does your hospital have a pressure ulcer committee?

Does your hospital have guidelines (a protocol) for the prevention of pressure ulcers?

Does your hospital have guidelines (a protocol) for the treatment of pressure ulcers?

Does your hospital have a person who is responsible for keeping the prevention and / or treatment guidelines up-to-date and bringing them to the staff's attention?

Does your hospital check if staff works in accordance with the guidelines?

Are patients with pressure ulcers reported to a central person in the institution (for instance a tissue viability nurse)?

Does your hospital regularly record the incidence or prevalence of pressure ulcers?

Are preventive materials, such as support surfaces, managed centrally at your hospital?

Are preventive materials, such as support surfaces, managed in a decentralized way at your hospital?

Has your hospital organized an extra training or a special meeting on the prevention and treatment of pressure ulcers in the last two years?

Does your hospital have a leaflet with information about the prevention of pressure ulcers for patients and / or caregivers?

Adequate prevention was defined as the proportion of patients with impaired mobility and/or activity (i.e., scoring less than 3 on the relevant items of the Braden scale) being provided with a dynamic support system or a static support system combined with repositioning according to a time schedule ${ }^{25}$. We calculated a sum score for the 11 enabling conditions used in each survey to evaluate the quality of the pressure ulcer prevention policy (see table 6.1). Enabling condition 8 and 9 were combined because they both assess the management of preventive materials. An affirmative answer about the presence of either condition 8 or indicator 9 resulted in a positive score on this item. Scores ranged from 0 (minimum quality) to 10 (maximum quality).

\section{Statistical analysis}

The case-mix adjusted prevalence was calculated by multiplying the ratio of observed to expected rates by the mean of the rates observed in each year. This method has been extensively described in a previous article, although new coefficients were calculated using the data from the 1998 survey $^{24}$. The model was cross-validated using the data of all successive surveys. The c-statistic, reflecting the ability of the model to assign a higher probability of risk to patients with pressure lesions, varied between 0.83 and 0.85 . Values greater than 0.70 are generally considered good ${ }^{23}$. Model calibration was tested with the Hosmer-Lemeshow goodness-of-fit test ${ }^{26}$. This test showed significant differences between the observed and expected values for the years 1999,2000, and 2002 when the same beta-coefficients were used. However, after new coefficients had been calculated for each year, these differences were no longer signifi- 
cant (p-values ranged from 0.25 to 0.41 ). These analyses were done using the Statistical Package for Social Sciences (SPSS), release 10.1.

To evaluate changes in the effect measures, multilevel analysis was used to estimate a linear trend model and trend differences for each hospital. The advantage of a hierarchical linear model approach for repeated measures is that all available data can be incorporated in the analyses, rather than only those cases with complete data ${ }^{27}$. Level-one units were measurement moments, while level-two units were hospitals that had participated more than once in the national survey. The deviance test, or likelihood ratio test, was used to assess the significance of the fixed parameters and to test the random parameters of the models.

The influence of the percentage of patients receiving adequate prevention and the total number of enabling conditions present on the case-mix adjusted prevalence was also assessed using a hierarchical linear model with the case-mix adjusted prevalence as the dependent variable and the total number of enabling conditions present and the percentage of patients receiving adequate prevention as the independent variables.

The multilevel analyses were performed using the MLwin program ${ }^{2 N}$.

A test assessing whether the variance of the random intercepts or of a random slope is zero was one-sided. All other tests were two-sided. An alpha of 0.05 was used for all tests.

\subsection{Results}

\section{Study sample}

The analyses were based on the databases of the surveys from 1998 to 2002 . After the exclusion of children and patients admitted with pressure ulcers, a total of 46,079 observations remained for the analyses, including 9,402 patients in $1998,8,566$ patients in $1999,8,554$ patients in $2000,8,312$ patients in 2001 , and 11,245 patients in 2002 . In all the survey years, about $54.0 \%$ of the patients were female.

Table 6.2 presents the characteristics of the patients for the five survey years for those factors that were incorporated in the model for case-mix adjustment. A total of 62 hospitals participated more than once: 20 hospitals participated twice, 19 hospitals participated three times, 4 hospitals participated four times and 19 hospitals participated in all five surveys.

\section{Changes over time}

Table 6.3 presents the changes over time of the case-mix adjusted prevalence, the percentage of patients receiving adequate prevention, and the total number 
Table 6.2 Characteristics of the patients in the five survey years $1998-2002$

\begin{tabular}{|c|c|c|c|c|c|}
\hline & $\begin{array}{l}1998 \\
(\mathrm{~N}=9,402)\end{array}$ & $\begin{array}{l}1999 \\
(\mathrm{~N}=8,566)\end{array}$ & $\begin{array}{l}2000 \\
(\mathrm{~N}=8,566)\end{array}$ & $\begin{array}{l}2001 \\
(\mathrm{~N}=8,312)\end{array}$ & $\begin{array}{l}2002 \\
(\mathrm{~N}=11,245)\end{array}$ \\
\hline Mean Age (SD) & $65.1(17.7)$ & $65.0(17.5)$ & $65.0(17.7)$ & $65.3(17.5)$ & $65.2(17.3)$ \\
\hline Median Age & 69 & 69 & 69 & 69 & 69 \\
\hline \multicolumn{6}{|l|}{ Nutrition } \\
\hline No problem & $75.9 \%$ & $75.3 \%$ & $73.0 \%$ & $70.0 \%$ & $71.2 \%$ \\
\hline Moderate & $18.3 \%$ & $19.1 \%$ & $20.6 \%$ & $22.3 \%$ & $22.0 \%$ \\
\hline Severe & $4.6 \%$ & $4.7 \%$ & $5.3 \%$ & $6.5 \%$ & $5.4 \%$ \\
\hline Very severe & $1.2 \%$ & $0.9 \%$ & $1.2 \%$ & $1.3 \%$ & $1.4 \%$ \\
\hline \multicolumn{6}{|l|}{ Incontinence } \\
\hline None & $80.5 \%$ & $81.4 \%$ & $80.5 \%$ & $80.4 \%$ & $80.6 \%$ \\
\hline Occasional & $7.3 \%$ & $7.5 \%$ & $7.5 \%$ & $7.7 \%$ & $7.7 \%$ \\
\hline Usually urine/faeces & $9.4 \%$ & $8.0 \%$ & $8.5 \%$ & $8.6 \%$ & $8.6 \%$ \\
\hline Complete & $2.8 \%$ & $3.1 \%$ & $3.6 \%$ & $3.3 \%$ & $3.3 \%$ \\
\hline \multicolumn{6}{|l|}{ Sensory perception } \\
\hline No impairment & $81.1 \%$ & $82.4 \%$ & $80.7 \%$ & $80.5 \%$ & $79.9 \%$ \\
\hline Slightly limited & $12.9 \%$ & $12.0 \%$ & $13.4 \%$ & $13.5 \%$ & $14.1 \%$ \\
\hline Highly limited & $4.0 \%$ & $3.7 \%$ & $4.0 \%$ & $4.0 \%$ & $3.9 \%$ \\
\hline Completely limited & $2.1 \%$ & $1.9 \%$ & $1.9 \%$ & $1.9 \%$ & $2.0 \%$ \\
\hline \multicolumn{6}{|l|}{ Activity } \\
\hline Walks frequently & $39.8 \%$ & $42.5 \%$ & $40.6 \%$ & $39.8 \%$ & $40.0 \%$ \\
\hline Walks occasionally & $23.9 \%$ & $23.3 \%$ & $24.2 \%$ & $25.9 \%$ & $25.7 \%$ \\
\hline Chairfast & $17.4 \%$ & $16.7 \%$ & $17.2 \%$ & $17.9 \%$ & $16.8 \%$ \\
\hline Bedfast & $18.9 \%$ & $17.5 \%$ & $18.1 \%$ & $14.4 \%$ & $17.6 \%$ \\
\hline \multicolumn{6}{|l|}{ Mobility } \\
\hline No limitations & $49.9 \%$ & $51.9 \%$ & $49.9 \%$ & $49.8 \%$ & $47.9 \%$ \\
\hline Slightly limited & $25.1 \%$ & $24.4 \%$ & $24.2 \%$ & $25.6 \%$ & $26.6 \%$ \\
\hline Highly limited & $16.3 \%$ & $16.3 \%$ & $17.5 \%$ & $17.0 \%$ & $17.3 \%$ \\
\hline Completely immobile & $8.7 \%$ & $7.4 \%$ & $8.5 \%$ & $7.6 \%$ & $8.3 \%$ \\
\hline \multicolumn{6}{|l|}{ Friction and shear } \\
\hline No apparent problem & $61.7 \%$ & $63.8 \%$ & $60.3 \%$ & $58.7 \%$ & $60.7 \%$ \\
\hline Potential problem & $21.1 \%$ & $20.0 \%$ & $22.5 \%$ & $24.5 \%$ & $22.6 \%$ \\
\hline Problem & $17.2 \%$ & $16.2 \%$ & $17.2 \%$ & $16.8 \%$ & $16.7 \%$ \\
\hline \multicolumn{6}{|l|}{ Ward specialization } \\
\hline Internal medicine & $32.7 \%$ & $33.1 \%$ & $32.3 \%$ & $29.4 \%$ & $28.2 \%$ \\
\hline Surgical & $26.5 \%$ & $25.9 \%$ & $28.1 \%$ & $25.2 \%$ & $26.0 \%$ \\
\hline Intensive care & $3.9 \%$ & $4.4 \%$ & $4.8 \%$ & $5.2 \%$ & $4.8 \%$ \\
\hline Neurology & $11.7 \%$ & $11.8 \%$ & $9.7 \%$ & $10.3 \%$ & $9.7 \%$ \\
\hline Orthopaedics & $8.6 \%$ & $9.1 \%$ & $8.8 \%$ & $8.2 \%$ & $7.7 \%$ \\
\hline Geriatrics & $1.2 \%$ & $1.3 \%$ & $1.1 \%$ & $1.9 \%$ & $1.7 \%$ \\
\hline Other & $15.4 \%$ & $14.3 \%$ & $15.2 \%$ & $19.8 \%$ & $17.5 \%$ \\
\hline
\end{tabular}


Table 6.3 Changes over time in the case-mix adjusted prevalence, percentage of patients receiving adequate prevention and total number of enabling conditions present

\begin{tabular}{|c|c|c|c|c|c|}
\hline \multicolumn{2}{|c|}{ Case-mix adjusted prevalence } & \multicolumn{2}{|c|}{$\begin{array}{l}\text { Percentage receiving adequate } \\
\text { prevention }\end{array}$} & \multicolumn{2}{|c|}{$\begin{array}{l}\text { Total number of enabling } \\
\text { conditions }\end{array}$} \\
\hline Parameter & Estimate (SE) & Parameter & Estimate (SE) & Parameter & Estimate (SE) \\
\hline \multicolumn{2}{|l|}{ Fixed } & \multicolumn{2}{|l|}{ Fixed } & \multicolumn{2}{|l|}{ Fixed } \\
\hline Intercept & $9.535(0.553)$ & Intercept & $22.527(2.112)$ & Intercept & $5.376(0.490)$ \\
\hline Time & $-0.414(0.144)$ & Time & $1.425(0.536)$ & Time & $0.433(0.114)$ \\
\hline \multicolumn{2}{|l|}{ Random } & \multicolumn{2}{|l|}{ Random } & \multicolumn{2}{|l|}{ Random } \\
\hline \multicolumn{2}{|c|}{ Level 2 variance } & \multicolumn{2}{|l|}{ Level 2 variance } & \multicolumn{2}{|l|}{ Level 2 variance } \\
\hline \multirow[t]{2}{*}{ Intercept } & $4.607(1.284)$ & Intercept & $77.773(20.253)$ & Intercept & $8.282(2.324)$ \\
\hline & & & & Time & $0.362(0.135)$ \\
\hline \multicolumn{2}{|c|}{ Level 1 variance $7.517(0.877)$} & Level 1 variance & $102.742(11.995)$ & Level 1 variance & $1.870(0.255)$ \\
\hline Deviance & 1077.210 & Deviance & 1630.051 & Deviance & 848.048 \\
\hline
\end{tabular}

Table 6.4 influence of adequate prevention and the total number of enabling conditions present on the case-mix adjusted prevalence

\begin{tabular}{ll}
\hline Parameter & Estimate (SE) \\
Fixed & \\
Intercept & $11.401(1.074)$ \\
Time & $-0.318(0.142)$ \\
Enabling conditions present & $-0.180(0.104)$ \\
Adequate prevention & $-0.032(0.027)$
\end{tabular}

\section{Random}

Level 2 variance

Intercept

$24.175(7.471)$

Adequate prevention

$0.02(0.007)$

Level 1 variance

$5.013(0.714)$

Deviance

934.468

of enabling conditions present. It shows that the case-mix adjusted prevalence decreased by 0.41 percent with every measurement $(95 \mathrm{CI} \%-0.70,-0.13)$, which means that the case-mix adjusted prevalence for hospitals that participated in all five years declined from $9.54 \%$ to $7.47 \%$ (see table 6.3 ). This decrease was the same for each hospital, as the random coefficient for time was not significant $($ Chi-square $=0.42 ; \mathrm{df}=2)$.

In successive surveys, the percentage of patients receiving adequate prevention increased by 1.43 percent $(95 \mathrm{CI} \% 0.37,2.48)$ which means that hospitals that participated in all five years provided adequate prevention to $7.13 \%$ more 
patients at risk. This increase was also the same for each hospital (Chi-square=1.96; $\mathrm{df}=2$ ).

The total number of enabling conditions present increased by $0.43(95 \mathrm{CI} \%$ $0.21,0.66$ ) between each survey, which means a total increase from 5.38 to 7.54 in five years of participation. As the random coefficient for time was significant $($ Chi-square $=23.16 ; \mathrm{df}=2)$ this increase differed between the hospitals. In fact, the variance of this coefficient $(0.36)$ shows that there were also hospitals in which the total number of enabling conditions present decreased.

\section{Influence of adequate prevention and enabling conditions on the case-mix adjusted prevalence of pressure ulcers}

To examine whether the case-mix adjusted prevalence had been influenced over time by the number of enabling conditions and the percentage of patients receiving adequate prevention, a hierarchical linear model was used, with the case-mix adjusted prevalence as the dependent variable and the total number of enabling conditions present and the percentage of patients receiving adequate prevention as the independent variables. The results of this analysis are presented in table 6.4. The total number of enabling conditions present had a significant effect on the change in case-mix adjusted prevalence $($ Chi-square $=125 ; \mathrm{df}=1$; $\mathrm{p}<0.00$ ), with the presence of more enabling conditions leading to a lower prevalence of pressure ulcers. This effect was the same for all hospitals, as the random coefficient of the quality was not significant (Chi-square $=3.629 ; 2 \mathrm{df} ; \mathrm{p}>0.05)$. The percentage of patients receiving adequate prevention also had an effect on the change in case-mix adjusted prevalence, in that a higher percentage led to lower case-mix adjusted prevalence. However, this effect was not significant (chi-square $=0.347 ; \mathrm{df}=1 ; \mathrm{p}>0.05$ ). The effect was not the same for all hospitals, however, as the random coefficient was significant $(\mathrm{Chi}$-square $=16.826 ; \mathrm{df}=2$; $\mathrm{p}<0.001)$.

\subsection{Discussion}

This study shows that regularly measuring the prevalence of pressure ulcers and giving feedback about the findings results in a decrease in pressure ulcers and an increase in the use of adequate preventive interventions and enabling conditions. It seems that the total number of enabling conditions present and the percentage of patients receiving adequate prevention are both intermediary factors in decreasing the prevalence. Examination of the association between these factors and the decrease in the case-mix adjusted prevalence, however, showed that only the association with the number of enabling conditions present was significant. No significant effect was found for adequate prevention 
use. This can be explained by the very restrictive definition of adequate prevention, which applied only to immobile and/or chairfast or bedfast patients. These patients are very vulnerable to developing pressure ulcers and providing them with adequate prevention may not have the intended preventive effect. After all, not all pressure ulcers are preventable ${ }^{29}$. Furthermore, adequate prevention, defined as the proportion of patients with impaired mobility and/or activity being provided with a dynamic support system or a static support system combined with repositioning according to a time schedule, may easily be overestimated. Errors may arise if patients are scored as receiving repositioning but in fact do not receive adequate repositioning, as such patients may be at higher risk of developing a pressure ulcer. This misclassification may mask a significant effect of adequate prevention.

Hospitals participated in our study voluntarily. This selection procedure may have led to overestimations in the findings, as these hospitals were very motivated to initiate activities to improve their pressure ulcer prevention policy. Actually, participating in the national survey was among the first activities undertaken by many hospitals ${ }^{30}$.

The quality of care has improved over the five survey years, as the prevalence of pressure ulcers has decreased, and the total number of enabling conditions present and the percentage of patients receiving adequate prevention have increased. This improvement could have been caused by various other factors besides monitoring and feedback, as we compared cross-sectional surveys over time without a reference group. However, monitoring and feedback are common tools for health care improvement and have been found to be effective in randomised controlled trials as well as in studies without a control group ${ }^{9 \cdot 10.31-34}$.

Pressure ulcers are a topic that does not generate a great deal of interest, and many health care professionals fail to recognize the importance of maintaining competence and keeping abreast of new developments. Previous research had shown that there were major flaws in the prevention of pressure ulcers'. Monitoring and feedback may serve as a trigger to focus attention on the pressure area care in order to improve the quality of care. Quality assurance and education have been found to have a greater positive impact on topics attracting little interest than on those drawing a great deal of attention ${ }^{35.36}$. Although Barczak et al. ${ }^{37}$ did not find a decrease in the national prevalence in the US after four national surveys, their study did not use case-mix adjusted prevalence rates to assess changes over time, so the lack of improvement may have been caused by differences in case-mix.

In our study, the improvements found under the influence of monitoring and feedback were small. It must be remembered, however, that the effects of audit 
and feedback on the performance of health care professionals are generally found to be small to moderate, and it is not yet clear what the most effective feedback should look like 9 . The only intervention we used was auditing pressure ulcer data and feeding back the results, which is in fact a passive quality improvement strategy. Combining feedback with more active interventions, such as educational materials or meetings, the use of opinion leaders or face-to-face interactions, may result in greater benefits ${ }^{38-40}$.

In conclusion, monitoring the prevalence of pressure ulcers and giving feed-back results in an improvement of the quality of care for pressure ulcers, as was demonstrated by a decrease in the prevalence of pressure ulcers, an increase in the use of adequate prevention and a greater number of enabling conditions present. It is very important to continue the surveys to prevent lack of attention for the topic leading to a deterioration of the quality of pressure ulcer care. Further research to find the most effective feedback approach is needed.

\section{References}

1. Bours GJWW, Halfens RJG, Huijer Abu-Saad H, Grol RTPM. Prevalence, prevention and treatment of pressure ulcers: descriptive study in 89 institutions in the Netherlands. Res Nurs Health. 2002; 25:99-110.

2. Stuurgroep-Decubitus. Decubitus kan beter voorkomen worden! Actieplan: preventie van decubitus. Woerden: NIGZ; 1997.

3. Bours GJJW, Halfens RJG, de Winter A. Landelijk prevalentie onderzoek decubitus: uitgebreide resultaten eerste jaarlijkse meting 1998. Maastricht: Universiteit Maastricht, Vakgroep Verplegingswetenschap, Stuurgroep Decubitus; 1998.

4. Bours GJJW, Halfens RJG, Joosten CMC. Landelijk prevalentie onderzoek decubitus: uitgebreide resultaten tweede jaarlijkse meting 1999. Maastricht: Universiteit Maastricht, Vakgroep Verplegingswetenschap, Stuurgroep Decubitus; 1999.

5. Bours GJJW, Halfens RJG, Joosten CMC. Landelijk prevalentie onderzoek decubitus: resultaten derde jaarlijkse meting 2000. Maastricht: Universiteit Maastricht, Sectie Verplegingswetenschap, Stuurgroep Decubitus; 2000.

6. Bours GJJW, Halfens RJG, Joosten CMC. Landelijk prevalentie onderzoek decubitus: resultaten vierde jaarlijkse meting 2001. Maastricht: Universiteit Maastricht, Sectie Verplegingswetenschap, Stuurgroep Decubitus; 2001.

7. Bours GJJW, Halfens RJG, Wansink SW. Landelijk prevalentie onderzoek decubitus: resultaten vijfde jaarlijkse meting 2002. Maastricht: Universiteit Maastricht, Sectie Verplegingswetenschap, Stuurgroep Decubitus; 2002.

8. Bero LA, Grilli R, Grimshaw JM, Harvey E, Oxman AD, Thomson MA. Closing the gap between research and practice: an overview of systematic reviews of interventions to promote the implementation of research findings. Br Med J. 1998; 317:465-468.

9. Thomson O'Brien MA, Oxman AD, Davis DA, Haynes RB, Freemantle N, Harvey EL. Audit and feedback: effects on professional practice and health care outcomes [Cochrane Review]. In: The Cochrane Library, Issue 1, 2002. Oxford: Update Software. Accessed February 12, 2002. 
10. Thomson O'Brien MA, Oxman AD, Davis DA, Haynes RB, Freemantle N, Harvey EL. Audit and feedback versus alternative strategies: effects on professional practice and health care outcomes [Cochrane Review]. In: The Cochrane Library, Issue 1, 2002. Oxford: Update Software. Accessed March 7, 2002.

11. Halfens RJG, Bours GJJW, Bronner CM. The impact of assessing the prevalence of pressure ulcers on the willingness of health care institutions to plan and implement activities to reduce the prevalence. J Adv Nurs. 2001; 36:1-9.

12. Bours GJJW, Halfens RJG, Lubbers M, Haalboom JRE. The development of a national registration form to measure the prevalence of pressure ulcers in the Netherlands. Ostomy Wound Manage. 1999; 45(11):28-40.

13. Bours GJW, Defloor T, Wansink SW, Clark M. Summary report on pressure ulcer presulence: data collected in Belgium, Italy, Portugal, Surden and the United Kingdom over the 14th and 15 th of November 2001. Oxford: EPUAP; 2002.

14. Boes C. Die Reliabilität und Validität der Braden Skala zur Einschätzung des Druckgeschwürrisikos. Pflege. 2000; 13:397-402.

15. Hamilton F. An analysis of the literature pertaining to pressure sore risk-assessment scales.J Clinic Nurs. 1992;1:185-193.

16. Bergstrom N, Braden BJ, Laguzza A, Holman V. The Braden scale for predicting pressure sore risk. Nurs Res. 1987; 36:205-210.

17. Halfens RJG, van Achterberg T, Bal RM. Validity and reliability of the Braden scale and the influence of other risk factors: a multi-centre prospective. Int J Nurs Stud. 2000;37:313-319.

18. US Department of Health and Human Services. Pressure ulcers in adults: prediction and prevention: (AHCPR Publication No 92-0047). Rockville, MD: author 1992.

19. European Pressure Ulcer Advisory Panel. A policy statement on the prevention of pressure ulcers from the European Pressure Ulcer Advisory Panel. Br J Nurs. 1998; 7:888-890.

20. Ende J. Feedback in clinical medical education. JAMA. 1983;250:777-781.

21. Centraal Begeleidingsorgaan voor Intercollegiale Toetsing. Herziening Consensus Decubitus. Utrecht: Centraal Begeleidingsorgaan voor de Intercollegiale Toetsing; 1992.

22. Iezzoni LI, ed. Risk adjustment for measuring healthcare outcomes. 2nd ed. Chicago: Health Administration Press; 1997.

23. Berlowitz DR, Bezerra HQ, Brandeis GH, Kader B, Anderson JJ. Are we improving the quality of nursing home care: the case of pressure ulcers. J Am Geriatr Soc. 2000;48:59-62.

24. Bours GJJW, Halfens RJG, Berger MPF, Huijer Abu-Saad H, Grol RTPM. The development of a model for case-mix adjustment of pressure ulcer prevalence rates. Med Care. 2003;41: 45-55.

25. Kwaliteitsinstituut voor de Gezondheidszorg CBO. Richtlijn Decubitus. Tweede herziening Utrecht: Kwaliteitsinstituut voor de Gezondheidszorg CBO; 2002.

26. Hosmer DW, Lemeshow S. Applied logistic regression. New York: John Wiley \& Sons; 1989.

27. Snijders TAB, Bosker RJ. Multilevel analysis. An introduction to basis and advanced multilevel modeling. London: Sage Publications Ltd; 1999.

28. Rasbash J, Browne W, Helay M, Cameron B, Charlton C. MLuin (Version Beta version 1.09.0001). London: Multilevel Models Project Institute of Education; 1999.

29. Barbenel JC, Hagisawa S. The limits of pressure ulcer sore prevention. Epuap Review. 2001;3:8-9.

30. Bours GJJW, Halfens RJG, Bosker L. Drie jaar landelijk registreren: hoe nu verder? Maastricht: Universiteit Maastricht, sectie Verplegingswetenschap / Nationaal Instituut voor Gezondheidsbevordering en Ziektepreventie; 2001. 
31. Gulacsi L, Kiss ZT, Goldmann DA, Huskins WC. Risk-adjusted infection rates in surgery: a model for outcome measurement in hospitals developing new quality improvement programmes. J Hosp Infect. 2000; 44:43-52.

32. Kiefe CI, Allison JJ, Williams OD, Person SD, Weaver MT, Weissman NW. Improving quality improvement using achievable benchmarks for physician feedback. JAMA. 2001;285:2871-2879.

33. Elferink-Stinkens PM. Quality management in obstetrics: reporting population adjusted intervention and mortality rates [proefschrift]. Nijmegen, Katholieke Universiteit Nijmegen; 2000.

34. Geubels ELPE. Prevention of surgical site infections through surveillance [proefschrift]. Utrecht: Julius Centre for Health Science and Primary Care, Universiteit Utrecht; 2002.

35. Palmer RH, Louis TA, Hsu LN, et al. A randomized controlled trial of quality assurance in sixteen ambulatory care practices. Med Care. 1985;23:751-770.

36. Sibley JC, Sackett DL, Neufeld V, Gerrard B, Rudnick KV, Fraser W. A randomized trial of continuing medical education. N Engl J Med. 1982;306:511-515.

37. Barczak CA, Barnett RI, Jarczynski-Childs E, Bosley LM. Fourth national pressure ulcer prevalence survey. Adv Wound Care. 1997;10:18-26.

38. Lomas J, Enkin M, Anderson GM, Hannah WJ, Vayda E, Singer J. Opinion leaders vs audit and feedback to implement practice guidelines: delivery after previous caesarean section. JAMA. 1991:265:2202-2207.

39. Hayes RP, Ballard DJ. Review: feedback about practice patterns for measurable improvements in quality of care: a challenge for PROs under the health care quality improvement program. Clinic Perform Qual Health Care. 1995;3:15-22.

40. Thomas LH, McColl E, Cullum N, Rousseau N, Souter J. Clinical guidelines in nursing. midwifery and the therapies: a systematic review. J Adv Nurs. 1999;30:40-50. 
CHAPTER 7

General discussion 


\subsection{Introduction}

The studies reported on in this thesis had two main purposes. The first was the development of a national system to monitor the prevalence of pressure ulcers in various health care settings, while the second was to examine how this monitoring system could be used as a tool to improve the quality of pressure ulcer care.

This chapter briefly summarizes the main findings and presents some theoretical and methodological reflections. The chapter ends with implications for practice and recommendations for future research.

\subsection{Main findings}

The main conclusion of this thesis is that it is possible to collect accurate and reliable data on the prevalence of pressure ulcers across a variety of health care settings, using a standardized method and instrument. This data collection procedure yields information on the scale of the problem at national, institutional, and ward levels. The analysis of the results revealed, firstly, that the average prevalence of pressure ulcers in the Netherlands is very high and, secondly, that Dutch health care workers often do not comply with the Dutch guidelines for the prevention and treatment of pressure ulcers. While the occurrence of pressure ulcers can be seen as an important indicator of the quality of care, it is essential to adjust for case-mix if the rates are used to compare institutions within the same settings on their relative performances. Using a hierarchical Bayesian approach yields better estimates of performance for small institutions, as this approach results in a greatly reduced variance of the estimator. The limited value of ranking institutions on their performance was demonstrated by calculating the confidence intervals around the ranks. Regular monitoring of the prevalence of pressure ulcers and feedback on the results led to a small but significant improvement in the quality of care. The decline of the (adjusted) prevalence rates was reinforced by an improvement in work processes and the enabling conditions in place.

\subsection{Theoretical reflections}

Importance of this study

Until the first pressure ulcer prevalence survey, which was performed in 1998, little was known about the occurrence of pressure ulcers in the various Dutch health care settings. This study showed that pressure ulcers were a seriously underestimated problem in Dutch health care and were twice as frequent as had 
been estimated before the first audit. As a result of these findings, more attention was paid to the problem of pressure ulcers, which appeared on the agenda of many organizations, such as the ministry of Health, Welfare and Sport and the Dutch Health Care Inspectorate. It was also found that the management of pressure ulcers varied widely and was hardly based on the national guidelines. Although the design of the study did not allow a causal relationship to be established between the low compliance with the guidelines and the high prevalence of pressure ulcers, research has shown that a decrease in prevalence can be achieved when nurses actually manage patients according to guidelines ${ }^{1}$.

\section{Pressure ulcer prevalence as an indicator of the quality of care}

Pressure ulcers (provided they are adjusted for case-mix) are seen as an indicator of the quality of hospital care. There has, however, been much debate about the question whether the appropriate marker of the quality of care is the prevalence rather than the incidence of pressure ulcers. Incidence data have been suggested to be more appropriate, as they reflect the nosocomial problem ${ }^{2}$. However, the relation between prevalence and incidence, where prevalence is expressed as the product of incidence and duration ${ }^{3,4}$, shows that prevalence incorporates the quality of preventive care as well as the treatment of pressure ulcers, whereas incidence only reflects the effectiveness of the preventive care. This makes prevalence, in our opinion, a better quality marker with a broader scope. At the same time, however, several factors have been shown to affect prevalence figures, such as the number of patients admitted with a pressure ulcer, admission and discharge practices, and case- $\mathrm{mix}^{5}$. Conclusions about the quality of care may be influenced by the degree to which the prevalence rate is affected by these factors. Correction for these factors, for instance by adjusting for case-mix, or looking only at setting-acquired lesions in the case of prevalence figures, can be assumed to increase the validity. However, an important limitation is that the figure itself does not show whether a high prevalence has its origin in ineffective prevention and / or ineffective treatment. Shedding more light on this would require prospective incidence studies or, preferably, continuous registration. However, collecting incidence data is very costly and labor-intensive compared with collecting prevalence data. In addition, the high frequency of observation and registration of the presence or absence of pressure ulcers necessary for an accurate incidence assessment may easily lead to inaccurate, inconsistent and incomplete data, and hence affects the validity and reliability of this measure as an indicator of the quality of care ${ }^{2,6}$. Moreover, a reliable and valid procedure for collecting this data on a large scale still needs to be developed. A computerized registration system is considered to be inevitable, and should preferably provide opportunities to record data on the total care process. 


\section{Case-mix adjustment}

The prevalence of pressure ulcers, controlled for case-mix, was used as an outcome indicator of the quality of care. The value of outcome data depends heavily on adequate case-mix adjustment. Research suggests that different risk adjusters, as well as the use of different methods to assess performance, can lead to different conclusions about the quality of care ${ }^{7-9}$. Although the content and quality of our data produced reliable adjustment factors, and the methods we used were methodologically rigorous, reflecting the state of the art as we know it today ${ }^{10}$, we cannot rule out that the use of other factors and / or methods could have produced different conclusions. Further research is urgently needed to ascertain which methods are best to discriminate between institutions in terms of quality.

\section{Audit and feedback to improve quality}

The present study applied an audit and feedback approach to the problem of pressure ulcers to improve the quality of care. We started by providing participating institutions with written feedback that described the mean performance of all similar health care settings. Later on in the project, case-mix adjusted prevalence rates were provided, which allowed the institutions to assess their relative performances while taking differences in their populations into account.

Only small improvements were seen after five years of monitoring with accompanying feedback, an outcome which is in agreement with findings by Thomson and colleagues, who concluded that "audit and feedback can be effective in improving the performance of health care providers, although the effects are generally small to moderate" 11,12 . A possible explanation is that participating institutions had difficulties interpreting the results and linking the feedback to practical and concrete measures for the improvement of the quality of care. Although the institutions were able to get the results at the institutional level immediately after the audit, there was a long gap between the moment of data gathering and the production of the national reports with comparative data and case-mix adjusted rates, which may also have hampered the planning and implementation of quality improvement activities. However, the most plausible explanation is that audit and feedback alone are not enough for substantial improvement, which is in line with the conclusions of various reviews that showed the use of combined and multifaceted interventions to be more effective in encouraging behavioral change among health care professionals than single interventions ${ }^{13-16}$. To date, it remains unclear what complementary interventions or components may enhance the effectiveness of audit and feedback ${ }^{12}$. Some studies ${ }^{17}$ suggest that targeted feedback, provided by a well-respected peer or opinion leader using clear and credible guidelines, may be most effective, 
particularly when embedded in a comprehensive program of continuous monitoring and improvement.

The emphasis in quality improvement activities should not only be on the performance of individual health care workers, but also on elements necessary for successful improvement of the quality at the organization level ${ }^{18}$. These can be characterized as elements that encompass the specific organizational structures and systems, a culture of quality within the institution that is supportive to quality improvement work, optimal training and information support systems, and the integration of quality improvement activities into strategic priorities of the organization ${ }^{19.20}$.

\subsection{Methodological reflections}

\section{Data collection}

The instrument for data collection was developed on the basis of a literature study and on responses from a Delphi panel consisting of experts in the field of pressure ulcers in various health care settings. This made the instrument applicable to a variety of health care settings. An internationally accepted four-stage grading system was used to assess the severity of the pressure ulcers ${ }^{21-24}$. The Braden scale was used for risk assessment, because it had been most widely tested in a range of population ${ }^{25-30}$. We trained the coordinators of the participating institutions and provided training materials to increase reliability. We only assessed interrater reliability in home care settings, where the Pearson correlation coefficient for the Braden scale was above 0.90 , a highly significant value. Cohen's Kappa for the various stages of the grading system varied, with the lowest agreement for grade I (Cohen's Kappa $=0.58$ ). All the other grades had values of 0.69 or higher. For all other settings, we relied for a reliable registration on consensus between the two nurses who examined the patient together. Introducing double checks in all settings, for instance at two randomly selected wards like we did in the European pressure ulcer prevalence survey, might have shed more light on the actual reliability. The accurate assessment of grade I pressure ulcers still results in much variance and the inclusion of this grade in quality of care audits is still a subject of debate ${ }^{31}$. We believe that registering grade $\mathrm{I}$ is important because early detection of grade I pressure ulcers is particularly valuable for triggering preventive interventions. However, including this grade in estimations of the relative performances of institutions may cause difficulties because a reliable diagnosis of grade $\mathrm{I}$ is still problematic. We therefore suggest registering all grades of pressure lesions, but to exclude grade I from analysis when data are used for relative performance assessment. 
outcome measures systematically and release the findings to the public in order to improve the quality of care ${ }^{39}$. The association between public release of performance data and improvements in health outcomes has been found to be highly variable ${ }^{40}$. On the one hand, there is some evidence, mainly from observational and descriptive studies that published data can influence provider behavior, resulting in better outcomes ${ }^{41}$. Other studies, however, have shown that hospitals rarely use the public data to stimulate quality improvement ${ }^{42,43}$. Skepticism arises from concerns related to the accuracy of the data, the relevance of the outcome measure, the time elapsed between the collection and the publication of the data, the lack of a performance-linked incentive mechanism, and inadequate risk-adjustment ${ }^{42-44}$.

The Dutch government introduced the Care Institutions Quality Act in 1996, based on the assumption that health care institutions are responsible for the quality of care they deliver. However, seven years after the introduction of this Quality Act, only a small number of institutions actually have a quality improvement system in place ${ }^{45}$. Transparency and public accountability of the care delivered by means of public release of performance data have been suggested to enhance the development of quality systems in the institur tions $^{30,46,47}$. The Dutch government is developing a framework for performance indicators for Dutch health care settings based on the Balanced Scorecard. The suggested approach is a combination of in-depth and comprehensive monitoring, which should prevent the unintended effects of focusing attention on only one topic ${ }^{48}$. The question arises whether pressure ulcers should be part of such a set of performance indicators for Dutch healthcare settings.

Although pressure ulcers are considered to provide a good indicator of the quality of care ${ }^{49,50}$, it is debatable whether the occurrence of pressure ulcers can be seen primarily as an internal or an external quality indicator. The purpose of an internal quality indicator is to initiate quality improvement activities by the institutions, while external quality indicators aim to provide the public with information on whether an institution provides sufficient quality and to compare institutions on their performance ${ }^{51.52}$. We propose that pressure ulcers can be used for both purposes. However, if they are to be used as an external quality indicator, the validity and reliability of the data should be guaranteed by using samples of sufficient size $e^{4,53}$. We believe that public disclosure of the results of the national pressure ulcer prevalence survey will inevitably lead to less reliable and therefore useless data. In the current situation, institutions volunteer to take part in our audit, and collect their own data, which is sent electronically to the research group. If the data is to be used as an external indicator, it may easily be manipulated by the institutions to produce better public results, or public disclosure may induce the participating institutions to withdraw from the 
Table 7.1 A model of indicators that can be used for internal control and evaluation as well as for external transparency and accountability in terms of pressure ulcers.

$\begin{array}{ll}\text { Aspect } & \text { Indicators } \\ \text { Structure: } & \text { Presence of a pressure ulcer committee. } \\ & \text { Presence of guidelines on prevention and treatment of pressure ulcers. } \\ \text { Presence of a person responsible for updating the pressure ulcer guidelines. } & \text { Compliance check on the use of guidelines. } \\ \text { Regular incidence or prevalence measurements. } \\ \text { Presence of a person to whom patients with pressure ulcers are reported. } \\ \text { Management of preventive materials. } \\ \text { Training on prevention and treatment of pressure ulcers, every two years. } \\ \text { Printed educational information on pressure ulcer prevention for patients. }\end{array}$

Process: $\quad$ Preventive interventions performed.

Treatment interventions performed.

Compliance of interventions with the most recent guidelines.

Outcome: Setting-acquired prevalence in the case of external use, adjusted for case-mix in:

Acute care hospital

Age

Activity

Nutrition

Mobility

Friction and shear

Incontinence

Sensory perception

Ward specialization
Nursing home

For

Activity
Dietary intake
Mobility
Friction and shear
Moisture
Sensory perception
Ward specialization

audit. Thus, before a decision is taken to publish the audit results, there should be a careful consideration of the purpose, risks and benefits of public disclosure. If pressure ulcer data is to be released, it should be adjusted for case-mix using a uniform and thoroughly tested, reliable adjustment model. A uniform adjustment is necessary to prevent institutions with poor outcomes from arguing that they treat more vulnerable patients, and to prevent institutions from 'shopping around' for a case-mix adjustment model that shows them to their greatest advantage. Furthermore, high-and low quality outliers should be identified using statistics that overcome small sample problems instead of on ranking, because using ranks to compare institutions may be seriously misleading, as precision is hard to achieve $\mathrm{e}^{54.55}$.

Table 7.1 presents a model, based on the various studies in this thesis, that can be used for internal control as well as for external accountability. The released data should not only focus on the outcome, but also should provide insight into the structural aspects and processes of care that may reveal the sources of quality variations. Furthermore, we would like to stress that the release of pressure ulcer 
data should be part of a broader set of quality indicators, to prevent the focus being only on pressure ulcers and other areas of care being neglected. Finally, guidance to assist a clear interpretation of the performance measures should be included, as users of the data may not be familiar with the statistical techniques used and might find the results difficult to interpret. Most of all, however, we strongly recommend obtaining a better understanding of the practical implications of public reporting before it is decided to release performance indicators.

\section{Recommendations for future research}

Several recommendations for future research have already been mentioned in the previous chapters of this thesis. This section summarizes the most urgent of these.

The prevalence of pressure ulcers as an indicator of the quality of care does not show whether a high prevalence has its origin in ineffective prevention or in ineffective treatment. Shedding more light on this requires a reliable and valid method for continuing registration. This can only be developed with the help of electronic patient records. This registration system should also provide an opportunity to record other indicators of the quality of care provided to patients.

While the present study was primarily designed to assess the prevalence of presser ulcers in various health care settings, it developed into a quality improvement system over time, as the content of the feedback was seen as a tool for improving the quality of care. However, to determine whether the decrease in prevalence can be attributed to the content of the feedback, a randomized controlled study needs to be initiated, involving various intervention groups, each receiving different combinations of feedback strategies, and a control group receiving the feedback as provided in the present study. Such a strategy should include the support of local networks of peers and trained colleagues in order to achieve the intended improvements.

Different case-mix adjustors and performance assessment methods produce different judgments about performance. These inconsistencies raise questions about the choice of methods to classify the institutions' performances. More research is required to ascertain which methods are best able to discriminate between institutions, taking account of smaller settings.

Audit and feedback was used in the present study as a strategy to improve the quality of care in terms of pressure ulcers. Although the quality of care did indeed improve, the improvements were small and varied across the institutions. The present study paid no attention to conditions that may facilitate or hamper quality improvement. Specific strategies should be designed to handle possible barriers and to make the best use of conditions already in place. Before any strategy is implemented, there should be a thorough diagnostic analysis of the 
participating institutions and of the target group, in order to promote the quality of care.

With the increasing demand for public disclosure, transparency and accountability, the public release of performance indicators seems inevitable. However, the benefits of disclosure for providers, consumers and administrators are not yet fully understood. Research should therefore be initiated to establish the impact of the public release of performance indicators.

\section{References}

1. Buss IC, Halfens RJG, Huijer Abu-Saad H, Kok G. Evidence-based nursing practice: both state of the art in general and specific to pressure sores. J Prof Nurs. 1999;15:73-83.

2. Gallagher SM. Outcomes in clinical practices: pressure ulcer prevalence and incidence studies. Ostomy Wound Manage. 1997;43(1):28-40.

3. Freeman J, Hutchison GB. Prevalence, incidence and duration. Am J Epid. 1980;112: 707-723.

4. Rothman KJ, Greenland S. Modem Epidemiology. New York, London: Lippincott Williams \& Wilkins; 1998.

5. Defloor T, Bours GJW, Schoonhoven L, Clark M. Draft EPUAP statement on prevalence and incidence monitoring. Epuap Review. 2002;4:13-15.

6. Frantz RA. Measuring prevalence and incidence of pressure ulcers. Adv Wound Care. 1997;10:21-24.

7. Iezoni LI. The risks of risk adjustment. JAMA. 1997;278:1600-1607.

8. DeLong ER, Peterson ED, DeLong DM, Muhlbaier LH, Hacket S, Mark DB. Comparing risk-adjustment methods for provider profiling. Stat Med. 1997;16:2645-2664.

9. Austin PC. A comparison of Bayesian Methods for profiling hospital performance. Med Dec Making. 2002;162-172.

10. Johnson ML. Risk assessment and adjustment: adjusting for sick patients or a sick system? [editorial]. Med Care. 2003;41:4-7.

11. Thomson O'Brien MA, Oxman AD, Davis DA, Haynes RB, Freemantle N, Harvey EL. Audit and feedback: effects on professional practice and health care outcomes [Cochrane Review]. In: The Cochrane Library, Issue 1, 2002. Oxford: Update Software. Accessed February 12, 2002.

12. Thomson O'Brien MA, Oxman AD, Davis DA, Haynes RB, Freemantle N, Harvey EL Audit and feedback versus alternative strategies: effects on professional practice and health care outcomes [Cochrane Review]. In: The Cochrane Library, Issue 1,2002. Oxford: Update Software. Accessed March 7, 2002.

13. Oxman AD, Thomson MA, Davis DA, Haynes B. No magic bullets: a systematic review of 102 trials of interventions to improve professional practice. Can Med Ass J. 1995;153: 1423-1431.

14. Bero LA, Grilli R, Grimshaw JM, Harvey E, Oxman AD, Thomson MA. Closing the gap between research and practice: an overview of systematic reviews of interventions to promote the implementation of research findings. Br Med J. 1998;317:465-468.

15. Grimshaw JM, Shirran L, Thomas R, et al. Changing provider behavior: an overview of systematic reviews of interventions. Med Care. 2001;39(suppl 2):II 2- II 45.

16. Grol R. Improving the Quality of Medical Care. Building bridged among professional pride, payer profit, and patient satisfaction. JAMA. 2001;286:2578-2585. 
17. Winkens $R$, Pop $P$, Grol $R$, et al. Effect of routine individual feedback over nine years on general practitioners'requests for tests. Br Med J. 1996;312:490.

18. Berwick DM. Continuous improvement as an ideal in health care. $N$ Engl $J$ Med. 1989;320:53-56.

19. O'Brien JL, Shortell SM, Hughes EFX, et al. An integrative model for organization-wide quality improvement: lessons from the field. Qual Manag Health Care. 1995;3:19-30.

20. Shortell SM, Bennett CL, Byck GR. Assessing the impact of continuous quality improvement on clinical practice: what it will take to accelerate progress. Milbank Q. 1998;76:593-624.

21. US Department of Health and Human Services. Pressure ulcers in adults: prediction and prevention. (AHCPR Publication No. 92-0047). Rockville: MD; 1992.

22. European Pressure Ulcer Advisory Panel. A policy statement on the prevention of pressure ulcers from the European Pressure Ulcer Advisory Panel [practice guideline]. $\mathrm{Br} J$ Nurs. 1998;7:888-890.

23. Centraal Begeleidingsorgaan Intercollegiale Toetsing. Herziening consensus decubitus. Utrecht: Centraal Begeleidingsorgaan voor de Intercollegiale Toetsing; 1992.

24. Kwaliteitsinstituut voor de Gezondheidszorg CBO. Richtlijn decubitus. Tweede herziening. Utrecht: Kwaliteitsinstituut voor de Gezondheidszorg CBO; 2002.

25. Braden BJ, Bergstrom N. Predictive validity of the Braden scale for pressure sore risk in a nursing home. Res Nurs Health. 1994;17:459-470.

26. Ramundo JM. Reliability and validity of the Braden scale in the home care setting. $J$ Wound Ostomy Continence Nurs. 1995;22:128-134.

27. Bergstrom N, Braden B, Kemp M, Champagne M, Ruby E. Predicting pressure ulcer risk: a multisite study of the predictive validity of the Braden scale. Nurs Res. 1998;47:261-269.

28. Boes C. Die Reliabilitat und Validität der Braden Skala zur Einschätzung des Druckgeschwürrisikos. Pflege. 2000;13:397-402.

29. Halfens RJG, van Achterberg T, Bal RM. Validity and reliability of the Braden scale and the influence of other risk factors: a multi-centre prospective. Int J Nurs Stud. 2000;37:313-319.

30. Bergquist S, Frantz R. Braden scale: validity in community-based older adults receiving home health care. Appl Nurs Res. 2001;14:36-43.

31. Lyder CH. Should stage I pressure ulcers be included in audits? : the United States experience [abstract]. Paper presented at: Education: experiences we can share: 5 th European Pressure Ulcer Advisory Panel open meeting; September 27-29, 2001, 2001; Le Mans, France.

32. Allcock $\mathrm{N}$, Wharrad $\mathrm{H}$, Nicolson $\mathrm{A}$. Interpretation of pressure-sore prevalence. J Adv Nurs. 1994:20:37-45.

33. Bours GJJW, Defloor T, Wansink S, Clark M. Summary report on pressure ulcer prevalence: data collected in Belgium, Italy, Portugal, Sweden and the United Kingdom over the 14th and 15th of November 2001. Oxford: EPUAP; 2002.

34. Dassen T, Eisermann HJ, Halfens R, et al. Dekubitus: Sturzereignisse, Pflege-abhängigkeit: Prävalenzerhebung 2001. Berlin: Zentrum für Human- und Gesundheitswissenschaften der Berliner Hochschulmedizin, Institut für Medizin-/Pflegepädagogik und Pflegewissenschaft; 2001.

35. Dassen T, Petermann B, Heinze C, et al. Dekubitus: Sturzereignisse, Pflegeabhängigkeit: Präıalenzerhebung 2002. Berlin: Zentrum für Human- und Gesundheitswissenschaften der Berliner Hochschulmedizin, Institut für Medizin-/Pflegepädagogik und Pflegewissenschaft; 2002.

36. Grimshaw JM, Campwell M, Eccles M, Steen N. Experimental and quasi-experimental designs for evaluating guideline implementation strategies. Fam Pract. 2000;17(suppl 1):S11-S18. 
37. Lipsey M, Wilson D. The efficacy of psychological, educational and behavioural treatment confirmation from meta-analysis. Am Psychol. 1993;48:1181-1209.

38. Halfens RJG, Bours GJW, Bronner CM. The impact of assessing the prevalence of pressure ulcers on the willingness of health care institutions to plan and implement activities to reduce the prevalence. J Adv Nurs. 2001;36:1-9.

39. Raad voor de Volksgezondheid \& Zorg. Volksgezondheid en zong. Zoetermeer: Raad voor de Volksgezondheid \& Zorg; 2001.

40. Marshall MN, Shekelle PG, Leatherman S, Brook RH. The public release of performance data: what do we expect to gain? A review of the evidence. JAMA. 2000;283:1866-1874.

41. Davies HTO, Marshall MN. Public disclosure of performance data: does the public get what the public wants? Lancet. 1999;353:1639-1640.

42. Rainwater JA, Romano PS, Antonius DM. The California Hospital Outcomes Project: How useful is California's report card for quality improvement? J Qual Improvement. 1998;24: 31-39.

43. Mannion R, Goddard M. Impact of published clinical outcomes data: case study in NHS hospital trusts. Br Med J. 2001;323:260-263.

44. Rosenstein AH. Use of performance data to change physician behavior [letter]. JAMA. 2000;284:1079.

45. Wagner C, Sluijs E. Kualiteitssystemen in zonginstellingen. Utrecht: NIVEL; 2000.

46. Raad voor de Volksgezondheid \& Zorg. Taakherschikking in de gezondheidszorg. Zoetermeer: Raad voor de Volksgezondheid \& Zorg; 2002.

47. Tweede Kamer der Staten-Generaal. Evaluatie Kualiteitsuet zorginstellingen. vergaderjaar 2002-2003;28 439(2): 1-9.

48. Delnoij D, ten Asbroek A, Arah O, Custers T, Klazinga N. Bakens zetten. Naar een Nederlands raamuerk van prestatie-indicatoren voor de gezondheidszorg. Amsterdam: Ministerie van Volksgezondheid, Welzijn en Sport / Universiteit van Amsterdam / Academisch Medisch Ziekenhuis; 2002.

49. Mukamel DB. Risk-adjusted outcome measures and quality of care in nursing homes. Med Care. 1997;35:367-385.

50. Lyder C. Pressure ulcer prevention and management. JAMA. 2003;289:223-226.

51. Klazinga N, Stronks K, Delnoij D, Verhoeff A. Indicators without a cause: reflections on the development and use of indicators in health care from a public health perspective. Int J Qual Health Care. 2001;13:433-438.

52. Berg M, Schellekens W. Paradigma's van kwaliteit: De verschillen tussen externe en interne kwaliteitsindicatoren. Med Contact. 2003;57:1203-1205.

53. Hofer TP, Hayward RA, Greenfield S, Wagner EH, Kaplan SH, Manning WG. The unreliability of individual physician "report cards" for assessing the costs and quality of care of a chronic disease. JAMA. 1999;281:2098-2105.

54. Goldstein H, Spiegelhalter DJ. League Tables and Their Limitations: Statistical Issues in comparison of institutional Performance. J Royal Stat Soc A. 1996;159:385-443.

55. Marshall EC, Spiegelhalter DJ. Institutional Performance. In: Leyland AH, Goldstein H, eds. Multilevel modeling of Health Statistics. New York: John Wiley \& Sons, Ltd; 2001:127-142. 
114 | 
Summary 
The introduction to this thesis (chapter 1 ) describes the background and relevance of the issue of quality improvement in terms of pressure ulcers. It has been found necessary to develop a uniform registration and monitoring system for the prevalence of pressure ulcers to assess the magnitude of the problem in Dutch health care settings. A uniform method of data collection allows prevalence rates in various health care institutions to be compared. However, health care settings may differ considerably in terms of patient population, which makes it essential to adjust for patients' risk of developing pressure ulcers. Although performance estimates may be used to rank hospitals, there is no straightforward way to calculate confidence intervals around the ranks, which means that the precision of the ranks cannot be evaluated. Monitoring and giving feedback was assumed to improve the quality of care. However, it was not clear whether continuous monitoring and feedback would result in improved care in terms of the prevalence and management of pressure ulcers.

Chapter 2 discusses the development of a national registration form to measure the prevalence of pressure ulcers, and a pilot study testing the reliability and feasibility of the form. The data collection form was based on a literature study and responses from a Delphi panel. The form includes six domains to be registered: characteristics of the health care institution, characteristics of the ward or team, characteristics of the patient, assessment of the risk of developing pressure ulcers, characteristics of pressure ulcers encountered (grading, duration, origin, and wound dressings used) and finally preventive interventions. The form was field tested at a university hospital, a nursing home and a home health care setting. The interrater reliability for the grading system used exceeded $94.0 \%$ for all three settings, while Cohen's Kappa varied from 0.49 for the home health care setting to 0.81 for the university hospital and 0.97 for the nursing home. The reliability of subscales of the Braden scale was only tested in the home health care setting, and Cohen's Kappa varied between 0.50 and 0.69 . The feasibility of using the form varied between the three health care settings, with nurses in the home health care setting being less satisfied with the form than nurses at the university hospital and the nursing home.

Chapter 3 reports on the results of the first national pressure ulcer prevalence survey and the degree of compliance with the Dutch guidelines on the prevention and treatment of pressure ulcers. An audit of 89 Dutch health care institutions was carried out using the newly developed registration form and a standardized method of data collection. A mean prevalence of $23.1 \%$ was found, ranging from $13.2 \%$ in the university hospitals to $32.4 \%$ in the nursing homes. The preventive interventions and the wound dressings used in the treatment of 
existing pressure ulcers were compared with the recommendations in the Dutch guidelines. Only half of the patients who were in need of a supportive device were actually positioned on such a device. Fewer than one-third of the patients who needed repositioning, nutritional interventions or education actually received these interventions. Only one-third of all existing pressure ulcers were dressed in accordance with the Dutch guidelines.

Chapter 4 reports on the development of a model for case-mix adjustment of pressure ulcer prevalence rates, to allow comparisons between acute care hospitals participating in the national pressure ulcer prevalence survey. Based on the prediction of a logistic model using age, nutrition, incontinence, activity, mobility, sensory perception, friction and shear, and ward specialization, the expected prevalence was calculated for each hospital, conditional on the patient's specific risk factors. The Hosmer-Lemeshow goodness of fit showed that there were no significant differences between the observed and expected values in either the derivation sample or the evaluation sample. The c-statistic indicated that the model discriminated well between patients with pressure ulcers and those without pressure ulcers. The adjusted prevalence was determined by calculating the ratio of the observed to the expected rate, multiplied by the mean of the prevalence observed in all participating hospitals. To test the validity of the adjusted prevalence as a measure of the quality of care, we assessed the relation between the adjusted prevalence and the percentage of immobile patients receiving adequate prevention, as well as that between the adjusted prevalence and the total number of enabling conditions present in the institution. Hospitals with more enabling conditions had a significantly lower adjusted prevalence than hospitals with fewer conditions. The percentage of immobile patients receiving adequate prevention was also significantly correlated with the adjusted prevalence: settings implementing more adequate prevention for immobile patients had significantly lower adjusted prevalence. Using case-mix adjusted prevalence rates instead of crude rates influenced the absolute and relative assessment of the performance.

Chapter 5 shows how multilevel analysis can be used to obtain Bayes estimators of the performance of Dutch nursing homes with variable numbers of patients and to evaluate the value of performance rankings by quantifying the uncertainty of the ranking. The Markov-Chain Monte Carlo (MCMC) method was used to estimate the posterior mean of the level-2 random coefficient, indicating the performance of a particular nursing home. The flexibility of MCMC methods also allowed point estimates to be obtained for rank numbered performances, including the corresponding confidence intervals. 
This analysis led to nursing homes with small numbers of patients being 'shrunk to the mean' in their performance, and revealed more reliable estimates, as expressed by a substantial reduction of statistical uncertainty. The confidence intervals of the rank numbers of performance were generally wide. As a result, most intervals overlapped, which means that the performance ranks of these nursing homes did not differ significantly. None of the highest ranked nursing homes could be classified among the ten best performing nursing homes, which illustrates the limited value of ranking as a measure of performance.

Chapter 6 describes how longitudinal audit and feedback can improve the quality of pressure ulcer care. Case-mix adjusted prevalence rates, the total number of enabling conditions, and the percentage of adequate prevention, calculated for acute care hospitals that had participated more than once in the national survey, were compared over a period of five years (from 1998 to 2002), using a multilevel linear trend model. In addition, we examined whether the total number of enabling conditions and the percentage of adequate prevention had resulted in a reduction in case-mix adjusted prevalence. The case-mix adjusted prevalence did indeed show a significant decrease over the five survey years, while the percentage of adequate prevention and the total number of enabling conditions showed a significant increase. The total number of enabling conditions had a significant effect on the decrease in case-mix adjusted prevalence. The percentage of adequate prevention also had an effect on the change in case-mix adjusted prevalence rates, although this effect was not significant. Ongoing monitoring and feedback resulted in a small but significant improvement in the quality of pressure ulcer care.

Chapter 7 presents a summary of the main findings and some theoretical and methodological reflections on the studies. Methodological points of interest include the data collection procedure, the generalizability of the findings, and the design used, particularly the uncontrolled before and after study used to evaluate the effects of audit and feedback. The theoretical reflections address the use of prevalence data as an indicator of the quality of care, the methods used for case-mix adjustment and the use of audit and feedback as a strategy for quality improvement. Furthermore, the chapter discusses the problem of public disclosure of performance data and topics for future research. 
Samenvatting 
De studie beschreven in dit proefschrift had twee doelstellingen. De eerste doelstelling was de ontwikkeling van een eenduidig registratiesysteem voor het opzetten van een landelijke registratie van decubitus. De tweede doelstelling was een verbetering van de kwaliteit van de decubituszorg door instellingen inzicht te geven in hun resultaten en de mogelijkheid te bieden zich met elkaar te vergelijken.

In de introductie van dit proefschrift (hoofdstuk 1) wordt de achtergrond en de relevantie beschreven ten aanzien van de verbetering van de kwaliteit van de decubituszorg. Het belang van een uniform registratie en monitoring systeem voor decubitus wordt onderstreept om inzicht te krijgen in de omvang van de decubitusprevalentie in Nederlandse gezondheidszorginstellingen. Bovendien kan het vóórkomen van decubitus gezien worden als een belangrijke indicator van de kwaliteit van zorg. Een uniforme methode van dataverzameling maakt het mogelijk om prevalentiecijfers van verschillende instellingen te vergelijken. Aangezien instellingen variëren in patiënten met een risico om decubitus te krijgen, is het noodzakelijk te corrigeren voor deze verschillen in patiëntenpopulatie bij het vergelijken van prevalentiecijfers waarbij instellingen in rangorde geplaatst kunnen worden aan de hand van het (gecorrigeerde) prevalentiecijfer. Een belangrijk nadeel van het maken van een rangorde is, dat het lastig is om een betrouwbaarheidsinterval te berekenen rondom de rangnummers. Hierdoor is er nauwelijks inzicht in de precisie van het rangnummer. Verondersteld wordt dat monitoren en feedback geven de kwaliteit van de decubituszorg verbetert. Onduidelijk is echter, of langdurig monitoren en feedback geven eveneens zal leiden tot een lagere prevalentie en verbetering van de decubituszorg.

Hoofdstuk 2 beschrijft de ontwikkeling van een registratieformulier om in verschillende soorten gezondheidszorginstellingen de prevalentie van decubitus te meten en de resultaten van de pilotstudie, uitgevoerd om de betrouwbaarheid en bruikbaarheid van het registratieformulier vast te stellen. Het registratieformulier is ontwikkeld aan de hand van een literatuurstudie en met behulp van een Delphi-panel. Het omvat zes categorieën items om te registreren: kenmerken van de instelling, kenmerken van de afdeling, kenmerken van de patiënt (demografische kenmerken en de reden van opname), inschatting van het risico op decubitus, kenmerken van de vastgestelde decubitus (gradatie, duur, ontstaan en de gebruikte wondbedekking), en de preventieve handelingen. Om het formulier op bruikbaarheid en betrouwbaarheid te testen is een pilotstudie uitgevoerd in een academisch ziekenhuis, een verpleeghuis en een thuiszorginstelling. De interbeoordelaars betrouwbaarheid van het gebruikte graderingsysteem voor decubitus was voor alle drie de instellingen boven de 
$94 \%$. Cohen's Kappa varieerde van 0,49 in de thuiszorginstelling, 0,81 voor het academische ziekenhuis en 0,97 voor het verpleeghuis. De betrouwbaarheid van de Braden schaal is alleen vastgesteld in de thuiszorginstelling. De Cohen's Kappa van de verschillende items van de Braden schaal varieerde hier tussen 0,50 en 0,69 . De verpleegkundigen in de thuiszorg ervoeren meer problemen met het formulier dan de verpleegkundigen in het academische ziekenhuis en verpleeghuis.

Hoofdstuk 3 geeft de resultaten weer van het eerste nationaal prevalentie onderzoek naar decubitus en de mate waarin Nederlandse verplegenden zich houden aan de richtlijnen voor de preventie en behandeling van decubitus. Een audit onder 89 verschillende gezondheidszorginstellingen is uitgevoerd met behulp van het registratieformulier en een uniforme meetmethode. De gemiddelde prevalentie was $23,1 \%$, waarbij de prevalentie varieerde van $13,2 \%$ in de academische ziekenhuizen tot $32,4 \%$ in de verpleeghuizen. De gebruikte preventieve maatregelen en middelen en wondbedekkingen zijn vergeleken met de aanbevelingen in de CBO- richtlijnen. Slechts de helft van de patiënten die volgens de richtlijnen een anti- decubitus- bed /-matras nodig had, had ook daadwerkelijk een anti-decubitus- bed /- matras. Minder dan eenderde van de patiënten die dit volgens de richtlijnen nodig hadden, kregen wisselligging. aanpassingen in de voeding of voorlichting om decubitus te voorkomen. Slechts eenderde van alle aangetroffen decubitusletsels waren verbonden met de door de richtlijnen voorgeschreven wondbedekkingen.

Hoofdstuk 4 beschrijft de ontwikkeling van een correctiemodel voor decubitus prevalentie zodat ziekenhuizen de (gecorrigeerde) prevalentie met elkaar kunnen vergelijken. Met behulp van een logistische regressie is voor ieder ziekenhuis de verwachte prevalentie geschat, waarbij rekening werd gehouden met verschillen in leeftijd, ondervoeding, incontinentie, activiteit, mobiliteit, zintuiglijke waarneming, schuif- en wrijfkrachten en soort afdeling. De interne validiteit van het model werd vastgesteld met behulp van de Hosmer-Lemeshow goodness of fit, waarbij het model geen significante verschillen liet zien tussen de geobserveerde en verwachte prevalentie. De c-statistic liet zien dat het model goed discrimineerde tussen patienten met decubitus en patiënten zonder decubitus. De gecorrigeerde prevalentie werd berekend door de geobserveerde prevalentie te delen door de verwachte prevalentie en deze breuk vervolgens te vermenigvuldigen met de gemiddelde prevalentie zoals waargenomen in alle ziekenhuizen. Om de validiteit te bepalen van de gecorrigeerde prevalentie als een maat voor de kwaliteit van zorg, werd de gecorrigeerde prevalentie gerelateerd aan het percentage immobiele patiënten dat adequate preventie ontvangt, 
en aan het totaal van bevorderende factoren binnen de instelling om een goed decubitusbeleid weer te geven. Immobiele patiënten kregen vaker adequate preventie in ziekenhuizen met een lagere gecorrigeerde prevalentie dan in ziekenhuizen met een hogere gecorrigeerde prevalentie. Ziekenhuizen met meer bevorderende factoren hadden een significante lagere gecorrigeerde prevalentie dan ziekenhuizen met minder bevorderende factoren. Het gebruik van gecorrigeerde prevalentiecijfers had invloed op de absolute en relatieve prestatie van ziekenhuizen op het gebied van decubitus.

Hoofdstuk 5 laat zien hoe met behulp van multi-level analyses de prestaties van verpleeghuizen op het gebied van decubitus kunnen worden geschat waarbij rekening wordt gehouden met de grootte van de verpleeghuizen. Ook wordt de waarde van rangordes geëvalueerd als manier om de prestaties van instellingen weer te geven, door het berekenen van de betrouwbaarheidsintervallen rondom de rangnummers. Met behulp van de Markov-Chain Monte Carlo (MCMC) methode werd de random coëfficiënt van ieder verpleeghuis geschat, gecorrigeerd voor risicofactoren. Deze random coëfficiënt weerspiegelt de prestatie van de verpleeghuizen. Door de flexibiliteit van de MCMC methode was het mogelijk om betrouwbaarheidsintervallen te berekenen rondom de rangnummers van de coëfficiënten. Het resultaat van deze analyses was dat verpleeghuizen met weinig patiënten meer naar de gemiddelde prestatie neigden dan verpleeghuizen met veel patiënten. Echter de coëfficiënten waren betrouwbaarder hetgeen bleek uit een kleinere standaardfout.

De verkregen betrouwbarheidsintervallen rondom de rangnummers waren erg groot, met als resultaat dat de meeste betrouwbaarheidsintervallen overlapten. Wat rangorde betreft kon er geen onderscheid worden gemaakt tussen de 10 verpleeghuizen met de kleinste coëfficiënt. Het maken van rangordes heeft dus een beperkte waarde.

In hoofdstuk 6 wordt onderzocht op welke manier longitudinale monitoring en feedback de decubituszorg kunnen verbeteren. Gecorrigeerde prevalentiecijfers, het totaal aan bevorderende factoren en het percentage immobiele patiënten met adequate preventie werden vergeleken over een periode van vijf jaar (1998-2002), voor instellingen die meer dan één keer hadden deelgenomen aan het prevalentie onderzoek. Voor deze vergelijking werd gebruik gemaakt van een multi-level lineair trend model. Ook werd onderzocht in hoeverre adequate preventie en bevorderende factoren binnen de instelling van invloed zijn op de gecorrigeerde prevalentie. De gecorrigeerde prevalentie daalde gedurende de vijf jaar monitoren en feedback geven, terwijl het aantal bevorderende factoren 
binnen de ziekenhuizen en het aantal immobiele patiënten dat adequate preventie ontving toenam.

Het totale aantal bevorderende factoren was significant gerelateerd aan een daling van de prevalentie. Dit gold ook voor het aantal patiënten dat adequate preventie ontving, echter dit effect was niet significant. Geconcludeerd kon worden dat longitudinaal monitoren en feedback geven resulteert in een kleine, maar significante verbetering van de decubituszorg.

Hoofdstuk 7 beschrijft de belangrijkste bevindingen van de verschillende studies en enkele theoretische en methodologische reflecties. Een methodologische reflectie wordt gegeven over de procedure van dataverzameling, de generaliseerbaarheid van de resultaten en het gebruikte design voor de effectmeting. Een theoretische reflectie wordt gegeven over het gebruik van prevalentie cijfers als maat voor kwaliteit van zorg, de gebruikte methode voor het corrigeren voor risicofactoren en het gebruik van audit en feedback als strategie voor kwaliteitsverbetering. Als laatste wordt het openbaar maken van prestaties van instellingen bediscussieerd en worden aanbevelingen gegeven voor verder wetenschappelijk onderzoek. 
124 


\section{Dankwoord}

Dit proefschrift is af. Voordat het naar de drukker gaat, wil ik allereerst een aantal mensen bedanken. Een aantal zonder wie de totstandkoming van dit proefschrift niet mogelijk zou zijn geweest, en een aantal zonder wie de totstandkoming een stuk moeilijker zou zijn geweest.

Op de eerste plaats wil ik Ruud Halfens, mijn co-promotor bedanken. Ruud, jij had het grootse idee om door heel Nederland het vóórkomen van decubitus te gaan meten, en je dacht wel dat ik dat zou kunnen uitvoeren en daar ook nog op zou kunnen promoveren. Jouw inschatting was goed, echter het ging niet altijd even gemakkelijk. Gelukkig schatte jij ook altijd precies goed in wanneer het te lastig en te moeilijk en te zwaar was. Jouw oplossingen en suggesties gaven dan weer op het juiste moment de duw in de goede richting.

Mijn promotoren Huda Huijer Abu-Saad en Richard Grol. Huda, jouw begeleiding was vooral op afstand, later zelfs op verre afstand toen je naar Libanon verhuisde om jouw carrière daar voort te zetten. Gelukkig bestaat er e-mail, waardoor jouw grondige en kritische opmerkingen op mijn manuscripten snel bij mij terechtkwamen. Huda, bedankt hiervoor!

Beste Richard, vooral gedurende het laatste traject heb ik volop gebruik kunnen maken van jouw vergaande deskundigheid op het gebied van de kwaliteit van zorg en alles wat daarmee te maken heeft. Daar waar ik twijfelde, maar niet helder kon aangeven wat er aan schortte, kon jij er feilloos de vinger op leggen en suggesties geven hoe ik hiermee om zou kunnen gaan. Richard, bedankt hiervoor en ik hoop dat we in de toekomst nog mogen samenwerken.

De Stuurgroep Decubitus wil ik hartelijk bedanken voor het feit dat ze aan de basis van de prevalentiemetingen hebben gestaan: zonder de plannen van deze enthousiaste groep mensen was decubitus niet zo in de belangstelling komen te staan. Speciaal wil ik hier Maarten Lubbers noemen voor de onvoorwaardelijke steun die hij de afgelopen jaren heeft gegeven aan de prevalentiemetingen.

Dank ook aan alle coördinatoren van de meer dan 200 instellingen in Nederland die hebben deelgenomen, of nog steeds deelnemen, aan het prevalentieonderzoek decubitus. Ik weet wat voor een klus het is om de verpleegkundigen en verzorgenden allemaal op één lijn en gemotiveerd te krijgen en te houden om ieder jaar opnieuw alle verdachte plekken op de juiste manier bij patiënten op te sporen. Zonder deze gegevens zou dit proefschrift er nooit zijn geweest en zou decubitus niet zo volop in de belangstelling zijn geraakt. 
Al deze instellingen werden geduldig te woord gestaan eerst door Kris Joosten en daarna door Sandrien Wansink. Beste Kris, je bent op het project gekomen in een periode waarin het niet langer meer mogelijk was dit alleen te runnen. Het was ongelooflijk in welk tempo jij alles reorganiseerde om zo efficiënt mogelijk alles te laten verlopen. Kris, ik heb niet alleen enorm veel van jou geleerd op het gebied van time-management, maar ook op persoonlijk vlak hielp jij de zaken te relativeren. Gesprekken met jou over de spirituele zaken in het leven heb ik lang gemist. Kris bedankt voor alle wijze lessen.

Sandrien, ik was zeer aangenaam verrast door het gemak waarmee je alle werkzaamheden van dit drukke project overnam van Kris, alsof je nooit anders had gedaan. Je organisatietalent is enorm: je krijgt het zelfs voor elkaar om tijd over te houden voor extra klussen. In hectische tijden ben jij degene die rust uitstraalt en overbrengt. Ik hoop dat we nog lange tijd samen aan dit project mogen werken, maar ik wil je bij deze toch alvast heel erg bedanken voor alles tot nog toe. Fijn dat je ook mijn paranimf wilt zijn, wat ook geldt voor Marianne Tilly. Marianne, je hebt me kilometers loopwerk bespaard en uren leeswerk bezorgd door zeer zorgvuldig literatuur te zoeken, te kopiëren of te bestellen. Bedankt voor dit alles en alle andere hand- en spandiensten, de crypto-lol en voor alle gezelligheid op onze kamer.

Een bijzonder woord van dank aan Carla Frederiks. Beste Carla, ons eerste contact was bij het Groene Kruis (is dat al zo lang geleden?), waar jij af en toe wilde werken als wijkverpleegkundige en ik je de ins en outs zou bijbrengen van dit vak. Later, toen ik aangesteld werd bij de vakgroep epidemiologie werd ik door jou besmet met het epidemiologievirus. Carla, ik heb veel van jou geleerd op het gebied van de methodologie en ik heb altijd genoten van jouw scherpzinnige humor. Fijn ook dat je voorzitter wilde zijn van de begeleidingscommissie van het prevalentieonderzoek. Ik hoop dat onze wegen zich nog zeer regelmatig zullen kruisen.

Jan Klerkx, heel erg bedankt voor het zorgvuldig corrigeren van mijn engels. Je verzekerde me dat het best wel mee viel, maar ik weet zeker dat je soms toch hebt moeten lachen om mijn engelse zinsconstructies.

Alle collega's en ex-collega's van de sectie verplegingswetenschap, allemaal tegelijk omdat ik anders net die ene zal vergeten, dank jullie wel voor alle belangstelling, gezelligheid en steun.

Hartelijk dank ook aan mijn collega decubitus onderzoekers, Lisette Schoonhoven, Tom Defloor, Erik de Laat, Marcel Pieterse, Inge Buss, Inge Duimel, Paul Keller, Jan Weststrate ooit verenigd in de EPURIG om lastige problemen ten aanzien van decubitus onderzoek te bespreken. Lisette, jij ging me voor en je verzekerde me dat het mij ook wel zou lukken. Je hebt gelijk! Hopelijk hebben 
we nog af en toe tijd voor die lange telefoongesprekken en een hapje eten als het zo uitkomt.

Familie en vrienden wil ik bedanken voor de afleiding, het medeleven, plezier en de stimulans. Pap en mam, bedankt dat jullie mij altijd alle kansen hebben gegeven en hebben meegegeven dat 'echte wijsheid niet geleerd kan worden.' Lieve pap, het liefste had ik gewild dat je nog bij de promotie had kunnen zijn, zoals jij steeds zei, dat je hoopte dit nog te zullen meemaken. Helaas heeft dit niet zo mogen zijn. Heel onverwachts heb je ons verlaten. Wie weet kun je een oogje in het zeil houden vanuit de plek waar je nu bent.

Lieve Karel, Ruud en Sanne, jullie spelen de belangrijkste rol in mijn leven. Tot slot wil ik ook jullie bedanken voor de onvoorwaardelijke steun en liefde in alle fasen van de totstandkoming van dit proefschrift. Sanne ons zonnetje, Ruud jouw bijzondere lessen, en Karel voor al het andere, want zonder jou had dit nooit gekund. 


\section{Curriculum vitae}

Gerrie Bours was born in Beegden, the Netherlands on October 28th, 1959. In 1978, after obtaining her secondary school diploma at the Scholengemeenschap St. Ursula in Horn, she started studying nursing (HBO-V) at the Gezondheidszorg Academie in Sittard, where she obtained her degree in 1982. After the birth of her son in 1983, she worked as a community nurse at Groene Kruis Heuvelland in Maastricht for seven years. After the birth of her daughter in 1987, she started studying Health Science at the Universiteit Maastricht, specializing in nursing science. She graduated in June 1991, having completed a thesis on predicting the duration of home maternity care. In 1990, she became a lecturer of nursing at Hogeschool Sittard, a job she held until 1993. From August 1993 to June 1995, she worked as an assistant professor at the Department of Epidemiology of the Universiteit Maastricht. In 1995, she moved to the Nursing Science department, where she was involved first in research on pain assessment in neonates and later in research on the evaluation of the implementation of specialized community nursing for patients with chronic obstructive pulmonary disease funded by the Dutch Asthma Foundation. She started the studies described in this thesis in February 1997. In 2001, she completed the Postdoctoral Epidemiology A training at the VU Medical Center in Amsterdam, organized by the EMGO Institute and the Department of Clinical Epidemiology and Biostatistics. She is currently still working at the Maastricht Nursing Science Department as a researcher and as an assistant professor, and is responsible for the development of the new Master's program called Advanced Clinical Nurse Specialist, to be started in 2004. 

